\title{
Caracterización del mercado de derivados cambiarios en Colombia*
}

\author{
Nathali Cardozo Alvarado* \\ Juan Sebastián Rassa Robayo** \\ Juan Sebastián Rojas Moreno
}

* Este trabajo fue publicado en Borradores de Economía, publicación de la Subgerencia de Estudios Económicos del Banco de la República. Los trabajos son de carácter provisional, las opiniones y posibles errores son responsabilidad exclusiva de los autores y sus contenidos no comprometen al Banco de la República ni a su Junta Directiva.

** Profesional especializado, Subgerencia Monetaria y de Inversiones Internacionales del Banco de la República. Profesional en Finanzas y Comercio Internacional. ncardoal@banrep.gov.co

*** Profesional especializado, Subgerencia Monetaria y de Inversiones Internacionales del Banco de la República. Ingeniero electrónico.jrassaro@banrep.gov.co

**** Jefe de la sección de desarrollo de mercados, Subgerencia Monetaria y de Inversiones Internacionales del Banco de la República; Master in Business Administration (MBA).jrojasmo@banrep. gov.co

Fecha de recepción: 20 de abril de 2015.

Fecha de aceptación: 15 de mayo de 2015.

Forma de citar:

Cardozo Alvarado, N., Rassa Robayo, J. S., Rojas Moreno, J. S. (2015). Caracterización del mercado de derivados cambiarios en Colombia. ODEON, 9, pp. 7-79. DOI: http://dx.doi. org/10.18601/17941113.n9.02 



\section{Introducción}

En los últimos años, los productos derivados han adquirido un papel protagónico en el desarrollo de los mercados financieros a nivel mundial, dada la creciente internacionalización de los mercados, así como los importantes avances en materia tecnológica y financiera (que permiten un mayor seguimiento de los diferentes mercados, negociaciones a mayor frecuencia, análisis de riesgo y administración de portafolio), que han dado origen a una amplia gama de mecanismos de cobertura de riesgo y a innovadoras estrategias de inversión a través de estos instrumentos.

En particular, el desarrollo del mercado de derivados en Colombia ha coincidido con mayores flujos de capitales desde y hacia el país, así como con una mayor disposición de los agentes para transferir los riesgos asociados a movimientos adversos en los precios de los activos. Lo anterior se ha visto reflejado principalmente en el incremento de los montos negociados de derivados de tasa de cambio, sobre todo desde el año 2008, donde los forwards peso-dólar han sido por excelencia los instrumentos con mayores volúmenes. Además, cabe señalar que a medida que el mercado de derivados ha obtenido mayor profundidad y que los diferentes agentes han adquirido mayor especialización en el diseño y la implementación de estrategias de cobertura e inversión, se ha dado lugar a la utilización de otro tipo de productos como los cross-currency swaps y las opciones.

El uso de derivados cambiarios ha tenido una creciente acogida entre los distintos sectores económicos del país, quienes de acuerdo con sus necesidades y perfiles de riesgo, los utilizan con fines de cobertura, especulación o arbitraje. En este sentido, resulta enriquecedor conocer a los diferentes agentes que participan en el mercado de derivados así como los precios, plazos, montos e instrumentos negociados, con el fin de entender los factores que afectan su comportamiento, así como la interacción entre los distintos participantes.

Con este objetivo, este documento se desarrolla en cuatro secciones. En la primera se presenta un marco teórico relacionado con el desarrollo del mercado de derivados financieros; en la segunda se muestra la evolución del mercado de derivados OTC (over the counter) en Colombia; en la tercera se presenta la caracterización del mercado de forwards, cross-currency swaps y opciones; y en la cuarta se presentan las conclusiones.

\section{Marco teórico}

Los derivados son contratos cuyo valor se deriva del precio de otro activo, denominado activo subyacente, que se cumplen en una fecha futura. A través de los 
derivados es posible tomar posiciones sobre una gran variedad de activos subyacentes como tasas de cambio, tasas de interés, acciones, entre otros, que de otro modo podrían implicar costos muy elevados. Los derivados más comúnmente utilizados son los swaps, forwards, futuros y opciones.

Tanto firmas como individuos utilizan los derivados con fines de cobertura, especulación o arbitraje. En particular, como lo menciona Álvarez (2012), las funciones de cobertura y especulación de los derivados facilitan la redistribución de riesgos entre agentes que desean desprenderse de ellos y agentes que, a cambio de una rentabilidad, desean adquirirlos.

La primera función de estos instrumentos es proporcionar un mecanismo de cobertura frente a un riesgo previamente existente relacionado con variaciones en el precio del activo subyacente que puedan ocasionar pérdidas a los agentes. Con respecto a este punto, el estudio publicado por Allayani y Ofek (1998) sobre las firmas que componen el índice bursátil S\&P, mostró que el mercado de derivados era utilizado principalmente por estas empresas para cubrir su exposición cambiaria. Al analizar los determinantes de las coberturas, estos autores encontraron que el uso de derivados estaba relacionado positivamente con el grado de exposición al riesgo cambiario, generado por ingresos y deudas denominadas en moneda extranjera, en línea con Géczy, Minton y Schrand (1997) que también asocian el uso de derivados con fines de cobertura con el tamaño de la empresa. Por su parte, el trabajo de Allayanis y Weston (2003) encuentra una relación negativa entre la volatilidad del flujo de caja y el retorno de los accionistas, y el de Allayanis y Ofek (2001) que muestra que el uso del mercado de derivados reduce la volatilidad de los flujos de caja.

En contraste con las operaciones de cobertura, las operaciones especulativas a través de los derivados permiten tomar nuevos riesgos, es decir, adquirir nuevas posiciones sobre el activo subyacente (Álvarez, 2012). Los agentes que utilizan estas estrategias juegan un papel importante en los mercados financieros en la medida en que proporcionan liquidez al sistema. Este aumento en la liquidez es uno de los aportes más valiosos del mercado de derivados, pues implica que inversionistas que buscan transferir o adquirir riesgos pueden vender (o comprar) más fácilmente sus activos, sin perder grandes sumas de dinero ni afectar significativamente el precio de mercado (George, 2009; Danthine, 1978).

Adicionalmente, los derivados ofrecen oportunidades para implementar estrategias de arbitraje, en la medida en que permiten aprovechar las imperfecciones o distorsiones en los mercados. Como resultado de la búsqueda constante de arbitrajes, los precios de los distintos activos subyacentes tienden a converger a su 
valor de equilibrio, reduciendo las imperfecciones que puedan producirse en la formación de precios (Álvarez, 2012).

El crecimiento significativo que ha tenido el mercado de derivados, como lo refleja la encuesta trianual de derivados del Bank of Internacional Settlements $(\mathrm{BIS})^{1}$, puede ser explicado por los beneficios que les proporciona a las empresas, a los inversionistas y a la economía en general. En primer lugar, se debe mencionar que los derivados financieros desempeñan un rol importante en el proceso de formación de precios (price discovery) del activo subyacente. De acuerdo con el estudio realizado por Kavussanos, Visvikis y Alexakis (2008), los precios del mercado de derivados reflejan rápidamente la información nueva con respecto al precio de contado del activo subyacente, lo cual pone de manifiesto la relación que existe entre estos dos mercados. La explicación se atribuye a los bajos costos implícitos en la negociación de derivados (bajos costos de transacción, bajos márgenes y una rápida ejecución de las operaciones) y a las oportunidades de apalancamiento que ofrecen, lo cual es consecuente con lo que se conoce como "trading cost hypothesis" introducido por Fleming, Ostdiek y Whaley (1996), según el cual los mercados con costos de transacción más bajos tienden a reaccionar con mayor rapidez a la nueva información disponible y, por tanto, mantienen el liderazgo en el proceso de formación de precios. Otra de las razones que explica por qué los derivados responden más rápidamente a la nueva información sobre el activo subyacente, se fundamenta en la ausencia de restricciones a las posiciones en corto que, de acuerdo con Diamond y Verrecchia (1987), retrasan el proceso de ajuste de los precios a nueva información disponible relacionada con noticias negativas.

Otra de las ventajas que favorece en gran medida la reasignación de riesgo entre los agentes a través de los derivados, es que estos instrumentos ofrecen oportunidades de apalancamiento a bajo costo, dado que no es necesario el flujo de dinero entre las partes del contrato en el momento de la negociación, permitiéndoles a los inversionistas diversificar su portafolio (Sill, 1997), y, en consecuencia, aumenta la liquidez del activo subyacente. Sin embargo, literatura relacionada con el apalancamiento a través de derivados, también ha incrementado las alertas sobre este mecanismo, ya que tiende a incrementar el precio del activo subyacente, dando lugar incluso a posibles burbujas de activos, y a un aumento en la fragilidad de las empresas del sistema financiero, desencadenando un posible efecto sistémico

\footnotetext{
1 De acuerdo con la encuesta, las negociaciones de derivados de tasa de cambio pasaron de US\$2.490 billones en 2010 a US\$3.298 billones en 2013.
} 
(Gerding, 2011). El alto grado de apalancamiento hace que surja un efecto multiplicativo, tanto en caso de ganancias como pérdidas, por lo que es conveniente adoptar medidas de precaución como complemento a las operaciones con fines de apalancamiento a través de estos instrumentos (Álvarez, 2012). En este punto, cabe señalar que el desarrollo del mercado de derivados a nivel mundial ha requerido de la implementación de una regulación robusta por parte de los entes de control que propenda por la estabilidad del sistema financiero dados los riesgos asociados a la negociación de estas operaciones (riesgo de crédito, principal, liquidez, legal, etc.). Adicionalmente, se busca eliminar la asimetría de información y fomentar la integridad del mercado dentro del sistema financiero.

Por su parte, cabe mencionar que en el trabajo de Géczy, Minton y Schrand (1997) se afirma que en un escenario de economías de escala, los $\operatorname{costos}^{2}$ son determinantes en el tipo de cobertura que adquieren las empresas a través de estos instrumentos. Por ejemplo, las empresas pueden optar por utilizar swaps de divisas de largo plazo para gestionar los riesgos cambiarios que se extienden por varios periodos, y que son conocidos con antelación (por ejemplo, pago de deuda denominada en moneda extranjera). De acuerdo con estos autores, las empresas que utilizan swaps tienen estadísticamente niveles más altos de deuda en moneda extranjera que aquellas empresas que no utilizan derivados sobre divisas. Por el contrario, los forwards podrían ser la alternativa de menor costo para transacciones frecuentes de corto plazo de las cuales no se conoce ex-ante el tiempo y el monto por cubrir (por ejemplo, ventas de bienes en moneda extranjera).

Específicamente, en el mercado de derivados cambiarios, se han desarrollado trabajos como el de Avalos y Moreno (2013), donde se encuentra evidencia de que después de la crisis de 2008, el estrés en el mercado cambiario ${ }^{3}$ en Chile fue menor que en otros países emergentes (incluyendo países de la región), debido a una mayor liquidez del mercado de derivados de tasa de cambio, específicamente el mercado de forwards NDF (Non Delivery Forward). De acuerdo con estos autores, las Administradoras de Fondos de Pensiones no disminuyeron las coberturas de sus inversiones en moneda extranjera, y de esta forma fueron contraparte de los bancos y de otros agentes del sector no financiero que buscaban tomar posiciones largas en dólares con fines de cobertura. En este trabajo también se argumenta que

2 Las empresas deciden con base en los costos asociados a la implementación y el mantenimiento de un programa de gestión de riesgo, y aquellos asociados con la elección de un determinado instrumento financiero derivado.

Medido como la desviación a tres meses de la paridad cubierta de tasa de interés.

PP. $7-79$ • N $.^{\circ} 9 / 2015$ 
un mercado de derivados sobre divisas con amplia liquidez podría reducir la necesidad de acumulación de reservas internacionales por parte de los Bancos Centrales. En línea con lo anterior, Becker y Fabbro (2006) encontraron que la economía australiana ha sido resistente a los distintos choques de tasa de cambio debido a que las firmas financieras y no financieras (principalmente firmas importadoras y manufactureras) han aprendido a cubrir sus exposiciones utilizando el mercado de derivados en la medida que este ha ido evolucionado.

Para el caso específico de Colombia, en donde el mercado de derivados sobre divisas es el más desarrollado entre los distintos tipos de activos, Kamil, Maiguashca y Pérez (2008) concluyeron que los cambios regulatorios han promovido su avance, contribuyendo a la participación de los fondos de pensiones que son oferentes naturales de cobertura en este mercado. Adicionalmente, encuentran que el nivel de deuda en moneda extranjera tiene una gran importancia en las decisiones de cobertura de las entidades. De acuerdo con este trabajo, el mercado de derivados ha permitido reducir los costos de fondeo accediendo al mercado internacional sin aumentar de forma importante los riesgos cambiarios. Los autores también encontraron que la demanda por coberturas del sector real en este país proviene principalmente de las empresas importadoras.

Con base en los importantes avances que ha presentado el mercado de derivados a nivel internacional, así como el impacto y los beneficios que la negociación de estos instrumentos pueden representar para las firmas y para el desarrollo económico, el presente documento realiza una caracterización del mercado de derivados en Colombia. En particular, se analizará un segmento específico del mercado como lo es el de tasa de cambio, dado que es por excelencia el más líquido y desarrollado en el país. En el documento se describirán y analizarán los distintos participantes del mercado, los precios, plazos, montos e instrumentos pactados, a partir de los reportes que envían diariamente los Intermediarios del Mercado Cambiario ${ }^{4}$ (IMC) al Banco de la República (BR) según lo establecido en la Circular Reglamentaria DODM-144. El análisis que se presenta a continuación se enfoca principalmente en el periodo comprendido entre enero de 2008, año a partir del cual se evidencia una tendencia de crecimiento en los montos negociados en el mercado de derivados colombiano, y junio de 2014.

Para el análisis se tendrán en cuenta las diferencias en la naturaleza de los participantes del mercado, por lo cual se analizará el comportamiento de entidades

4 Los IMC canalizan ingresos y egresos de divisas de la operaciones obligatoriamente canalizables a través del mercado cambiario. 
como filiales extranjeras de intermediarios locales (intragrupo), el offshore, las empresas del sector real, los IMC y otras entidades vigiladas por la Superintendencia Financiera de Colombia. Adicionalmente, el análisis del sector real se realizará teniendo en cuenta sus actividades de comercio exterior.

\section{Evolución del mercado de derivados en Colombia}

De acuerdo con la encuesta trianual realizada en 2013 por el BIS, las negociaciones de derivados sobre divisas en el mercado mostrador oTC a nivel global ascendieron a US $\$ 3.298$ billones, lo cual representa un aumento de $32 \%$ con respecto a los resultados de la encuesta del año $2010^{5}$ (ver Reporte de Mercados Financieros. Cuarto Trimestre de 2013). En particular, los FX swaps continúan siendo los instrumentos más transados en el mercado de derivados sobre divisas a nivel mundial (US\$2.228 billones) seguidos por los forwards (US\$ 680 billones) y las opciones (US\$337 billones) (gráfico 1 y tabla 1). Sin embargo, cabe resaltar que el volumen transado en opciones sobre divisas fue el que presentó el mayor incremento porcentual (62\%) frente a la encuesta anterior, seguido por los forwards (43\%), los FX swaps (26\%) y los cross-currency swaps (26\%).

Tabla 1

Variación de negociaciones por instrumento (US\$billones)

\begin{tabular}{|l|c|c|c|}
\cline { 2 - 4 } \multicolumn{1}{c|}{} & Monto negociado 2013 & Cambio frente a 2010 & Crecimiento (\%) \\
\hline \multicolumn{1}{c|}{ Total } & 5.345 & 1.373 & 34,58 \\
Por instrumento & & & \\
Spot & 2.046 & 558 & 37,50 \\
Forward & 680 & 205 & 43,31 \\
FX Swap & 2.228 & 469 & 26,66 \\
Currency Swap & 54 & 11 & 26,28 \\
Opciones & 337 & 130 & 62,62 \\
\hline
\end{tabular}

Fuente: Reporte de Mercados Financieros. Cuarto Trimestre de 2013. Banco de la República.

5 La encuesta reunió información sobre el volumen de negociación en el mercado cambiario de contado y de derivados отс de tasa de cambio y tasa de interés registrado en el mes de abril de 2013. 
Gráfico 1

Negociaciones cambiarias por instrumento (US\$ billones)

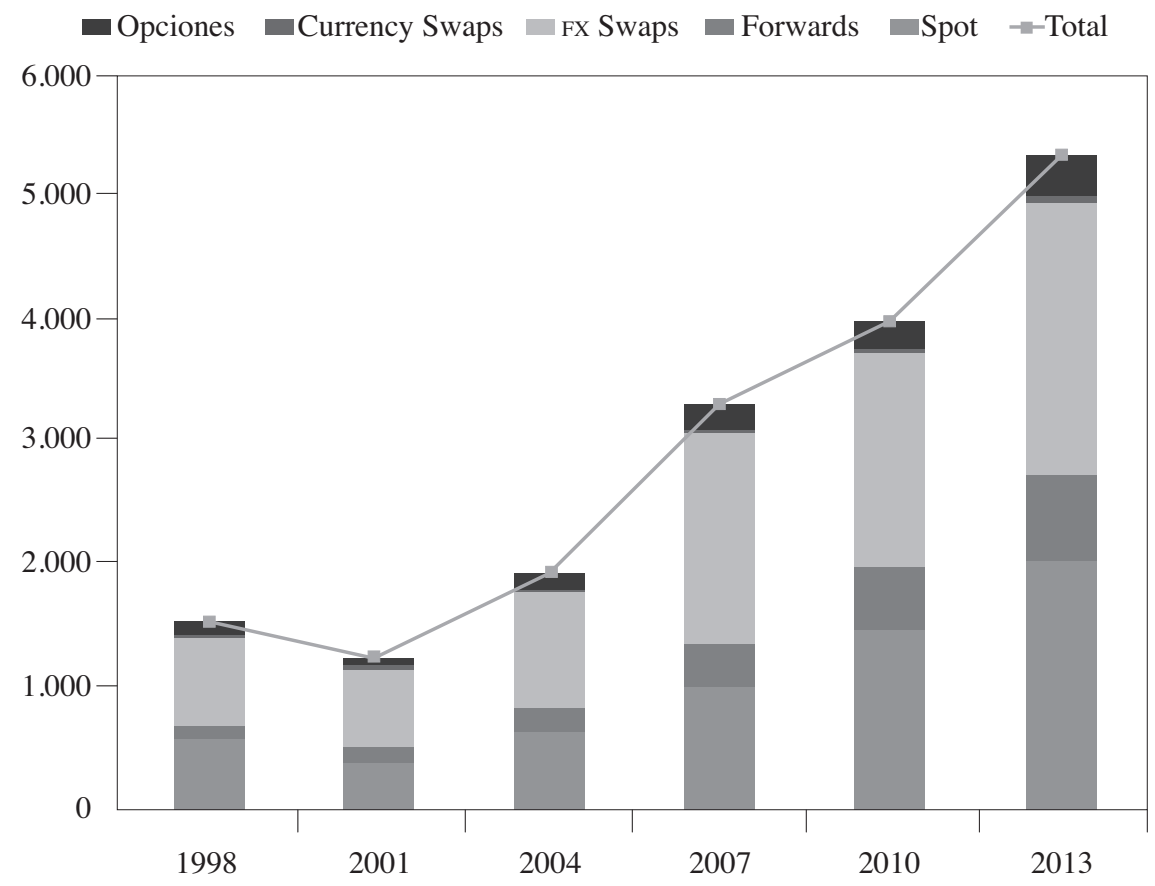

Fuente: Reporte de Mercados Financieros. Cuarto Trimestre de 2013. Banco de la República.

Para el caso particular de Colombia, la mayor parte de los derivados se realizan en el mercado отс, y en general estos tienen como subyacente la tasa de cambio. Como se observa en el gráfico 2, en 2013 el monto negociado en derivados sobre tasa de interés en Colombia correspondió al $8 \%$ del total transado en derivados cambiarios, lo cual contrasta con otros países de la región, como Brasil y México, en donde los derivados sobre tasa de interés han presentado un mayor desarrollo.

En el gráfico 3 se puede observar que en el mercado отс los derivados cambiarios de países emergentes, incluyendo Colombia, continúan rezagados con respecto a economías desarrolladas. Desde el año 2001, los volúmenes negociados en los países emergentes no han presentado cambios significativos con respecto al tamaño económico de estos países. 
Gráfico 2

Negociaciones derivados tasa de interés/derivados tasa de cambio

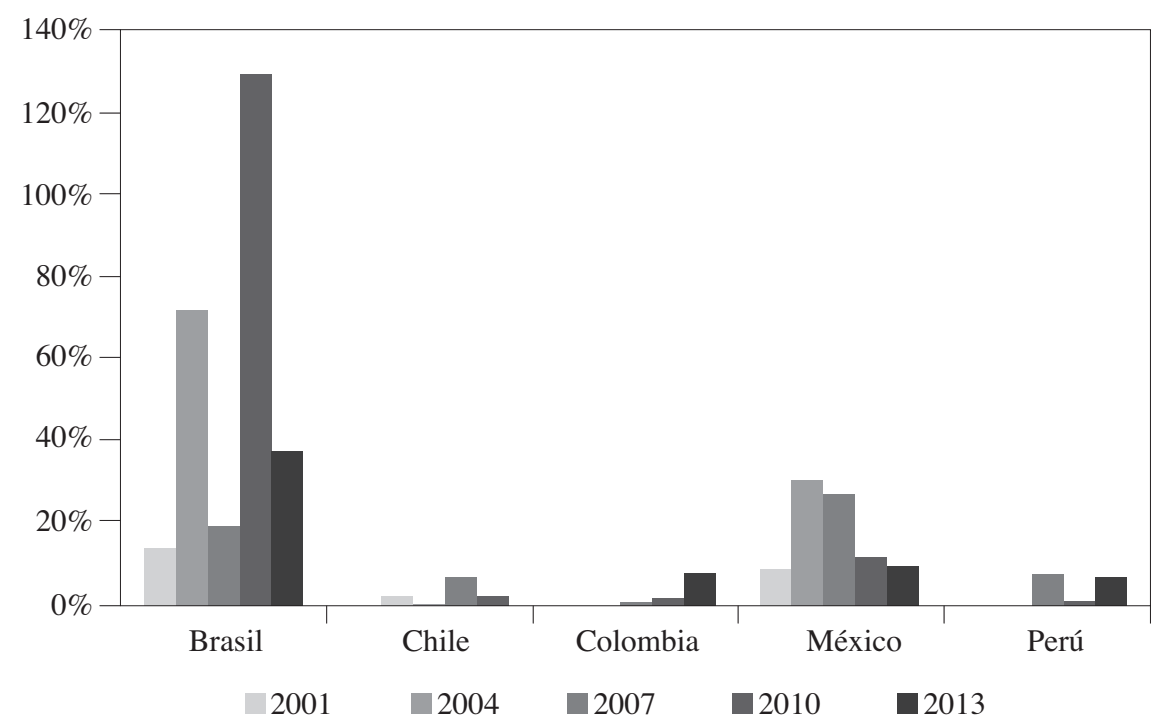

Gráfico 3

Negociaciones anualizadas de derivados cambiarios/PIB (número de veces)

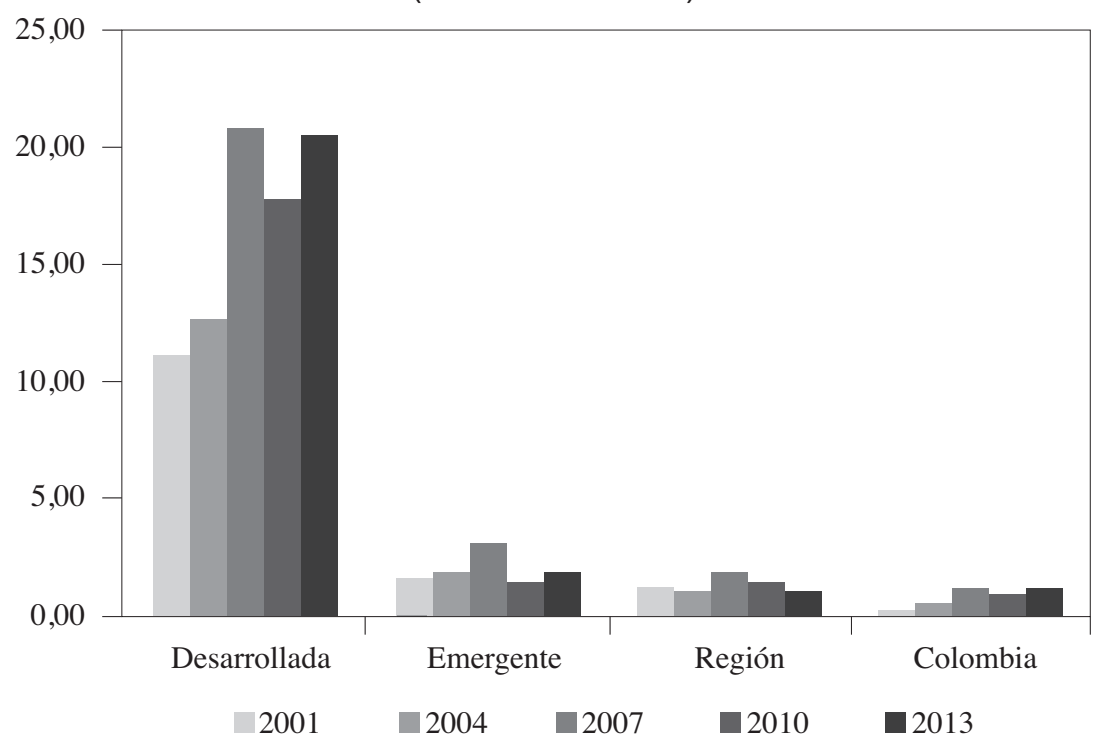


Al comparar el tamaño del mercado de derivados cambiarios OTC como proporción del PIB entre algunos países de Latinoamérica ${ }^{6}$, se encuentra que en Colombia continúa existiendo un rezago importante frente a países como Chile y México, aunque supera a países como Brasil y Perú (gráfico 4). Cabe resaltar que en Brasil este resultado no es directamente comparable dado que los futuros son por excelencia los productos más transados, y la encuesta el BIS no arroja información sobre la negociación de estos instrumentos.

Gráfico 4

Negociaciones anualizadas de derivados cambiarios/PIB

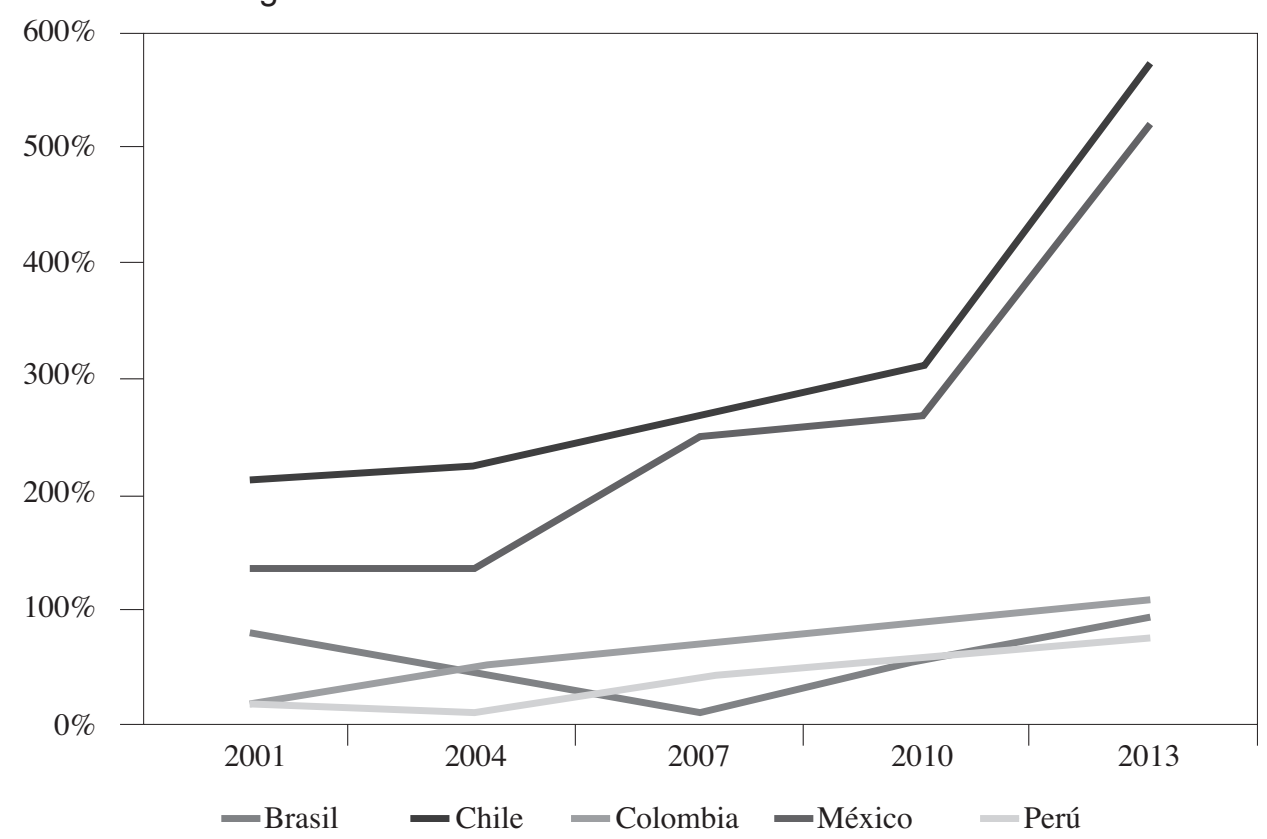

El crecimiento del monto promedio diario negociado en el mercado de derivados cambiarios entre 2010 y 2013 fue de $41 \%$ en Perú (US\$167 millones), 49\% en Colombia (US\$502 millones), $79 \%$ en Brasil (US\$4.239 millones), $110 \%$ en Chile (US\$3.124 millones) y $114 \%$ en México (US\$ 13.330 millones). Perú y Colombia son los países de la región que presentaron el menor crecimiento de este mercado, tanto en monto como en porcentaje, durante este periodo.

6 Colombia, Brasil, Perú, Chile y México. 
El crecimiento de las negociaciones en el mercado cambiario de Colombia, Chile y Perú de los últimos tres años se debió principalmente al aumento de las negociaciones de forwards (tabla 2). Por su parte, en Brasil el crecimiento estuvo impulsado por el mercado de forwards y de cross-currency swaps, y en México por el de los FX swaps (el instrumento con mayores negociaciones desde 2007 en este país).

Tabla 2

Variación de negociaciones diarias promedio entre 2010 y 2013, desagregadas por instrumento (US\$ billones)

\begin{tabular}{|l|c|c|c|c|}
\cline { 2 - 5 } \multicolumn{1}{c|}{} & Forwards & Fx Swaps & Currency Swaps & Opciones \\
\hline Brasil & 2.606 & 204 & 2.185 & -756 \\
\hline Chile & 2.398 & 690 & -102 & 138 \\
\hline Colombia & 461 & 14 & -10 & 37 \\
\hline México & 1.071 & 12.010 & 113 & 135 \\
\hline Perú & 102 & 52 & 6 & 6 \\
\hline
\end{tabular}

\section{Mercado de derivados de tipo de cambio colombiano}

Al analizar la composición del mercado de derivados de tipo de cambio en Colombia, se encuentra que, en línea con lo mencionado previamente, los forwards continúan siendo el principal instrumento negociado (gráfico 5). Al evaluar los reportes que los IMC envían al BR, se encuentra que las negociaciones de derivados sobre tasa de cambio por parte de estas entidades, se han incrementado de forma importante en los últimos años, impulsadas principalmente por el mercado de forwards peso-dólar (gráfico 6). Este instrumento continúa aumentando su participación relativa en el mercado frente a otro tipo de productos, como las opciones peso-dólar y los cross-currency swaps.

El aumento de los montos negociados en el mercado de derivados de tasa de cambio ha ido de la mano de una mayor especialización de los distintos agentes en este mercado, así como de una mayor demanda por coberturas debido a factores como: el crecimiento de la inversión de portafolio en el exterior por parte de los fondos de pensiones y cesantías (FPC), la mayor inversión extranjera de portafolio en Colombia, y las necesidades de cobertura por parte del sector real. 
Gráfico 5

Montos promedios diarios negociables sobre derivados de tasa de cambio (millones de usD)

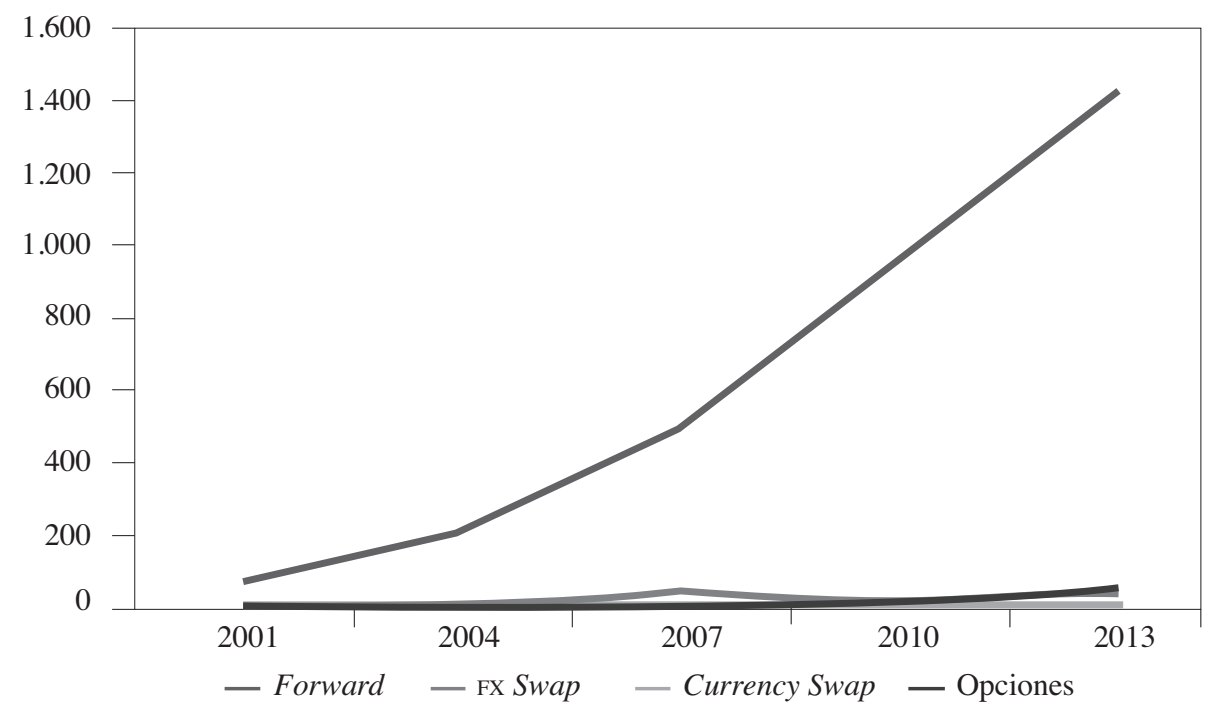

Fuente: BIS.

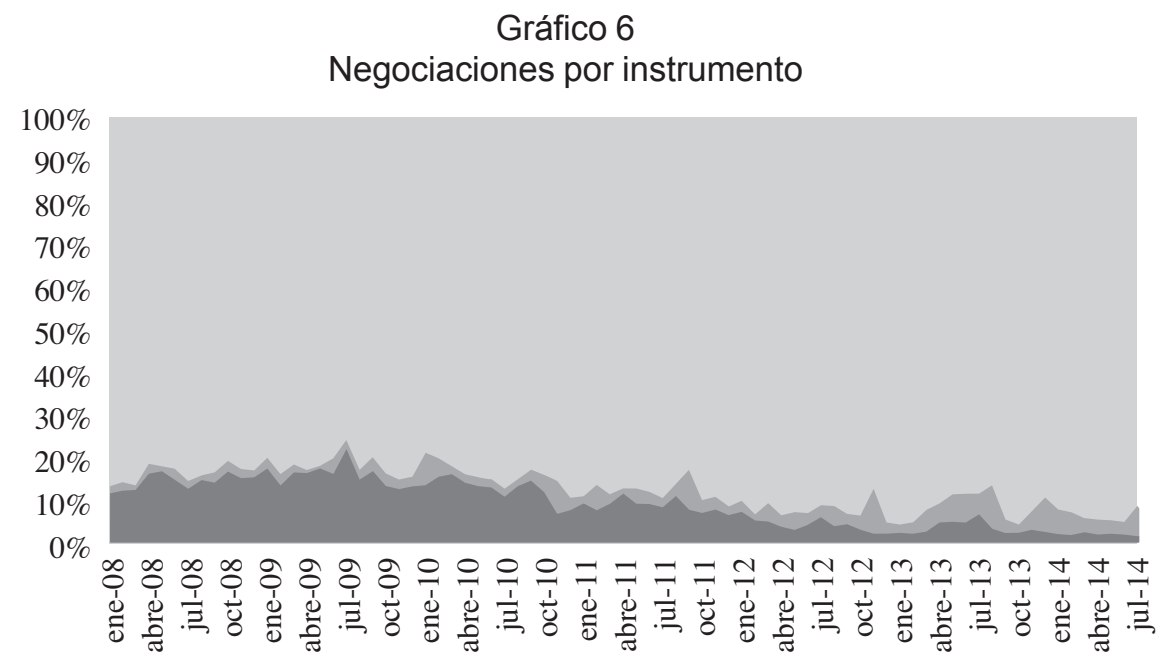

- Swap peso-dólar $\quad$ Opción peso-dólar $\quad$ Forward peso-dólar 
En este trabajo se hará énfasis en las operaciones peso-dólar, ya que el $95 \%$ de los derivados de tasa de cambio en el mercado colombiano tienen como subyacente el dólar americano (tabla 3).

Tabla 3

Distribución por monedas de los derivados de tasa de cambio por tipo de instrumento

\begin{tabular}{|l|c|c|c|c|c|}
\hline \multicolumn{7}{|c|}{ Distribución (\%) } \\
\hline & Total (\%) & Forwards (\%) & Fx Swaps (\%) & Currency Swaps (\%) & Opciones (\%) \\
\hline COP-USD & 94,9 & 95,0 & 85,8 & 100,0 & 100,0 \\
\hline COP-EUR & 0,0 & 0,0 & 0,0 & 0,0 & 0,0 \\
\hline COP-OTRAS & 0,0 & 0,0 & 0,0 & 0,0 & 0,0 \\
\hline USD-EUR & 3,5 & 3,5 & 6,4 & 0,0 & 0,0 \\
\hline USD-MXN & 0,4 & 0,4 & 0,0 & 0,0 & 0,0 \\
\hline USD-JPY & 0,4 & 0,3 & 2,2 & 0,0 & 0,0 \\
\hline USD-CAD & 0,5 & 0,4 & 3,9 & 0,0 & 0,0 \\
\hline USD-GPB & 0,1 & 0,0 & 1,1 & 0,0 & 0,0 \\
\hline USD-CHF & 0,0 & 0,0 & 0,6 & 0,0 & 0,0 \\
\hline USD-AUD & 0,0 & 0,0 & 0,0 & 0,0 & 0,0 \\
\hline USD-OTRAS & 0,1 & 0,1 & 0,0 & 0,0 & 0,0 \\
\hline
\end{tabular}

Fuente: cálculos Departamento de Desarrollo de Mercados, Banco de la República.

En el análisis que se presenta a continuación sobre los mercados de forward pesodólar, cross-currency swaps y opciones peso-dólar, se entiende que por lo menos una de las contrapartes de las operaciones corresponde a un IMC, a menos que se especifique lo contrario. En algunas secciones se tratarán las operaciones que realizan agentes locales con agentes del exterior.

\subsection{Mercado de forwards peso-dólar}

\subsubsection{Cantidades}

Los montos negociados en este mercado han venido en aumento desde 2004, pasando de un promedio mensual cercano a US $\$ 5.000$ millones a uno de US $\$ 25.000$ millones en 2014 (gráfico 7). En cuanto a los participantes del mercado de forwards 
peso-dólar (gráfico 8), se destaca el aumento en las negociaciones por parte de los IMC con agentes offshore. Actualmente, entre estos agentes se realizan cerca del $40 \%{ }^{7}$ de las negociaciones en este mercado, seguido por las operaciones entre IMC, y las operaciones entre IMC con FPC.

Gráfico 7

Montos negociados mensuales Forward peso-dólar y Fx Swap 2004-2014

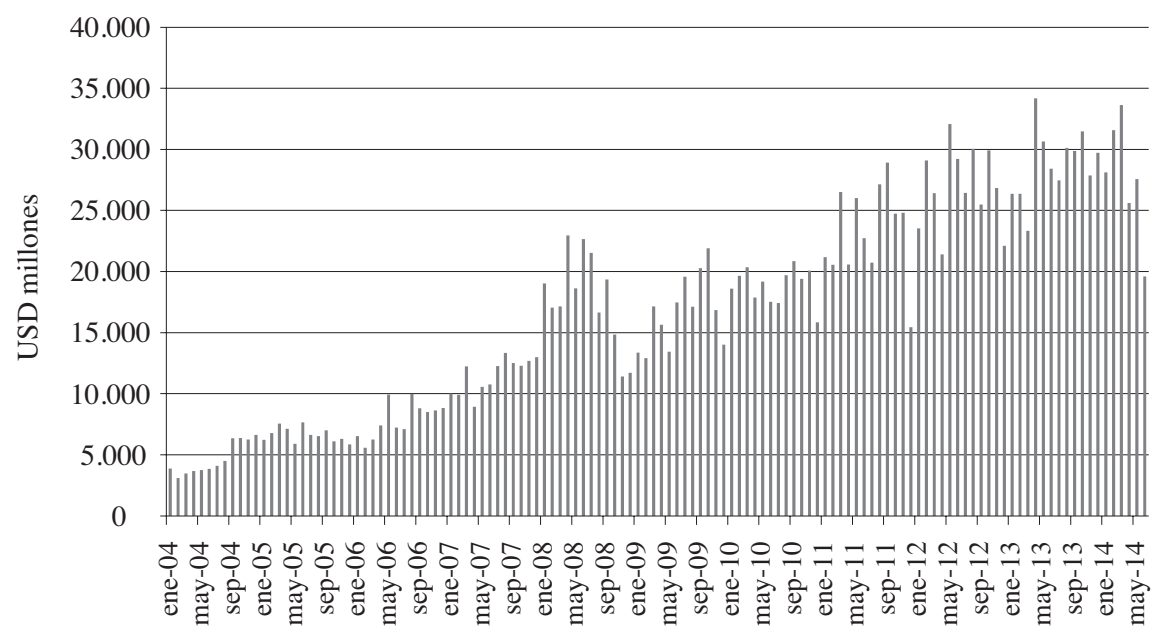

Gráfico 8

Distribución por contraparte Forward peso-dólar y Fx swap 2004-2014

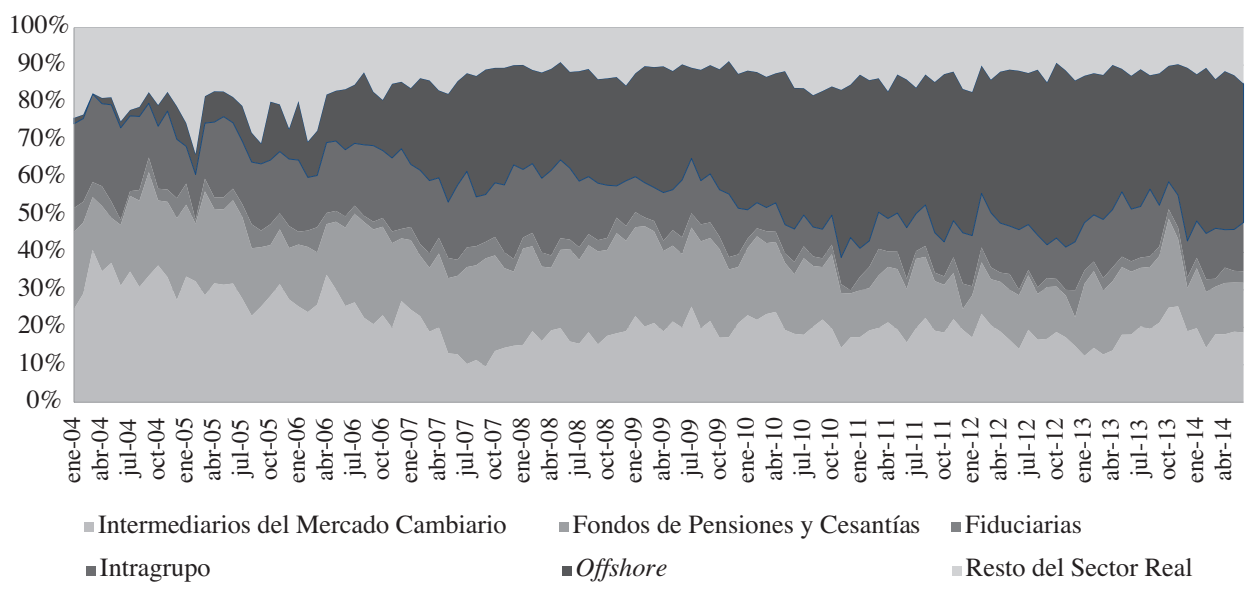

7 Si se incluyen las negociaciones de los IMC con empresas del exterior de su mismo grupo financiero (intragrupo), este porcentaje asciende a $54 \%$. 
En línea con el crecimiento en el volumen negociado, el número de participantes también ha aumentado (gráfico 9), pasando de un promedio mensual de 610 en 2008 a 965 entre enero y julio de 2014. En particular, el desarrollo del mercado pudo haber permitido una mayor oferta de coberturas para el sector real, lo cual estuvo acompañado por el aumento de la exposiciujmjkón de este sector a la tasa de cambio peso-dólar, vía operaciones de comercio exterior y endeudamiento externo.

Gráfico 9

Número de participantes. Forward peso-dólar y FX Swap 2008-2014

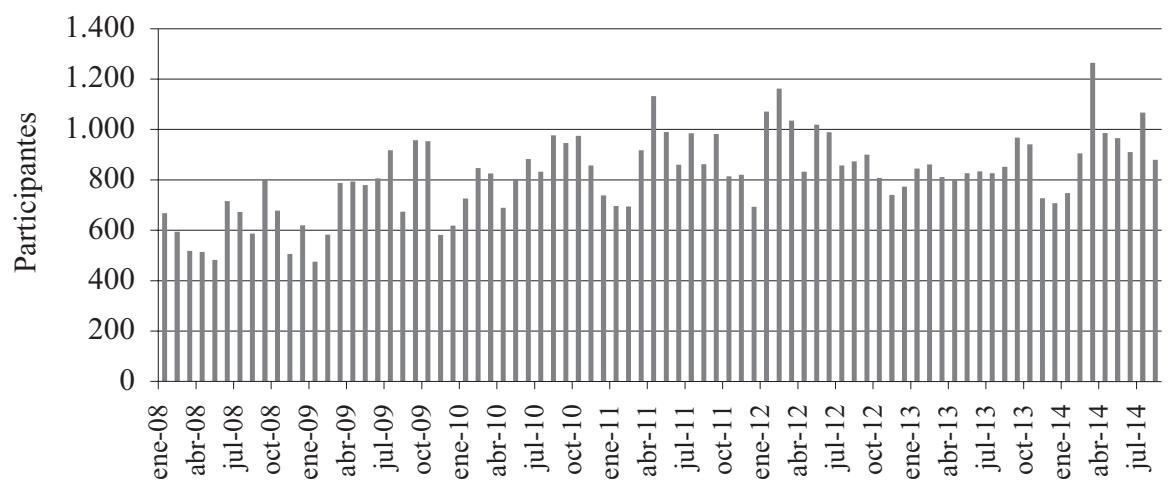

Los forward peso-dólar se realizan en su mayoría a corto plazo, y se concentran principalmente en plazos menores a 30 días. El plazo promedio de negociación se ubicó en 40 días entre 2004 y 2006, disminuyó entre 2007 y 2009, y posteriormente aumentó hasta ubicarse actualmente alrededor de 40 días (gráfico 10).

Gráfico 10

Plazo mensual ponderado por monto. Forward peso-dólar y Fx Swap 2004-2014

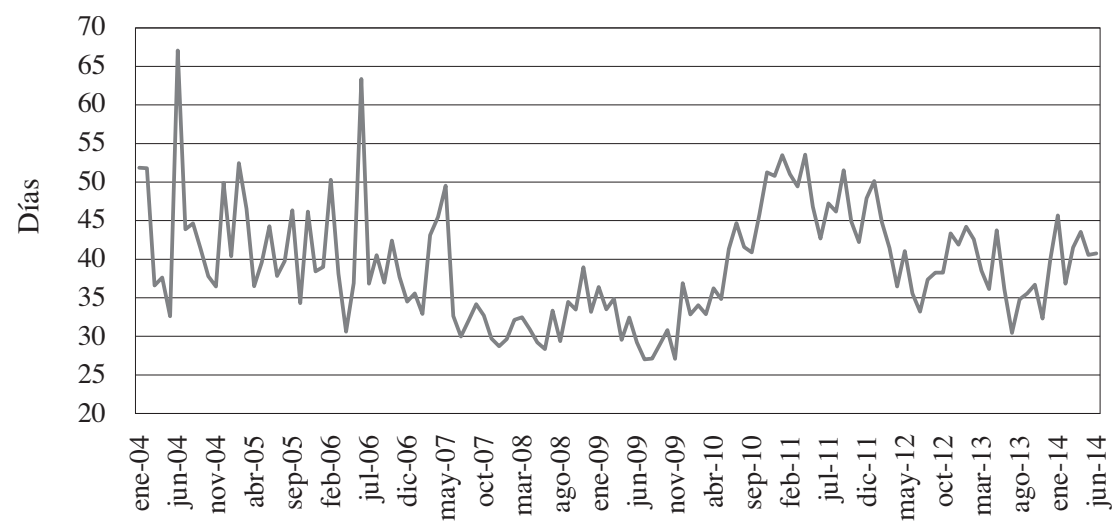


Al desagregar el plazo de los forwards peso-dólar negociados por los distintos sectores, se encuentra que el sector real pacta las coberturas a mayor plazo (cerca de 70 días en promedio) (gráfico 11). Lo anterior puede atribuirse a que estos agentes buscan mantener una cobertura estructural dada la exposición cambiaria de sus ingresos (o egresos), su riesgo de balance (que es una exposición de largo plazo), y los créditos en moneda extranjera que generalmente tienen un plazo mayor a un mes.

Por otra parte, los agentes del exterior (offshore e intragrupo) y los FPC en promedio pactan operaciones a un plazo cercano a 30 días. En el caso de los agentes del exterior, el mercado de forwards peso-dólar puede ser utilizado con fines especulativos o de cobertura, tanto de sus inversiones de capital en el país (inversión extranjera directa o inversión de portafolio) como de los flujos asociados. Adicionalmente, las coberturas a corto plazo de los FPC podrían estar motivadas por la alta liquidez de los plazos cortos en este mercado.

Gráfico 11

Plazo ponderado por monto por sector

Forward peso-dólar y Fx Swap

2004-2014

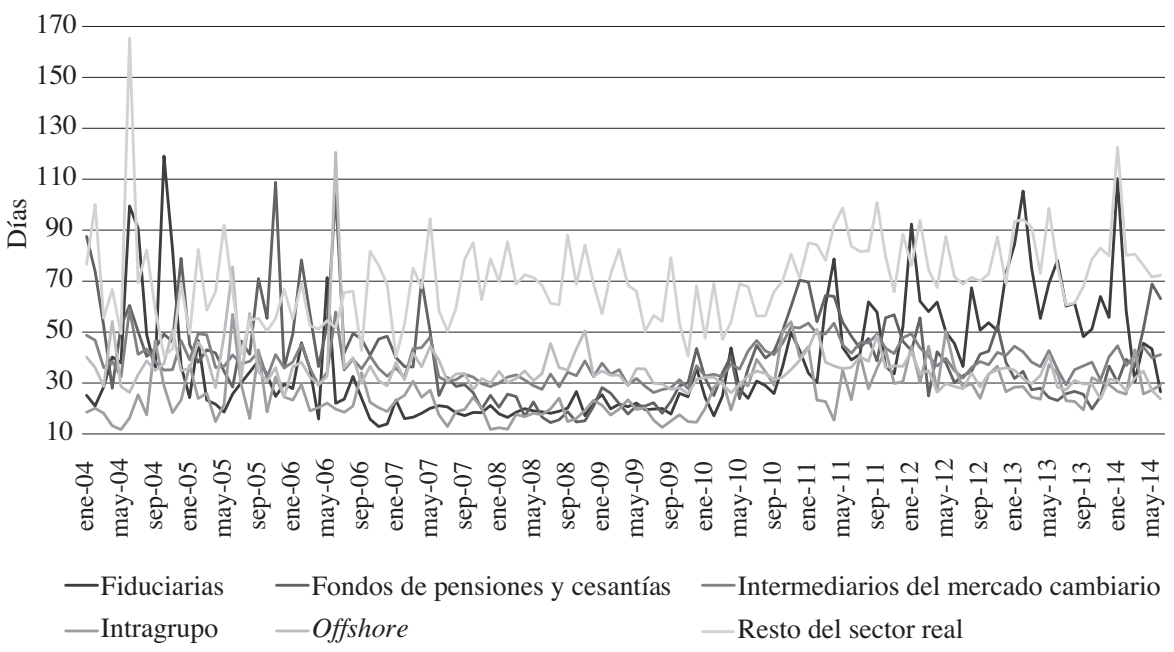

En cuanto a la modalidad de cumplimiento de las operaciones, como se puede observar en el gráfico 12, casi la totalidad de las operaciones se realizan con cumplimiento financiero (NDF). En estas operaciones no hay intercambio de los flujos totales de divisas y pesos, sino que se realiza una liquidación en la cual se calcula un 
flujo neto a partir de las pérdidas o ganancias de cada agente frente a la tasa de referencia del día del vencimiento. La alta negociación de forwards con cumplimiento financiero puede ser explicada por el hecho que la reglamentación cambiaria del BR solo autoriza realizar derivados cambiarios con cumplimiento efectivo (Delivery Forward), si estos están cubriendo operaciones obligatoriamente canalizables por el mercado cambiario u otras de las operaciones contempladas por la regulación ${ }^{8}$.

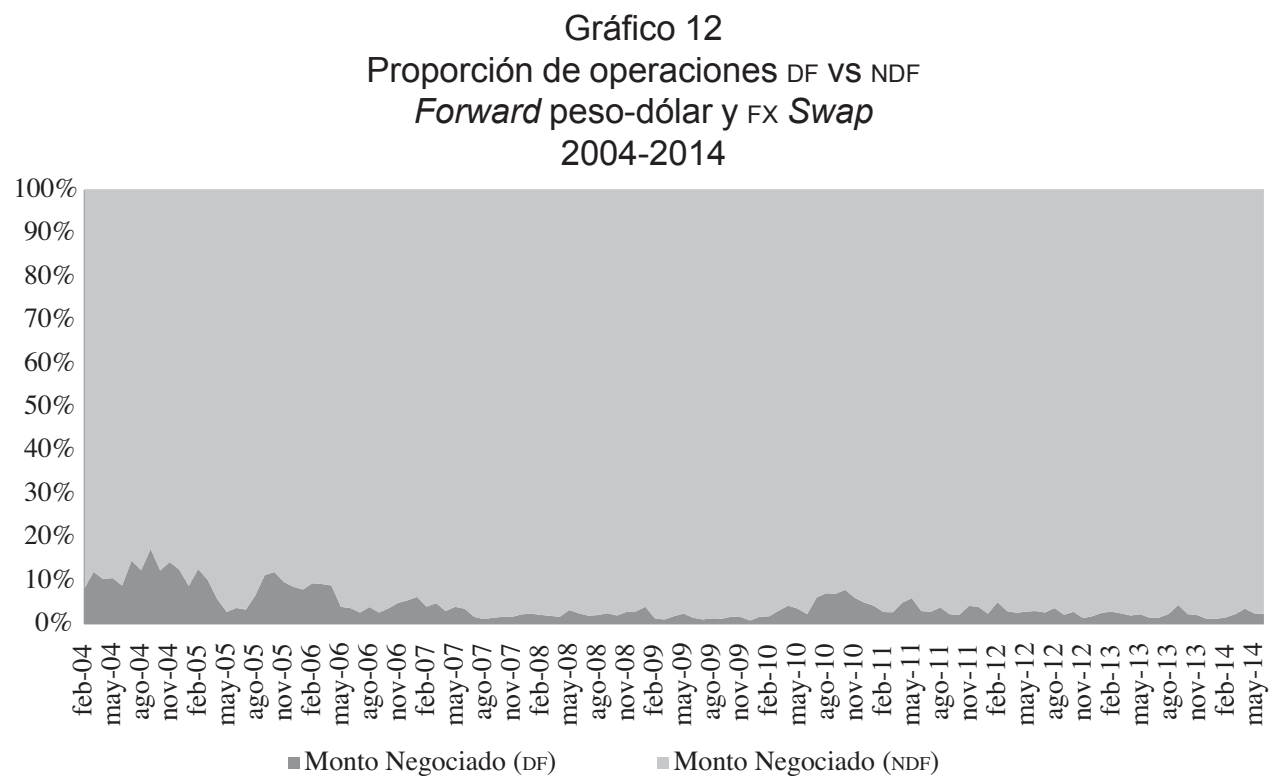

Adicionalmente, se ha observado que los IMC buscan compensar la exposición cambiaria tomada en el mercado de derivados mediante operaciones inversas en el mismo mercado. En caso de no encontrar la cobertura en el mercado de derivados, los IMC generalmente realizan la cobertura con cambios en sus activos líquidos en moneda extranjera-Posición Propia de Contado (PPC)- con el fin de mantener

$8 \quad$ Entre ellas se encuentran: i) una obligación de pago con el exterior que resulte de la compra de bienes de usuarios de las zonas francas o de residentes no usuarios que hagan depósitos de mercancía en las zonas francas; ii) una obligación o un derecho con el exterior que surja de operaciones de envío y recepción de giros y remesas en moneda extranjera de sociedades de intermediación cambiaria y de servicios financieros especiales; iii) inversión extranjera directa o emisiones en el mercado público de valores en Colombia realizadas por no residentes. 
su exposición cambiaria total -Posición Propia (PP)- constante $^{9}$ (gráfico 13). Lo anterior genera una relación entre el mercado forward y el mercado de contado.

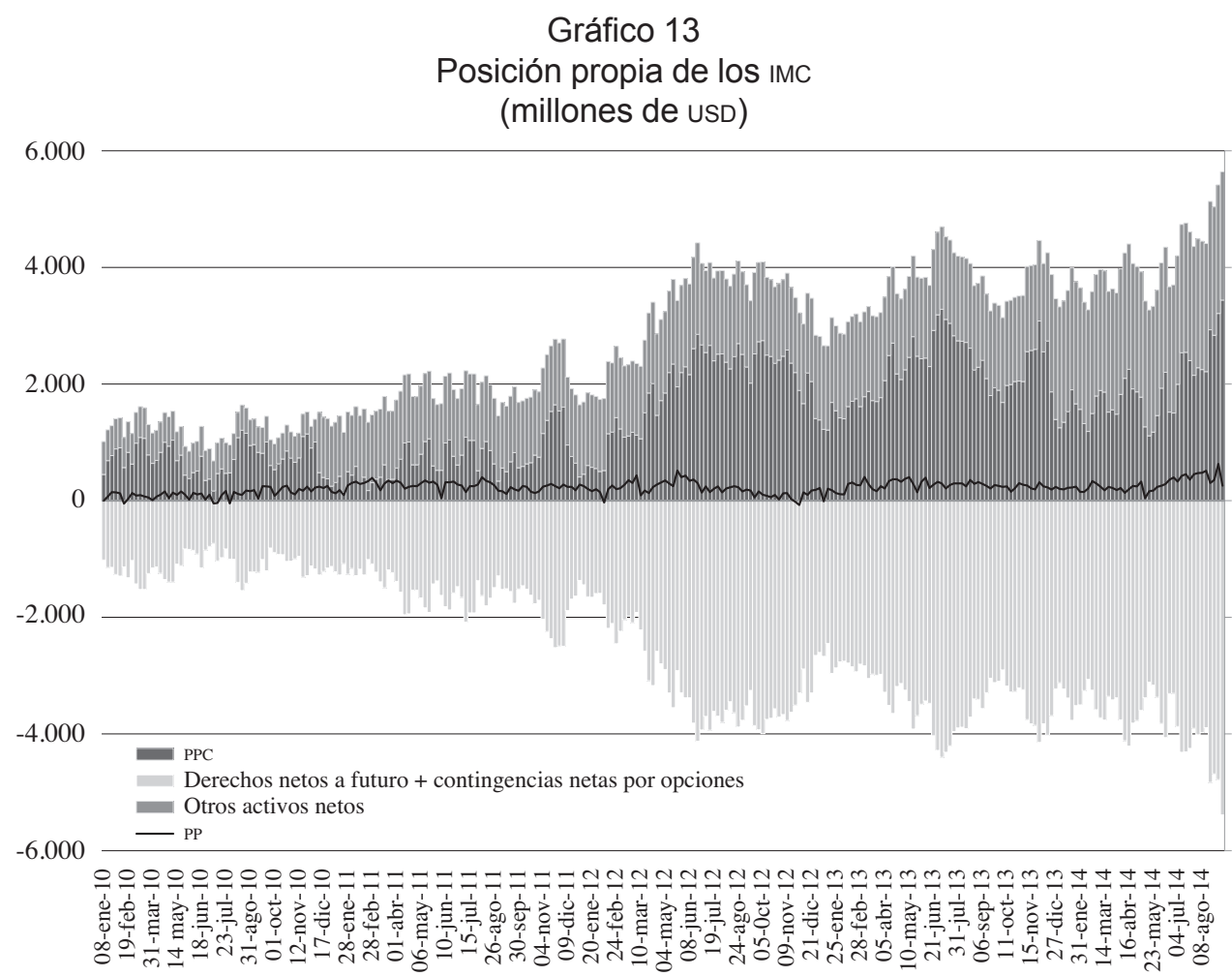

Por otra parte, y en línea con el crecimiento de este mercado, y posiblemente impulsado por cambios regulatorios, la compensación de estos productos a través de la Cámara de Riesgo Central de Contraparte (CRCC) ha aumentado desde 2010 (fecha en la cual se empezaron a compensar los productos a través de esta entidad), presentando un promedio mensual de US\$3.000 millones en 2013 y de US\$3.500 millones entre enero y junio 2014. La eliminación de las operaciones de derivados compensadas en la CRCC del cómputo de los activos ponderados por riesgo en la relación de solvencia, y la exclusión de los forwards compensados en una CRCC del cálculo de la posición bruta de apalancamiento $(\mathrm{PBA})^{10}$, pudieron impulsar la compensación y liquidación de estos contratos a través de esta entidad.

9 Para mayor información de la PP y PPC consultar el Anexo 1.
$10 \quad$ Para mayor información ver Anexo 1. 
Aunque cerca del $11 \%$ de los forwards peso-dólar negociados en lo corrido de 2014 se han llevado a la CRCC (gráfico 14), se debe resaltar que el 15\% de las negociaciones totales son realizadas entre IMC. Esto significa que cerca del $80 \%$ de las operaciones interbancarias se estarían compensando y liquidando actualmente a través de una CRCC. De igual manera, vale la pena resaltar que aunque las negociaciones de forwards entre IMC y agentes del sector real también pueden ser compensadas y liquidadas a través de esta entidad, esta no es una práctica común en el mercado.

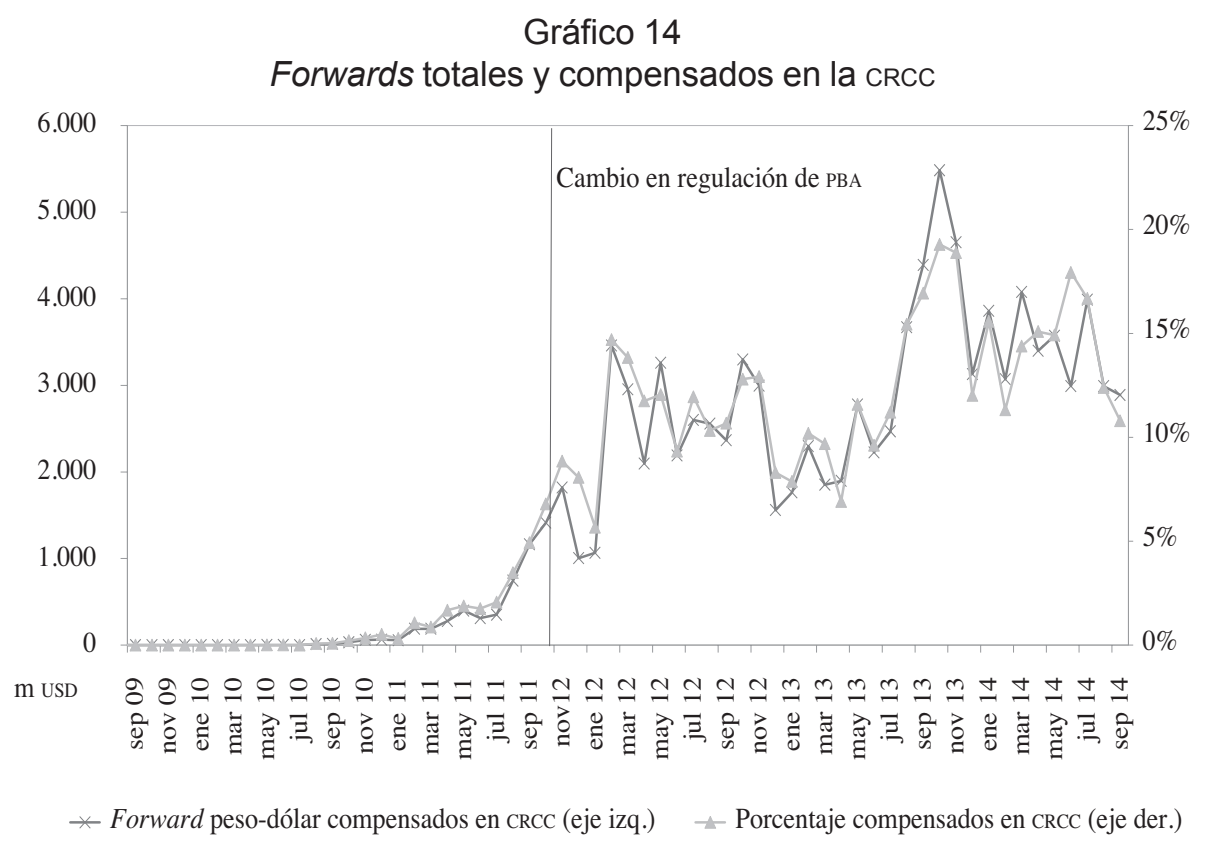

\subsubsection{Precios}

Una variable que permite monitorizar la evolución de los precios de los contratos forwards es la devaluación implícita ${ }^{11}$. Esta se define como el porcentaje en el cual la tasa de cambio pactada a futuro está por encima de la tasa de cambio de contado en el momento de la operación, y se expresa en términos anuales con el fin de realizar comparaciones entre los contratos que se transan a diferentes plazos. De acuerdo con la relación de paridad explicada en el Anexo 1, la diferencia entre la

$11 \quad$ Para mayor información ver Anexo 1.

PP. $7-79 \cdot N .^{\circ} 9 / 2015$ 
tasa de interés interna y externa (devaluación teórica), y la devaluación implícita se deberían comportar de manera similar con el fin de evitar oportunidades de arbitraje. En el gráfico 15 se evidencia para el plazo de un mes que, en general, la devaluación implícita fluctúa alrededor del diferencial entre la tasa de las simultáneas y la LIBOR, aunque en algunos periodos se aleja de este valor.

\section{Gráfico 15}

Diferencia tasa interna y externa vs. Devaluación implícita contratos forward

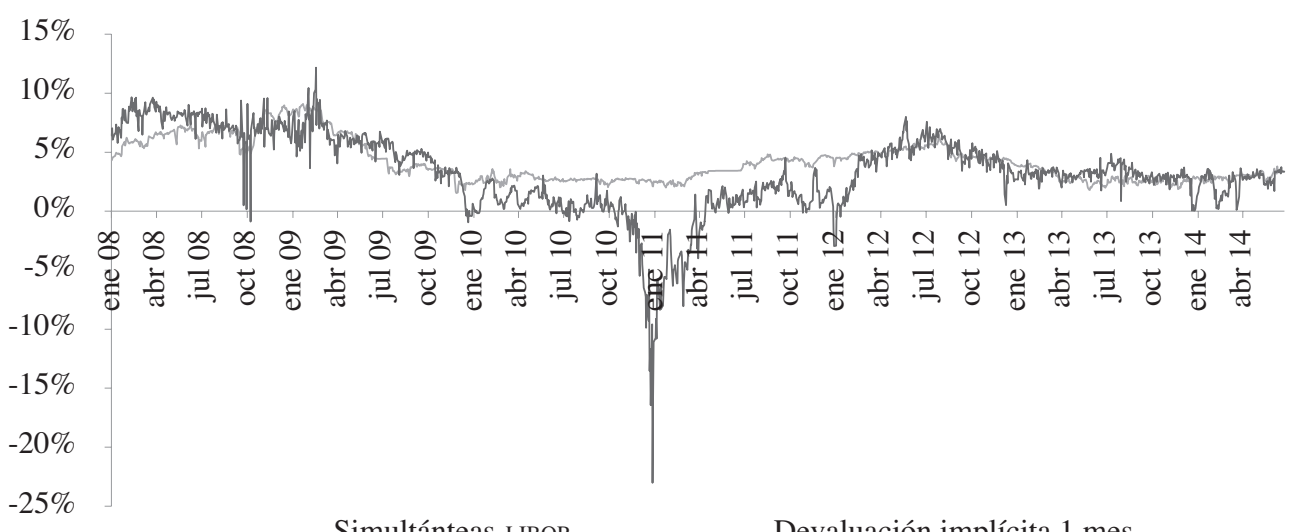

— Simultánteas-LIBOR — Devaluación implícita 1 mes

Como se observa, en algunos periodos la devaluación implícita se ha ubicado significativamente por debajo de la devaluación teórica, hecho que fue más pronunciado hacia finales de 2010 y que continuó durante 2011. Estas desviaciones pueden ser explicadas por distintos factores dentro de los que se encuentra la regulación sobre la PPC $^{12}$ (gráfico 16). Cuando la PPC se acerca a su límite inferior, aumenta el costo de oportunidad de una compra de dólares a futuro por parte de los IMC, considerando que si la cobertura de dichas posiciones no se encuentra en el mercado de derivados, es necesario realizarla mediante la oferta de divisas en el mercado de contado en momentos en los que la PPC es muy cercana a cero. En caso que el intermediario no encuentre la cobertura, este debe tomar la exposición cambiaria correspondiente a la operación, lo cual motivaría un desplazamiento hacia abajo de la curva de demanda de dólares a futuro de los IMC. Lo anterior, ocasionaría una caída de los precios pactados en estas operaciones.

12 El límite inferior de la posición propia de contado es $0 \%$ del patrimonio técnico de las entidades. 
Gráfico 16

Devaluación implícita contratos forward vs. PPC

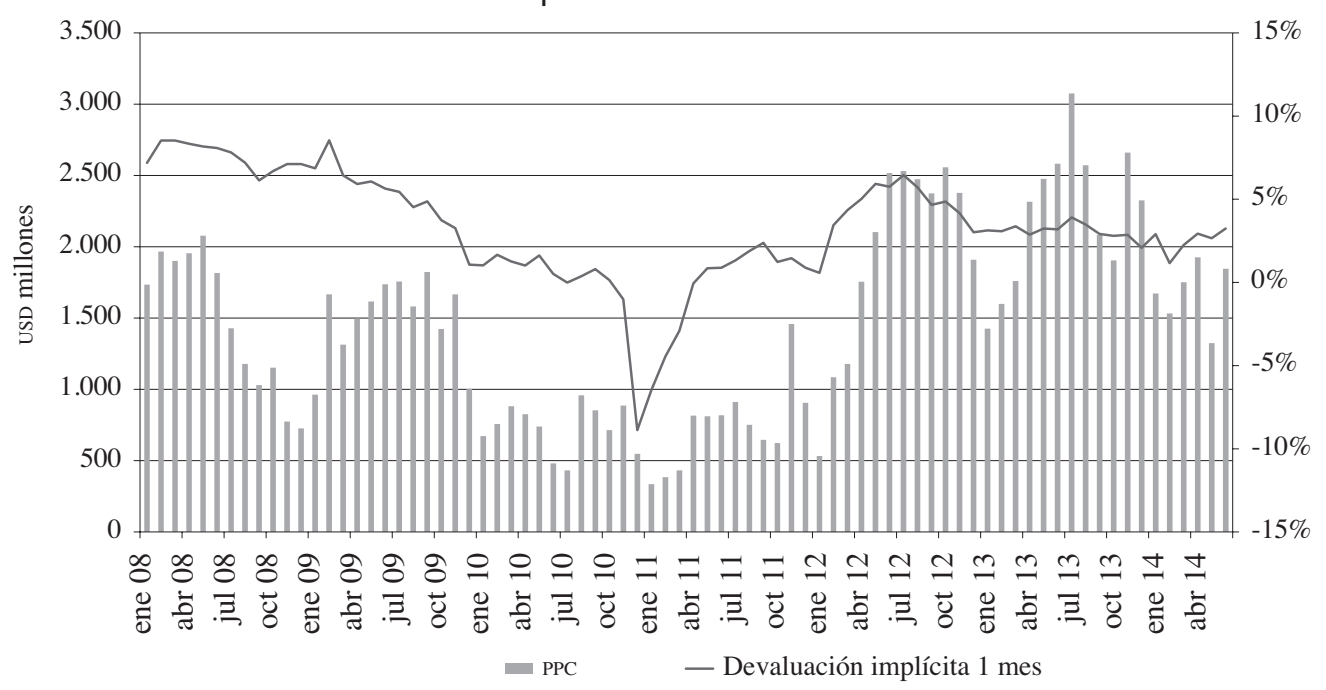

Al analizar la devaluación implícita por tipo de agente, se observa que el comportamiento es similar para los diferentes sectores (gráfico 17). No obstante, en algunos periodos, como entre 2007 y 2009, las devaluaciones implícitas de las negociaciones entre entidades de un mismo grupo financiero del exterior (intragrupo) se encuentran considerablemente por debajo de las devaluaciones negociadas con otros agentes.

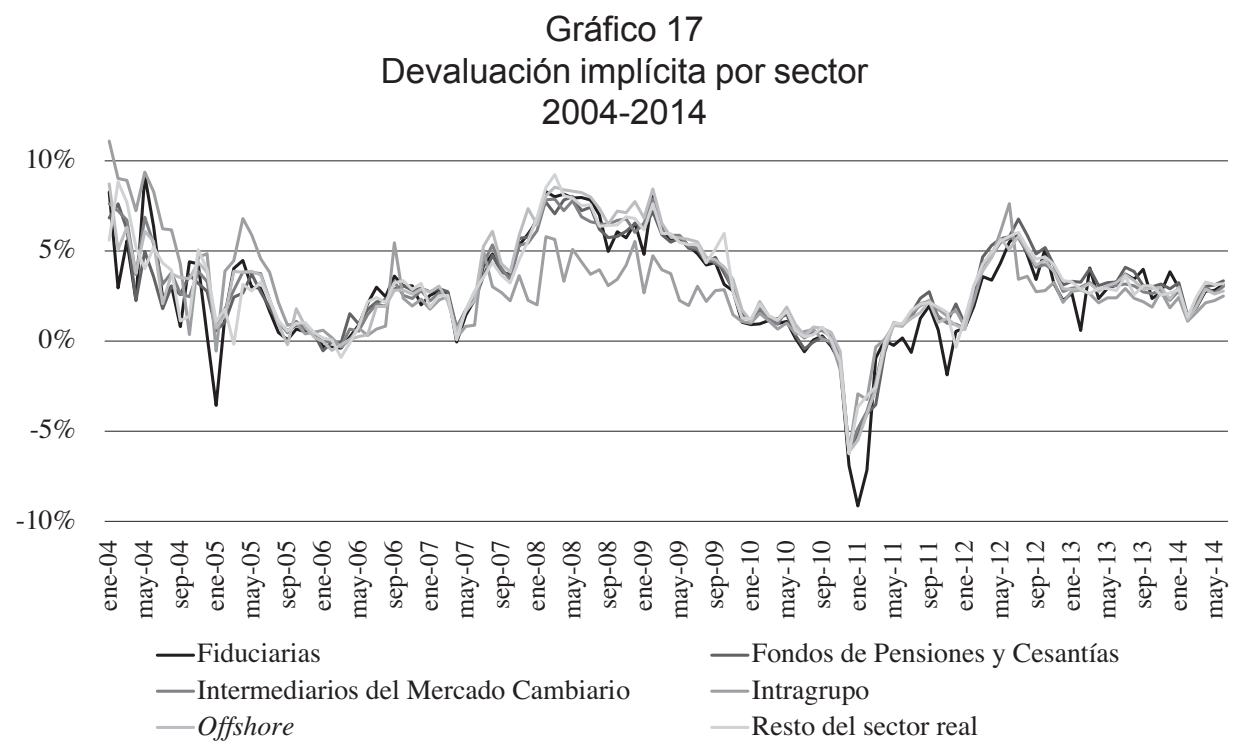


Por otra parte, el spread entre las devaluaciones implícitas de las operaciones de compra y venta de los IMC es diferente para el sector real y el intragrupo. El spread del sector real es mayor al de los otros sectores, posiblemente debido a que este es un sector más segmentado y a que participa con montos menores, lo que los hace tomadores de precios (tabla 4). Por su parte, las operaciones con el intragrupo presentan diferencias negativas (los IMC les venden a precios menores a los que les compran) en algunos periodos. Aunque en la tabla 4 se tienen en cuenta operaciones a distintos plazos, se debe resaltar que al realizar este análisis discriminando por el plazo de las operaciones, la conclusión general se mantiene. En el Anexo 2 se presentan estos cálculos.

Tabla 4

Promedio diferencia devaluación implícita compra y venta por sector

\begin{tabular}{|c|c|c|c|c|}
\hline & $\begin{array}{c}\text { Fondos de pensiones } \\
\text { y cesantías (\%) }\end{array}$ & Intragrupo (\%) & Offshore (\%) & Sector real (\%) \\
\hline 2008 & 0,23 & $-0,37$ & 0,97 & 1,10 \\
\hline 2009 & 0,42 & 0,81 & 0,65 & 2,09 \\
\hline 2010 & $-0,37$ & 0,44 & 0,24 & 1,63 \\
\hline 2011 & 0,37 & 0,81 & 0,53 & 2,09 \\
\hline 2012 & 0,13 & $-0,67$ & 0,86 & 1,65 \\
\hline 2013 & 0,13 & 0,11 & 0,51 & 1,58 \\
\hline 2014 & 0,37 & $-0,09$ & 0,38 & 1,70 \\
\hline
\end{tabular}

A continuación se presenta el comportamiento de los diferentes tipos de agentes en el mercado de forwards peso-dólar, con el fin de destacar características particulares en cada uno de ellos.

\subsubsection{Contrapartes}

\subsubsection{Características de los agentes offshore}

Como se observa en el gráfico 18, los agentes offshore son compradores netos de dólares en forwards peso-dólar y mantienen saldos significativamente mayores a los que presentan en otros derivados, en los cuales, como se analizará más adelante, también presentan una posición larga en dólares. Esto puede obedecer a la cobertura de las inversiones realizadas por los extranjeros en moneda local. 


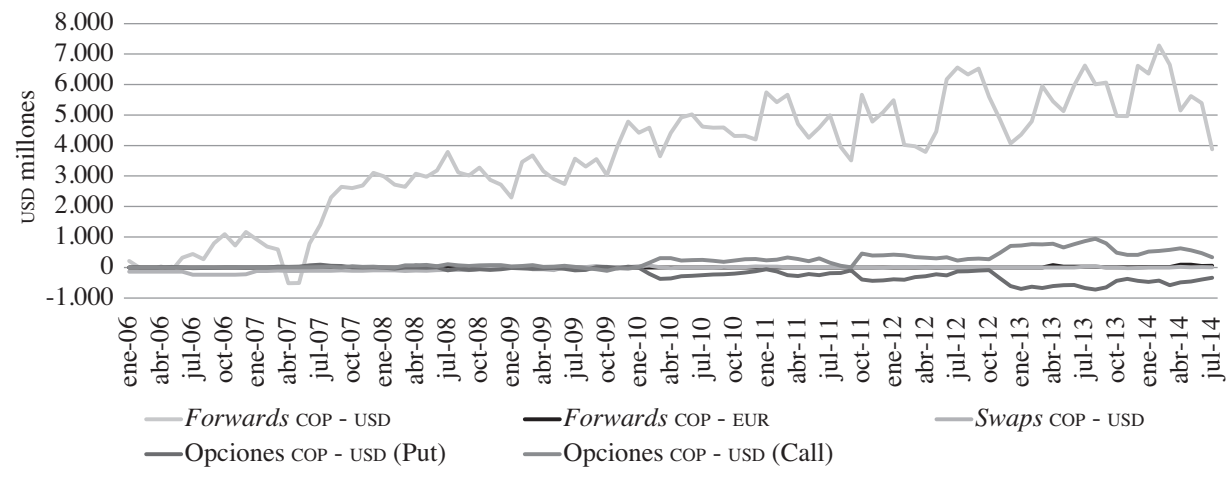

Adicionalmente, y en línea con su saldo neto de compra, estos agentes realizan una mayor cantidad de negociaciones de compra de dólares a futuro que de venta (gráfico 19). Las compras de dólares a futuro pueden estar relacionadas con la cobertura de sus inversiones en Colombia, mientras que las ventas pueden estar relacionadas con la cobertura de flujos asociados a entradas de divisas. Se debe resaltar que en los últimos años, la proporción de ventas negociadas con respecto a las negociaciones totales ha aumentado considerablemente (en 2008 esta proporción correspondía a $28 \%$, mientras que en 2014 esta proporción se ubica en $43 \%)$. Esto puede estar relacionado con la cobertura de los flujos de entradas de divisas por inversiones y con mayores apuestas a favor del peso colombiano, ante expectativas de apreciación debido a factores como fundamentales positivos de la economía colombiana, que llevaron al aumento de su calificación de deuda soberana en varios niveles, $\mathrm{y}$ a las amplias condiciones de liquidez internacional a partir de la crisis de 2008, que en conjunto motivaron a los inversionistas extranjeros a buscar mayores rendimientos en países emergentes.

Adicionalmente, si bien la posición estructural de estos agentes en el mercado de forwards es de compra, la volatilidad de su posición podría estar asociada al uso de este mercado como mecanismo para reducir o incrementar su exposición al riesgo local. Se ha encontrado que los momentos en los cuales la posición compradora (definida como el cambio en su saldo neto en el mes) del offshore ha sido superior a una desviación estándar frente a su promedio han coincidido con picos negativos 
en la inversión de portafolio (salidas netas de divisas) ${ }^{13}$ (gráfico 20). Tres de estos picos coinciden con aumentos en la percepción de riesgo internacional - medida a través de los Credit Default Swaps (CDS) de Colombia y de la región-, mientras que el pico restante, coincide con un deterioro en la confianza a nivel local ${ }^{14}$. Adicionalmente, se debe resaltar que los episodios de salidas de divisas por el concepto de inversión de portafolio, han coincidido con compras netas por encima de US\$500 millones por parte de los agentes offshore ${ }^{15}$. También se resalta el caso particular de marzo de 2014, cuando la alta cantidad de ventas de dólares a futuro por parte del offshore podría ser explicada por entradas de capitales ante la mayor participación de Colombia en los índices de deuda de JP Morgan, y ante expectativas de apreciación del peso por esta misma razón. Lo anterior podría dar evidencia de la relación entre la utilización del mercado de forwards y los flujos de capitales.

Gráfico 19

Montos negociados entre el offshore y los IMC

Forward peso-dólar

2006-2014

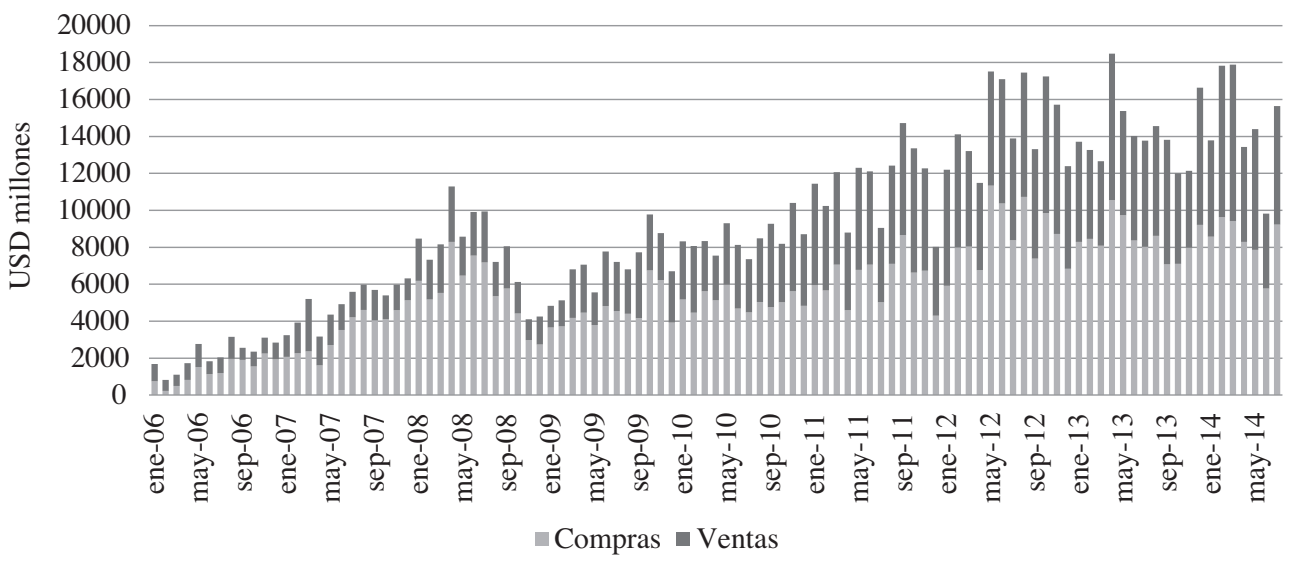

13 Se debe mencionar que en cuatro de los cinco picos señalados, coincide con incrementos en la percepción de riesgo, mientras que en el pico restante (noviembre de 2010), se observa que es en el siguiente mes en el cual cae de forma importante la inversión de portafolio en Colombia.

14 El pico que no está asociado a un aumento en la percepción de riesgo internacional corresponde a octubre de 2010.

15 De esta forma compran los dólares a futuro con vencimiento en las fechas que planean liquidar sus posiciones, y reducen su exposición al riesgo en Colombia. 
Posición offshore vs. Inversión extranjera de portafolio

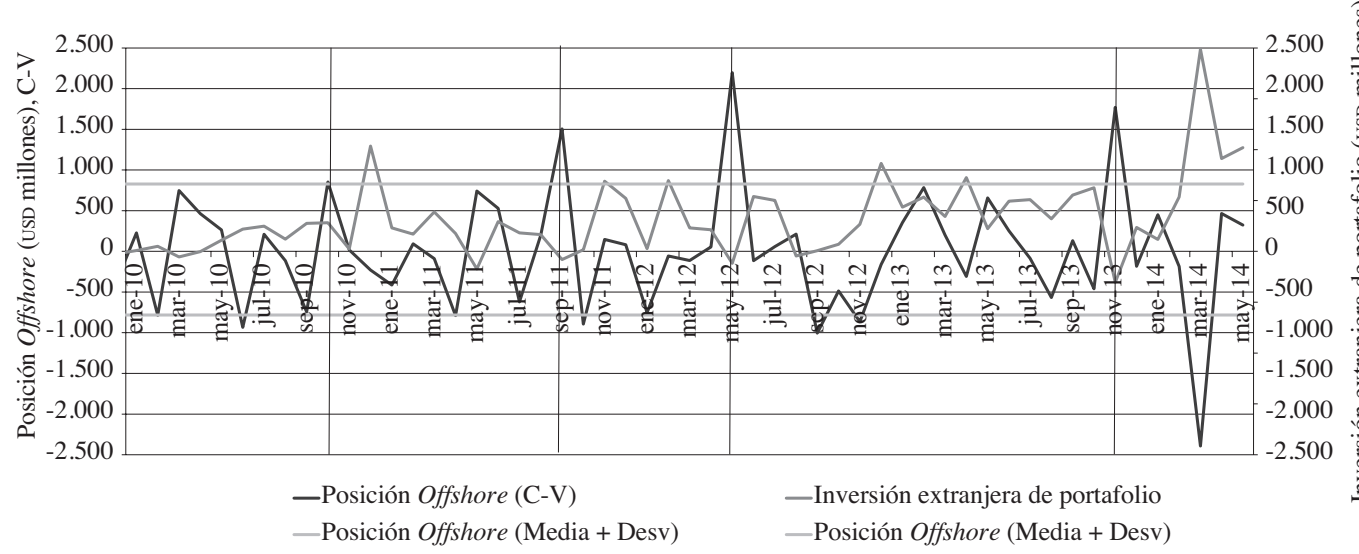

Vale la pena resaltar que de acuerdo con algunos participantes del mercado, las compras o ventas de los agentes offshore en el mercado forward se trasladan rápidamente al mercado de contado, por lo cual sus negociaciones generan volatilidad en el mercado de divisas.

\subsubsection{Características de los agentes del sector real}

El mercado de forwards peso-dólar es el más utilizado por el sector real debido a que es el derivado más líquido, lo que les permitiría obtener coberturas a menores precios. Adicionalmente, desde el punto de vista de los IMC, estos instrumentos tienen plazos más cortos que los demás tipos de derivados cambiarios, y de esta forma les generan una menor exposición crediticia frente a sus clientes.

Históricamente, el sector real ha presentado un saldo neto de compra con el sector financiero en las operaciones forward peso-dólar (gráfico 21). El saldo de compras netas ha tenido una tendencia creciente, y ha presentado saltos en algunos periodos en 2007 y 2010. Esta tendencia puede estar relacionada con el comportamiento de la devaluación implícita de estos contratos y por el aumento en la demanda por coberturas. En términos de montos negociados, desde finales de 2009 se destaca el incremento en la negociación de forwards peso-dólar por parte de este sector, debido posiblemente a que después de la crisis de 2008, una mayor cantidad de empresas buscaron cobertura ante los riesgos asociados a la tasa de cambio. No obstante, a partir de este salto, los montos negociados totales se han mantenido relativamente estables (gráfico 22). 
Gráfico 21

Saldo sector real (C-V)

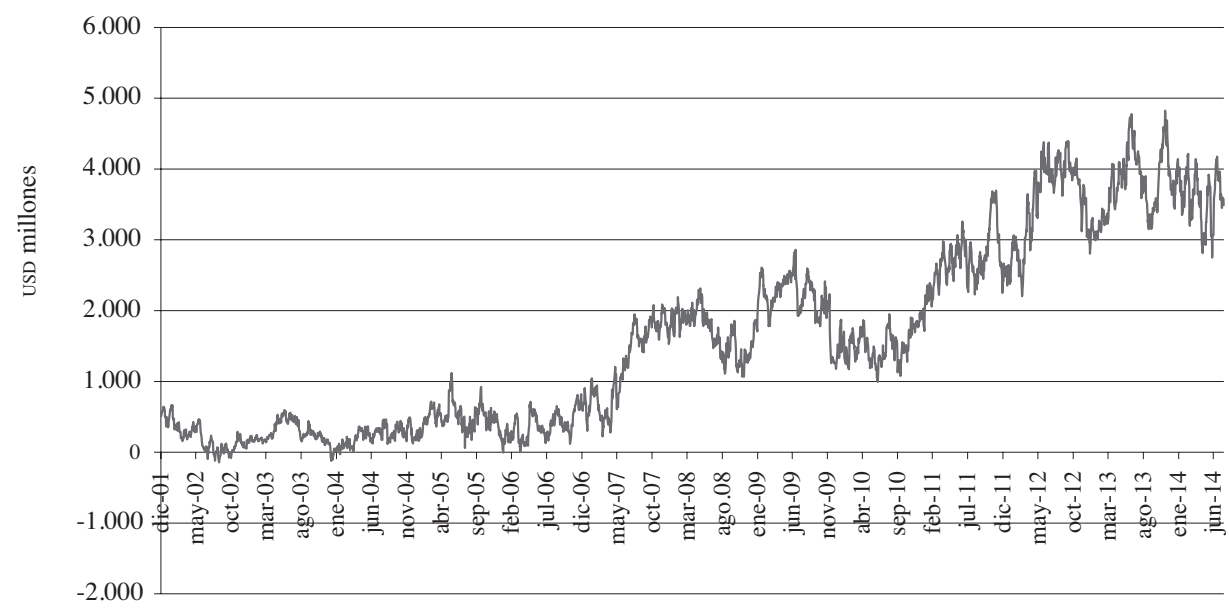

Gráfico 22

Montos negociados por el sector real Forward peso-dólar y Fx Swap

2008-2014

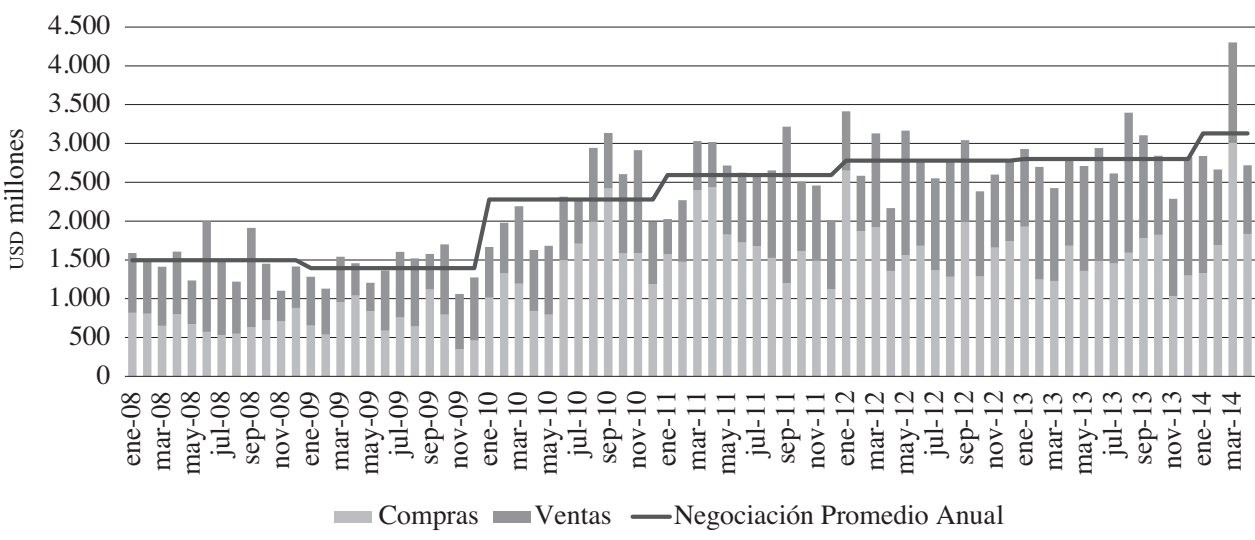

En cuanto a la composición de este sector, se resalta la alta cantidad y heterogeneidad de las empresas que participan en el mercado (gráfico 23), además de la tendencia creciente que presenta el número de participantes desde 2009. En particular, los subsectores con mayor participación dentro del sector real son comercio e industria manufacturera (gráfico 24). Teniendo en cuenta lo anterior, y el diferencial entre las tasas a las cuales el sector financiero les vende y les compra dólares en estos contratos, se considera que este sector se caracteriza por ser tomador de precios. 
Gráfico 23

Número de participantes

Forward peso-dólar y Fx Swap

2008-2014

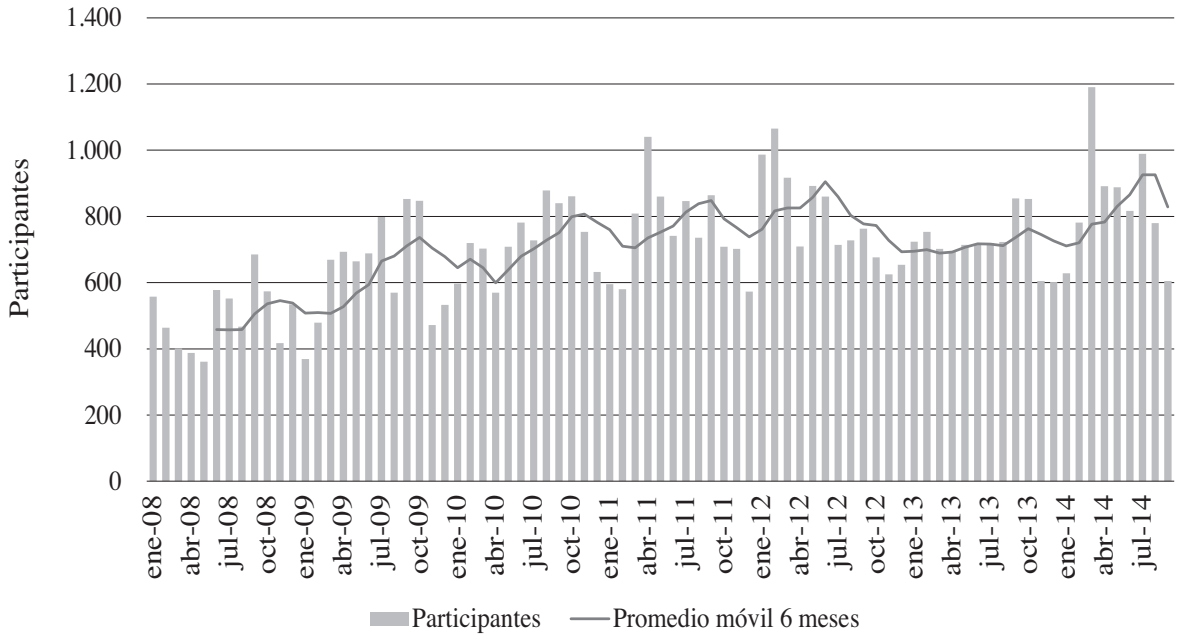

Gráfico 24

Distribución por subsectores

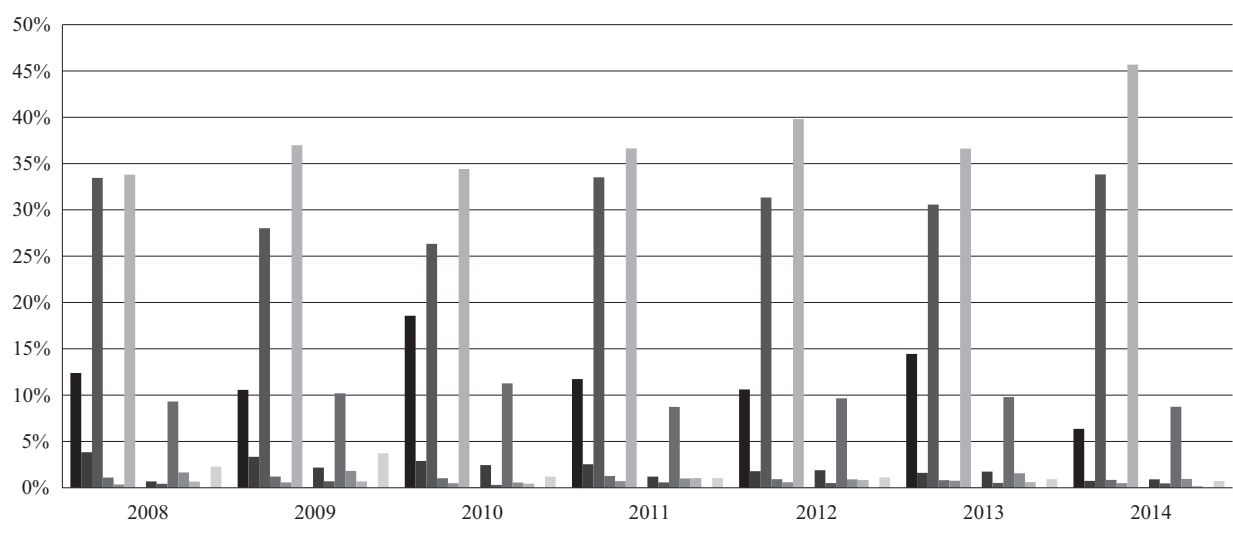

- Agricultura, ganadería, caza, silvicultura, extracción de madera, pesca y actividades de servicios conexas

- Industria manufacturera

- Comercio

- Actividades empresariales: actividades inmobiliarias, alquiler de maquinaria y equipo, informática y actividades conexas, investigación y desarrollo, otras actividades empresariales 
Por otra parte, se destaca que las empresas del sector real también utilizan el mercado de forwards peso-dólar con el fin de aprovechar las bajas tasas de interés internacionales y obtener costos de fondeo menores a los que se podrían obtener en moneda local, sin necesidad de tomar la exposición cambiaria resultante de los créditos en moneda extranjera. Como se puede observar en el gráfico 25 , en periodos en los cuales la devaluación implícita de los contratos forward se encuentra por debajo de la devaluación teórica, los desembolsos de endeudamiento externo han aumentado. De esta forma, se evidencia que las empresas pueden aprovechar las desviaciones del mercado de forwards con respecto al precio teórico, obteniendo el equivalente a un crédito en pesos con una tasa de interés menor a la del mercado local. Para crear el crédito sintético en moneda local, las empresas reciben créditos en moneda extranjera, al tiempo que compran dólares a futuro, lo cual garantiza el monto en pesos necesario para cubrir los pagos asociados al crédito.

Gráfico 25

Desembolsos de endeudamiento externo vs. diferencia entre devaluación implícita observada y teórica

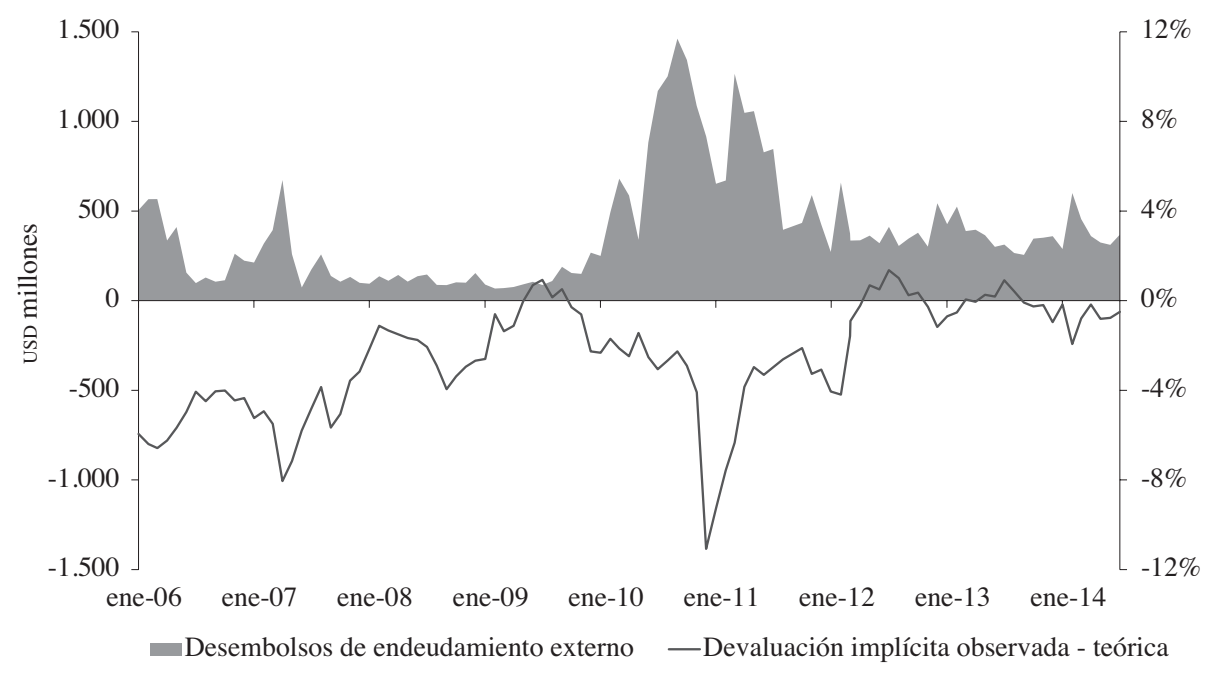

En línea con lo anterior, también se ha observado que en momentos en los cuales el precio de los contratos forward con respecto a su valor teórico disminuye, los agentes del sector real aumentan su porcentaje de cobertura de los créditos en moneda extranjera (gráfico 26). 


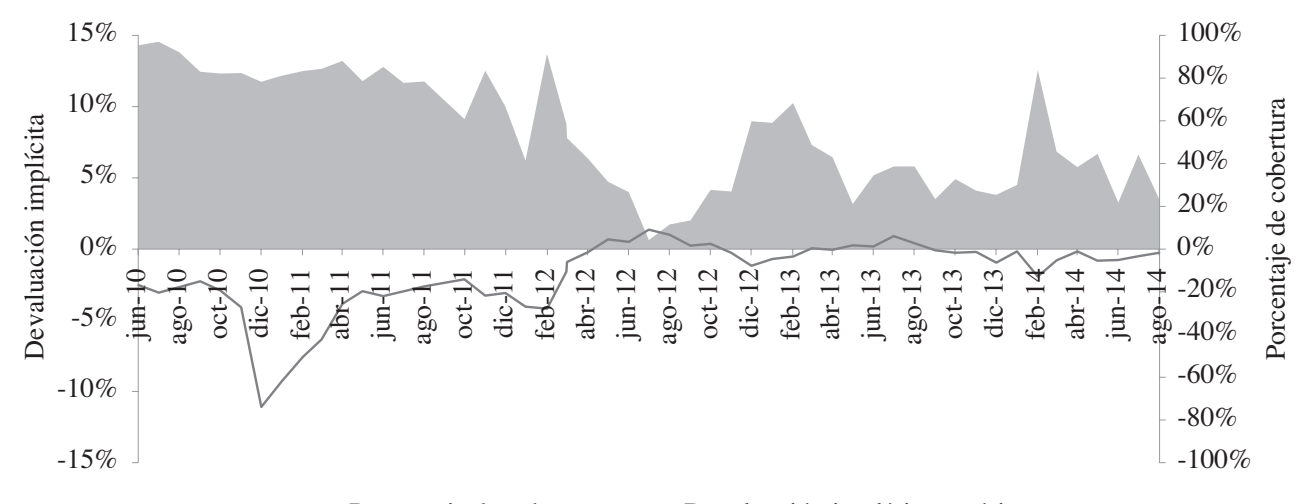

De acuerdo con los intermediarios del mercado, cuando las devaluaciones implícitas de los contratos forward se encuentran altas, es posible que los agentes del sector real utilicen estas condiciones del mercado con el objetivo de realizar estrategias de arbitraje. De esta forma, algunas empresas podrían utilizar sus excesos de liquidez en moneda local para comprar dólares y venderlos a futuro a un precio favorable por encima del teórico.

Las operaciones que les permiten beneficiarse de las distorsiones en el mercado de derivados, son posibles en la medida en que las empresas del sector real no están sujetas a regulaciones como la PPC, por lo cual pueden realizar los ajustes pertinentes para aprovechar las distorsiones de mercado.

Por otra parte, al analizar la información que los agentes del sector real reportan al BR sobre los forwards peso-dólar negociados con agentes del exterior, se encuentra que en promedio estas operaciones ascienden a los US\$266 millones por mes, por lo cual se concluye que la mayor parte de sus operaciones las realizan con los IMC (US\$3.290 millones al mes en promedio) (gráfico 27). 


\section{Gráfico 27}

Negociaciones sector real por contraparte

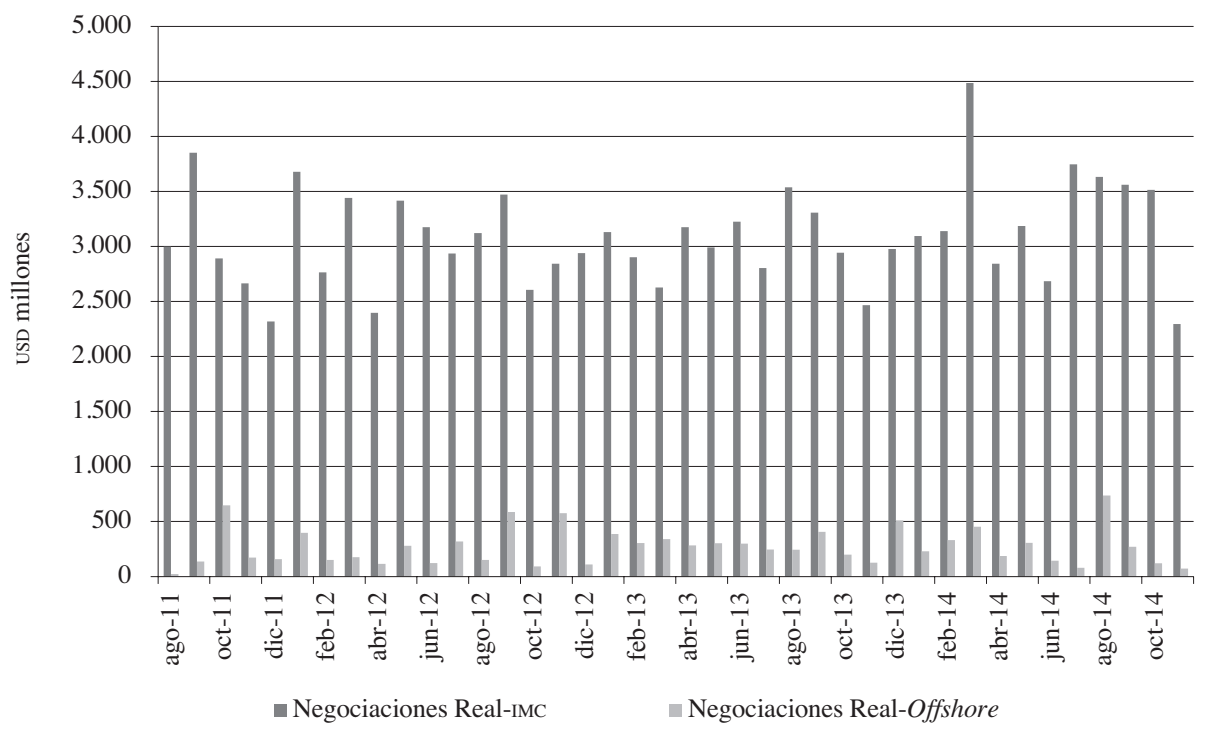

Finalmente, de acuerdo con algunos agentes del mercado, los forwards peso-dólar le son ofrecidos al sector real con fines de cobertura y no de especulación. A continuación se presenta el análisis de los agentes del sector real diferenciados de acuerdo con su actividad de comercio exterior.

Características de importadores y exportadores. Con el fin de establecer el tipo de actividad de comercio exterior que llevan a cabo las empresas del sector real, se tuvieron en cuenta las operaciones de comercio que fueron reportadas al BR en los años 2013 y 2014. Con base en dicha información, se determinó si el agente correspondía a un importador neto (o exportador neto) si presentaba un mayor volumen de importaciones (exportaciones) que de exportaciones (importaciones). Posteriormente, este resultado se utilizó como base para determinar las empresas importadoras y exportadoras de los años anteriores. Una vez identificadas las empresas importadoras y exportadoras netas, se encontró que desde el 2009, el sector real está compuesto principalmente por empresas importadoras netas, seguidas por empresas exportadoras netas, y, en una menor proporción, por empresas de las cuales no se encontró registro de operaciones de comercio exterior (gráfico 28). Esto va en línea con lo encontrado en años anteriores por Kamil, Maiguashca y Pérez (2008). En los últimos años, el sector importador ha aumentado su participación en este mercado, y en 2014, cerca del $63 \%$ de las operaciones del sector real son realizadas por estos agentes, frente a una participación de cerca del 38\% en 2008. 
Gráfico 28

Distribución de empresas del sector real

Forward peso-dólar y Fx Swap

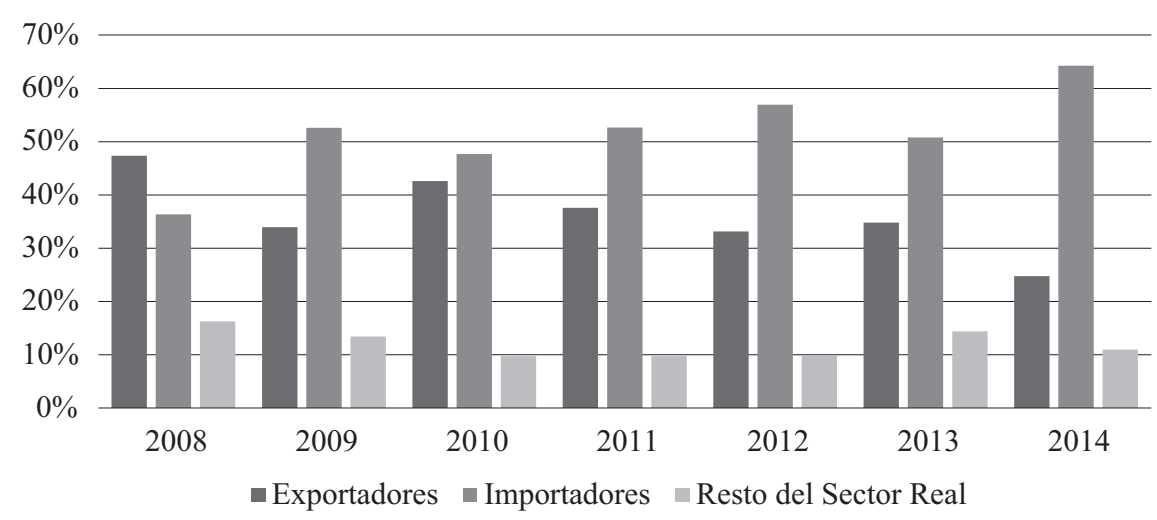

Las negociaciones de los agentes del sector real van en línea con el supuesto de que este sector participa principalmente en este mercado con fines de cobertura. Por lo general, las empresas exportadoras netas pactan contratos de venta de dólares a futuro (gráfico 29), lo cual les permitiría asegurar su ingreso futuro en pesos, y las empresas importadoras netas realizan en su mayoría compras de dólares a futuro, probablemente con el fin de cubrir sus costos futuros en moneda extranjera (gráfico 30).

Gráfico 29

Montos negociados por exportadores

Forward peso-dólar y Fx Swap

2008-2014

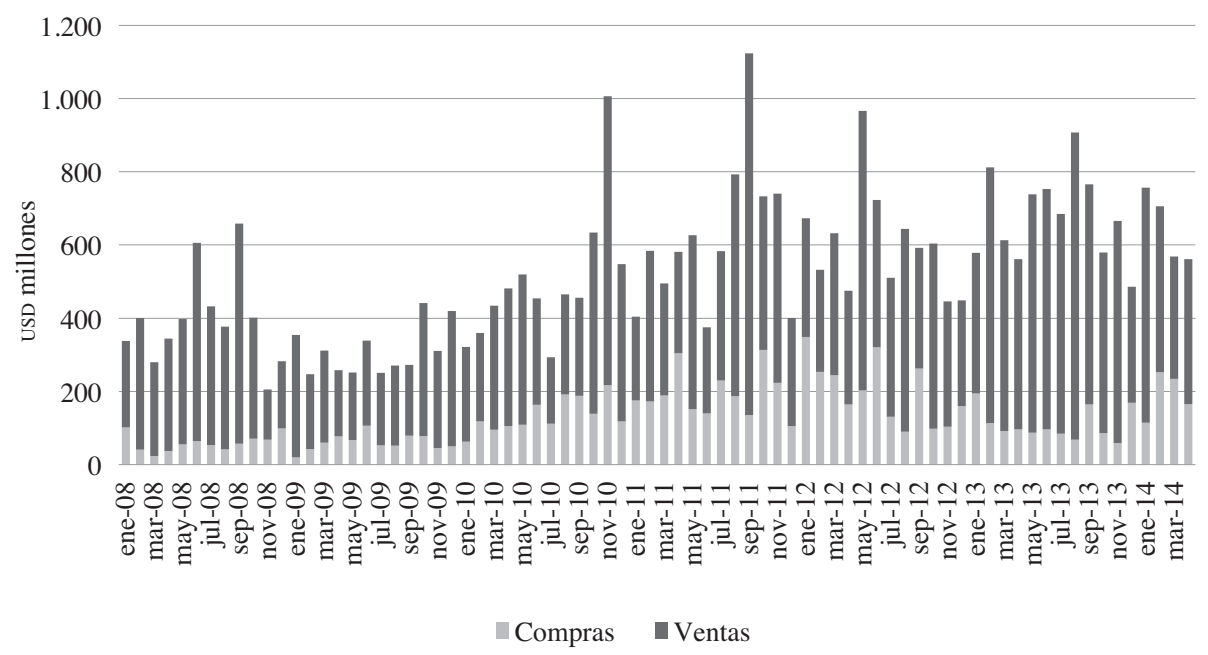


Gráfico 30

Montos negociados por importadores

Forward peso-dólar y Fx Swap

2008-2014

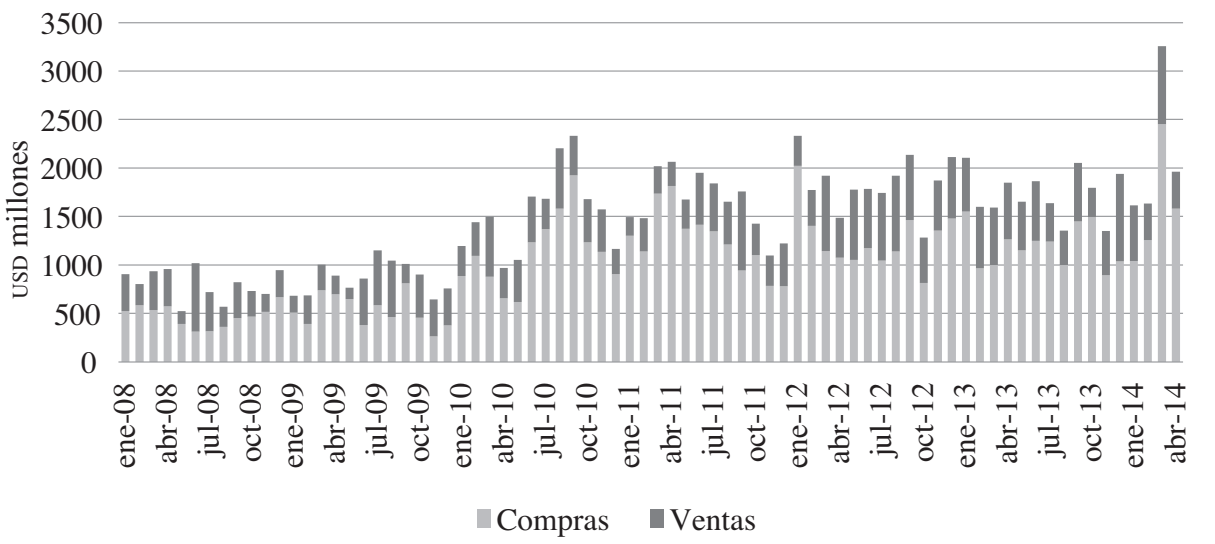

Con respecto a los saldos, se puede observar el mismo comportamiento mencionado, ya que los importadores históricamente presentan un saldo comprador neto y los exportadores un saldo vendedor neto (gráficos 31 y 32). Se destaca que el saldo del sector exportador presenta una mayor volatilidad.

Gráfico 31

Saldos de compra y venta de los exportadores

Forward peso-dólar y Fx Swap

2008-2014

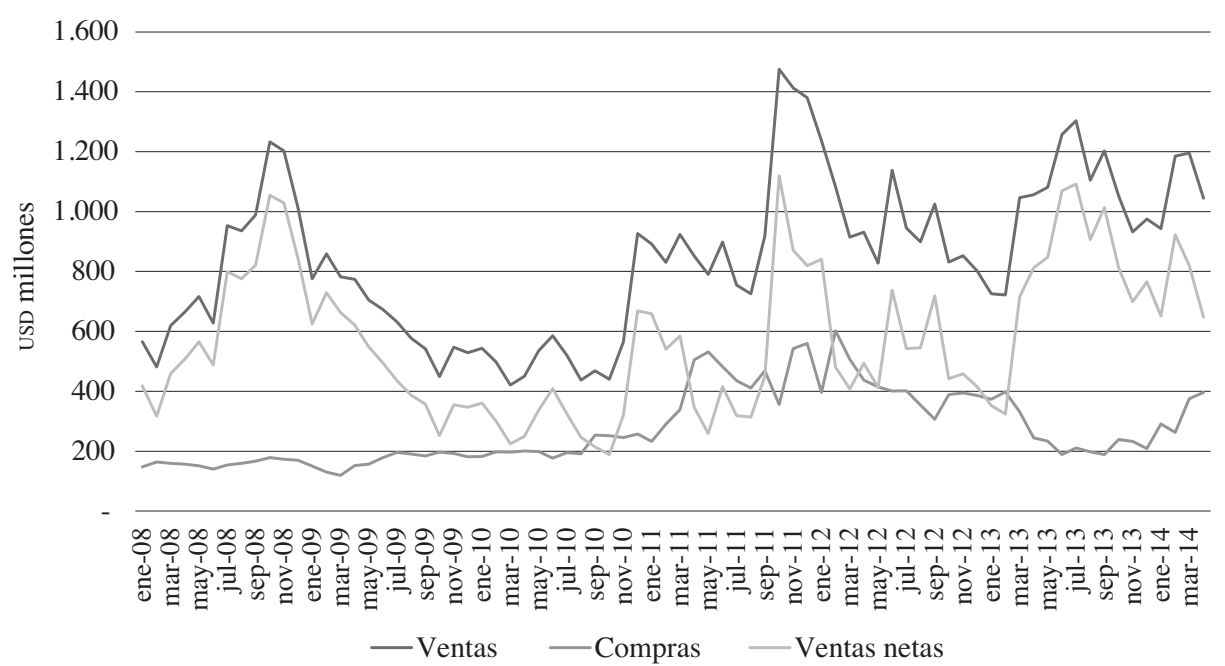

PP. $7-79$ • N. $.^{\circ} 9 / 2015$ 
Gráfico 32

Saldos de compra y venta de los importadores

Forward peso-dólar y FX Swap

2008-2014

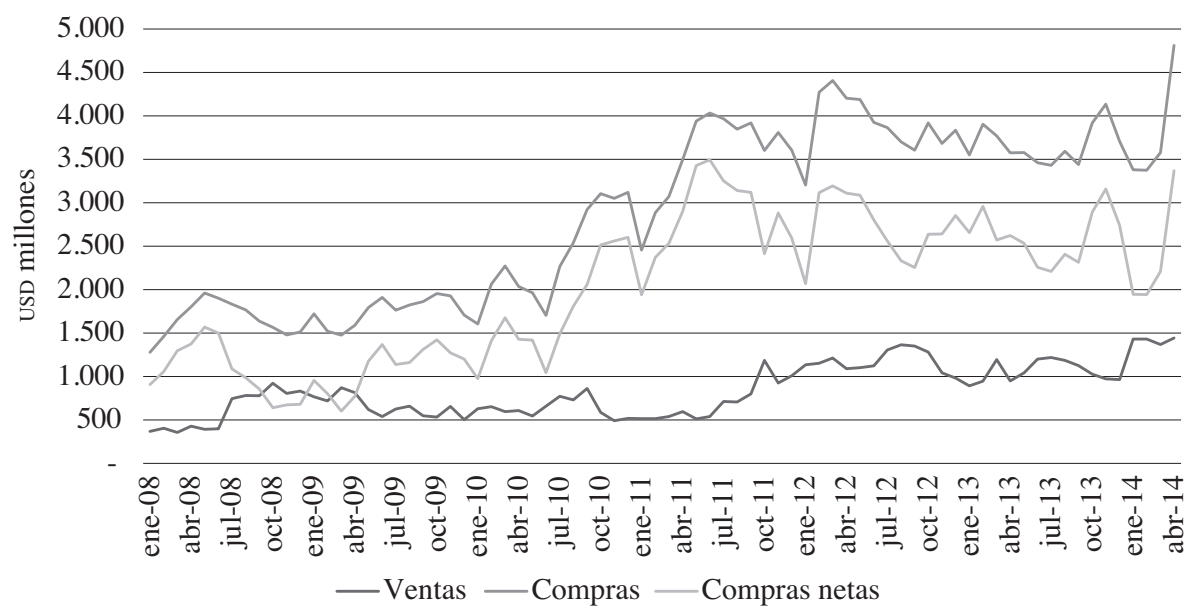

El comportamiento de los saldos de las firmas exportadoras no parece estar estrechamente ligado al de las exportaciones, y su porcentaje de cobertura sobre el total de las exportaciones es reducido (gráficos 33 y 34). En contraste, el comportamiento del saldo de las empresas importadoras parece tener una tendencia similar al de las importaciones (gráficos 35 y 36) y sus compras netas han aumentado, posiblemente en respuesta a la profundización de este mercado en los últimos años, lo que le ha permitido aumentar el porcentaje de cobertura de sus operaciones.

Gráfico 33

Proporción de los saldos de compra de exportadores vs. exportaciones

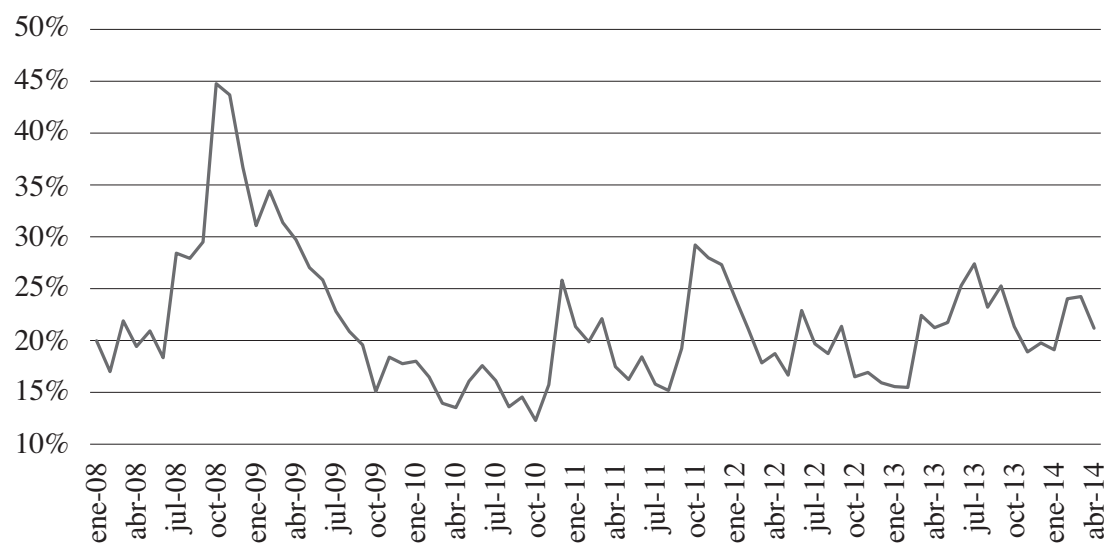




\section{Gráfico 34}

Saldos de ventas en forwards de exportadores vs. exportaciones

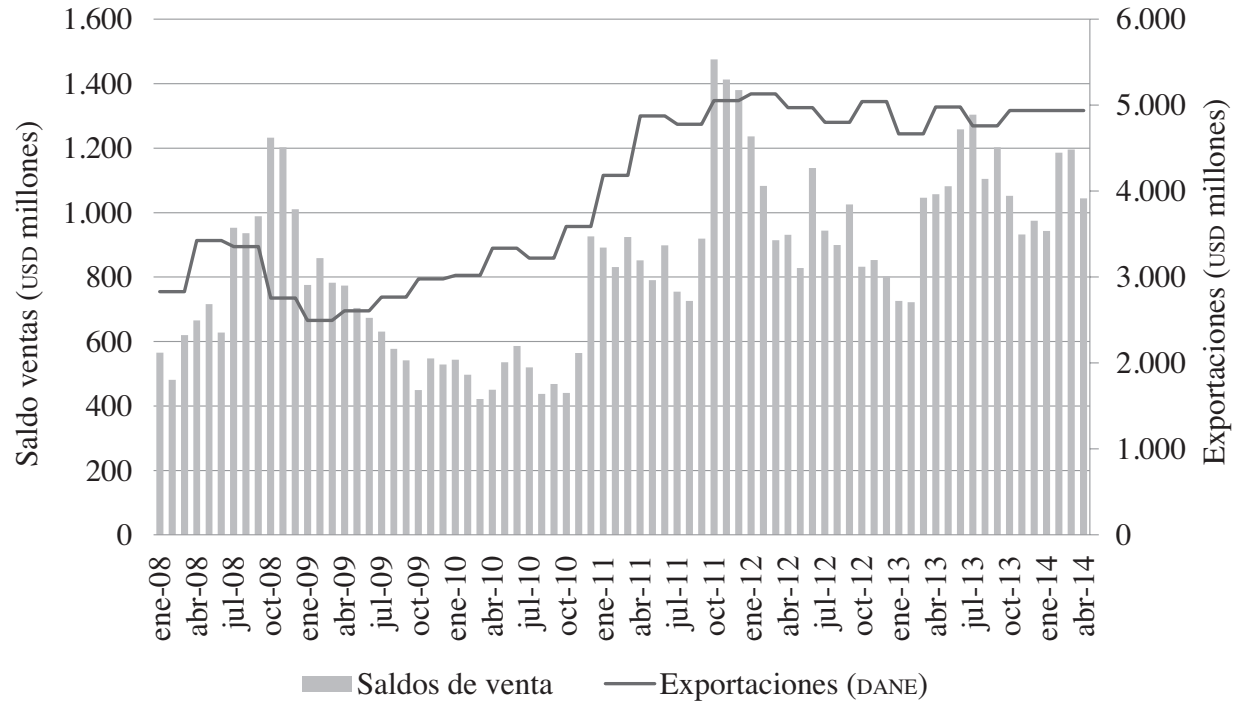

Gráfico 35

Proporción de los saldos de compras de importadores vs. importaciones

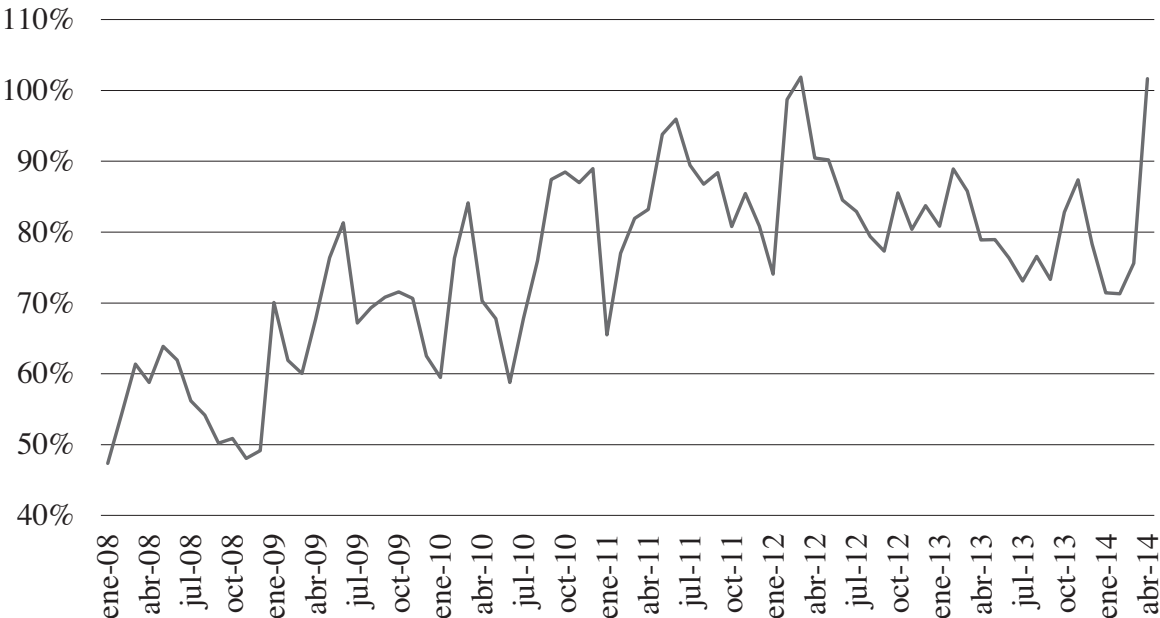


Saldos de compras en forwards de importadores vs. importaciones

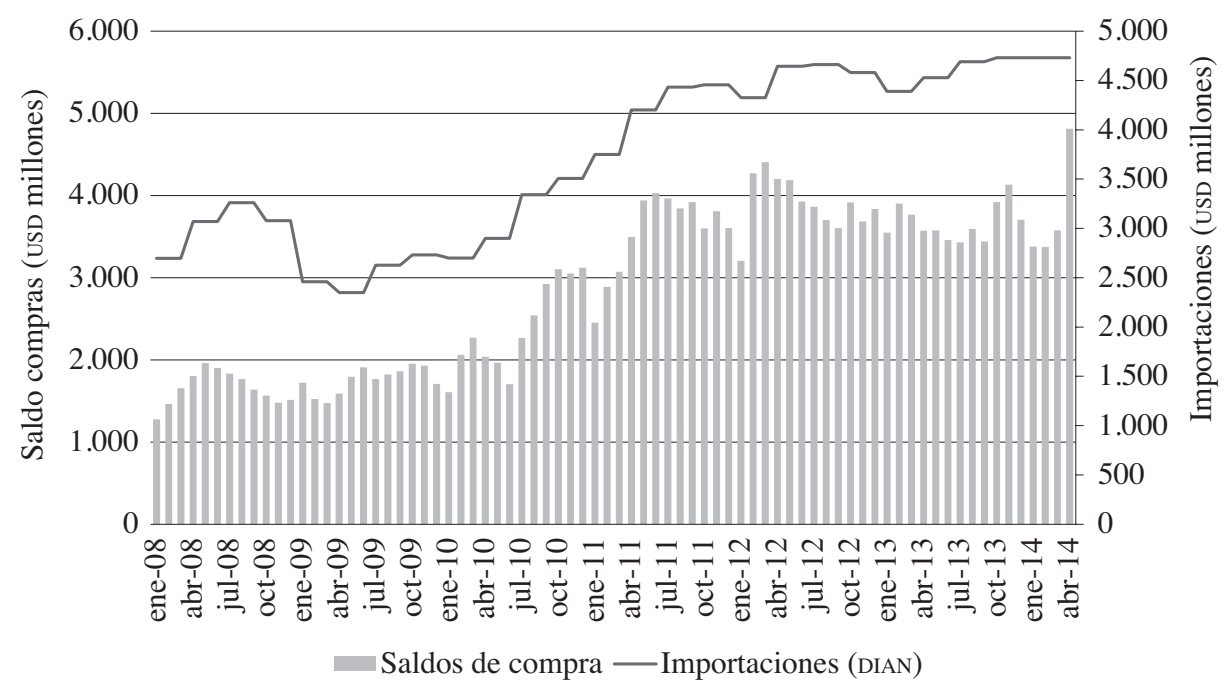

De acuerdo con agentes del mercado, en general las firmas del sector real tienen una demanda proyectada de cobertura para todo el año y aprovechan los momentos que consideran favorables para efectuarla, para lo cual se tienen umbrales de tasas de cambio definidos. Por otra parte, es interesante observar que mientras los importadores tienen un alto porcentaje de cobertura de sus flujos, los exportadores se cubren en menor proporción y en particular cuando las tasas forward son altas. Por este motivo, las operaciones de las empresas exportadoras en este mercado son más sensibles a variaciones en el precio pactado. De acuerdo con lo manifestado por algunos agentes del mercado, el bajo porcentaje de cobertura de las exportaciones puede ser explicado por la falta de penetración e información sobre los beneficios del mercado de derivados entre los distintos gremios exportadores, así como por subsidios ofrecidos por el Gobierno que desincentivan la adquisición de estos productos. Lo anterior, se debe a que los agentes del sector exportador podrían esperar subsidios en casos de pérdidas importantes ante una depreciación, lo cual reduciría sus necesidades de cobertura cambiaria.

Por otra parte, como complemento a las oportunidades de arbitraje en el mercado de forwards por parte del sector real que fueron resaltadas en los gráficos 25 y 26, se analizó la posición neta de las empresas exportadoras en contratos con cumplimiento efectivo, en las cuales se transfieren completamente los flujos de divisas y pesos acordados. Se encontró que su evolución parece estar ligada a la prefinanciación de exportaciones, y presentan una posición compradora en estas 
operaciones (gráfico 37). La cobertura natural de estas empresas es una posición vendedora, por lo cual las operaciones de compra con cumplimiento efectivo podrían estar relacionadas con el aprovechamiento de las distorsiones en el mercado de forwards para el manejo de su liquidez en moneda local.

Gráfico 37

Posición neta delivery exportadores (C-V) vs. Prefinanciación de exportaciones

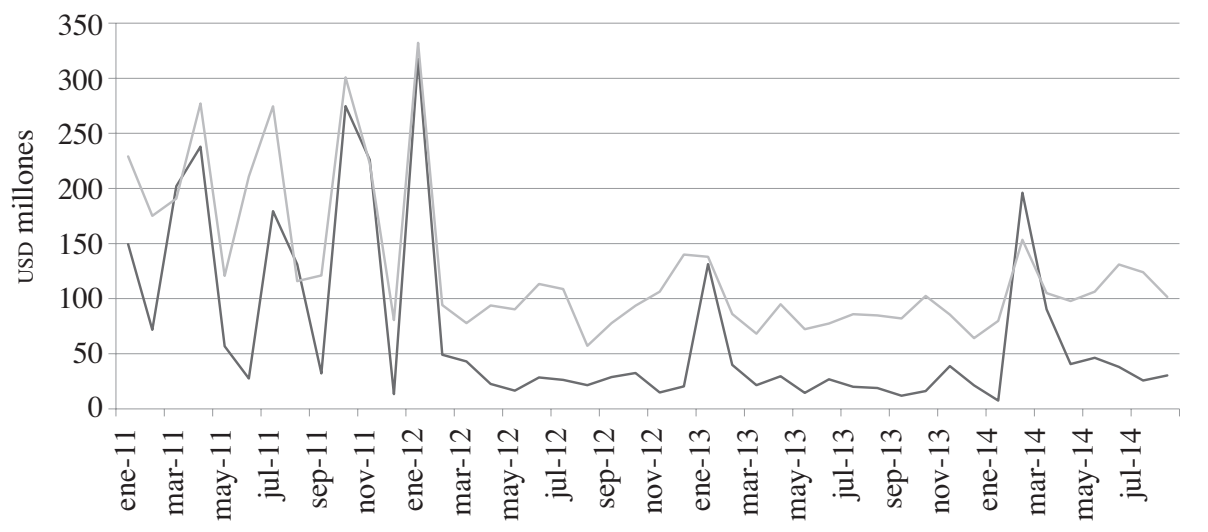

—Posición neta DF exportadores (compras-ventas) — Prefinanciación de exportaciones

$\mathrm{Al}$ analizar el plazo promedio mensual de las negociaciones de los importadores y exportadores en este mercado, se observa que han tenido un comportamiento similar en los últimos años. Sin embargo, la volatilidad de las negociaciones de los exportadores, en términos de plazo, es mayor. Esto es consistente con la evidencia señalada anteriormente (gráfico 38).

Por otro lado, se analizaron las negociaciones de los participantes del sector real, con el fin de encontrar patrones que determinen las coberturas cambiarias. Al observar la correlación móvil a 1 y 6 meses de las ventas realizadas por los exportadores con los PIPS ${ }^{16}$, se encuentra (como se esperaría) que esta es positiva. Para el plazo de 1 mes, desde 2012, la correlación diaria ha sido en promedio de 0,32 , y para el plazo de 6 meses se ha ubicado, en promedio, en 0,25. Esto implicaría que a tasas más favorables, los exportadores realizan una mayor cantidad de coberturas, negociando ventas de divisas a futuro (gráfico 39).

16 Se refiere a la diferencia entre la tasa de cambio pactada en los contratos forward y la tasa de contado. 
Plazo mensual ponderado por monto importadores y exportadores 2004-1014

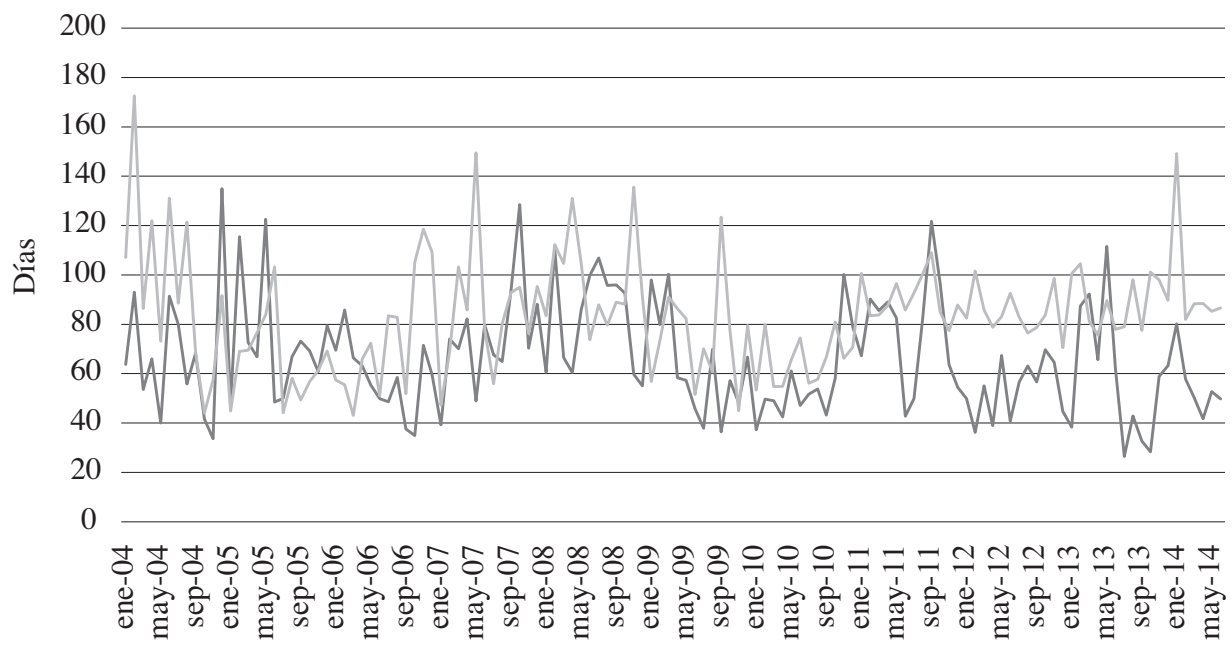

—Exportadores_Importadores

Gráfico 39

Correlación ventas exportadores vs. PIPS

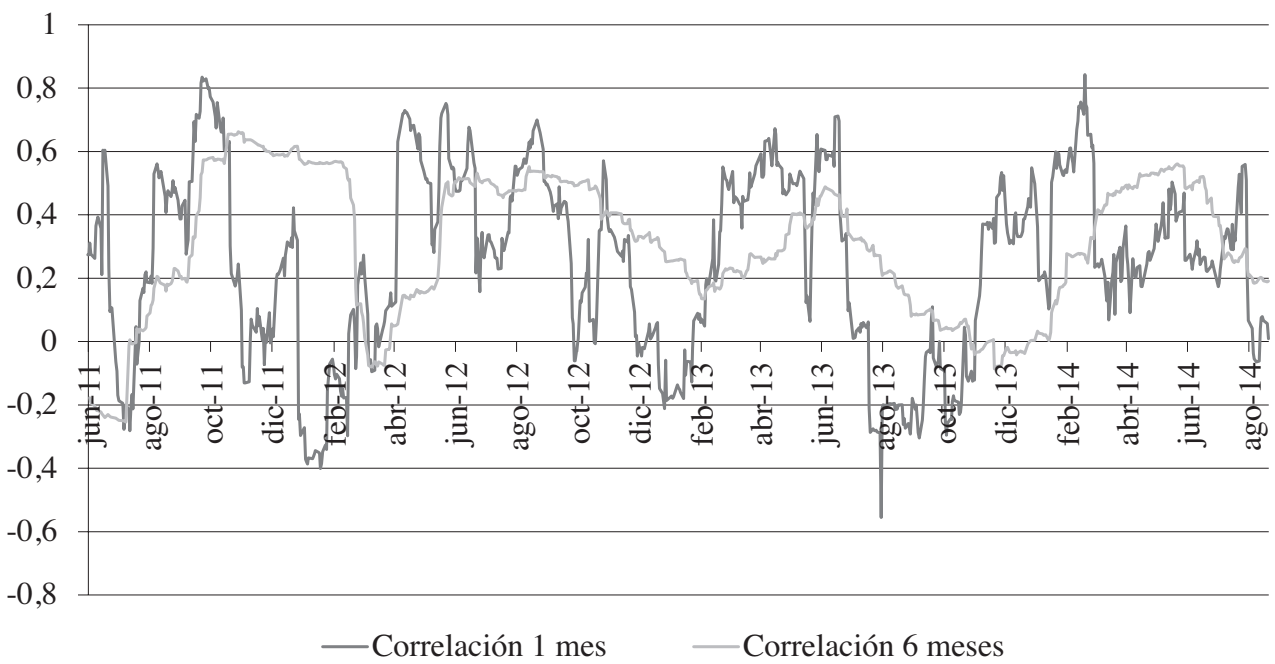

Por otra parte, dado que las compras del sector importador tienen una relación menos estrecha con los precios en el mercado de contado y de futuro, esto podría indicar que estos agentes realizan sus coberturas de forma estructural. Desde el año 
2012, la correlación diaria para el plazo de 1 mes ha sido en promedio de $-0,13$, y para el plazo de 6 meses se ha ubicado en promedio en -0,1. Así, de acuerdo con el gráfico 40, la relación de sus negociaciones netas está relacionada de forma negativa con los PIPS, aunque en promedio la magnitud de las correlaciones es menor a la observada en las empresas exportadoras.

Gráfico 40

Correlación compras importadores vs. PIPS

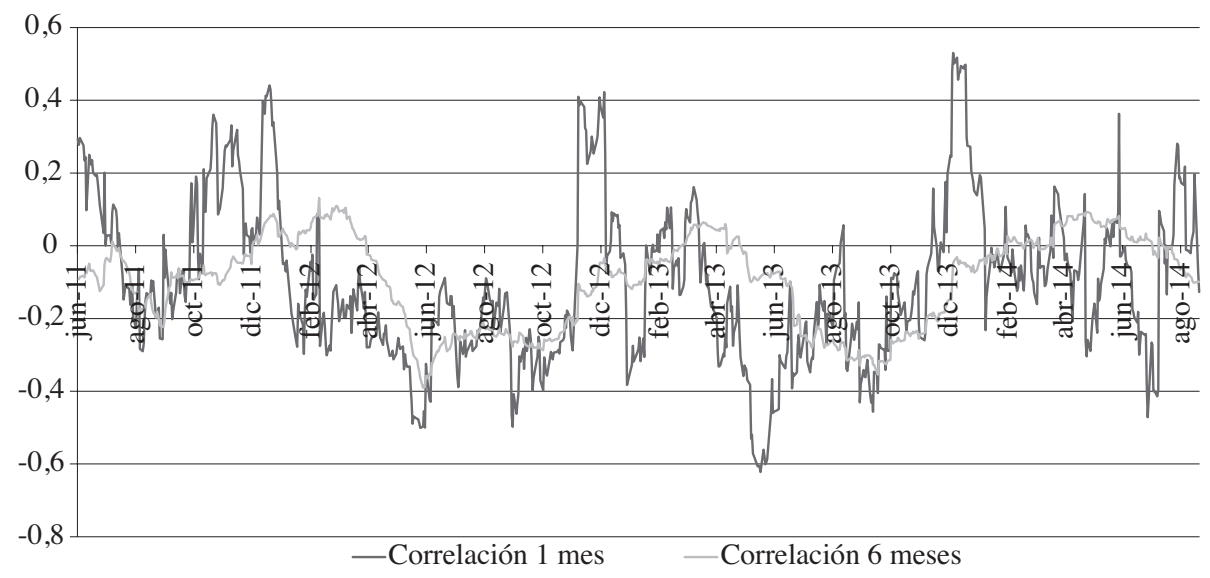

\subsubsection{Características de los Fondos de Pensiones y Cesantías}

A continuación se analiza el comportamiento de los FPC en el mercado de forwards peso-dólar, ya que tienen una participación significativa sobre las negociaciones totales. Los FPC participan en este mercado con el fin de realizar sus apuestas sobre el comportamiento de la tasa de cambio, y de cubrir sus inversiones en moneda extranjera con venta de divisas a plazo, de acuerdo con sus expectativas de tasa de cambio. Como se observa en el gráfico 41, el saldo de los Fondos de Pensiones Obligatorias (FPO) en sus operaciones a futuro se relaciona con el comportamiento de sus inversiones en moneda extranjera. Aunque los FPO utilizan estos productos con el fin de cubrir sus inversiones en moneda extranjera, estos agentes cambian su saldo de cobertura en línea con la exposición cambiaria deseada. 
Gráfico 41

Saldo ventas a futuro e inversiones moneda extranjera

Fondos de pensiones obligatorias

(USD millones)

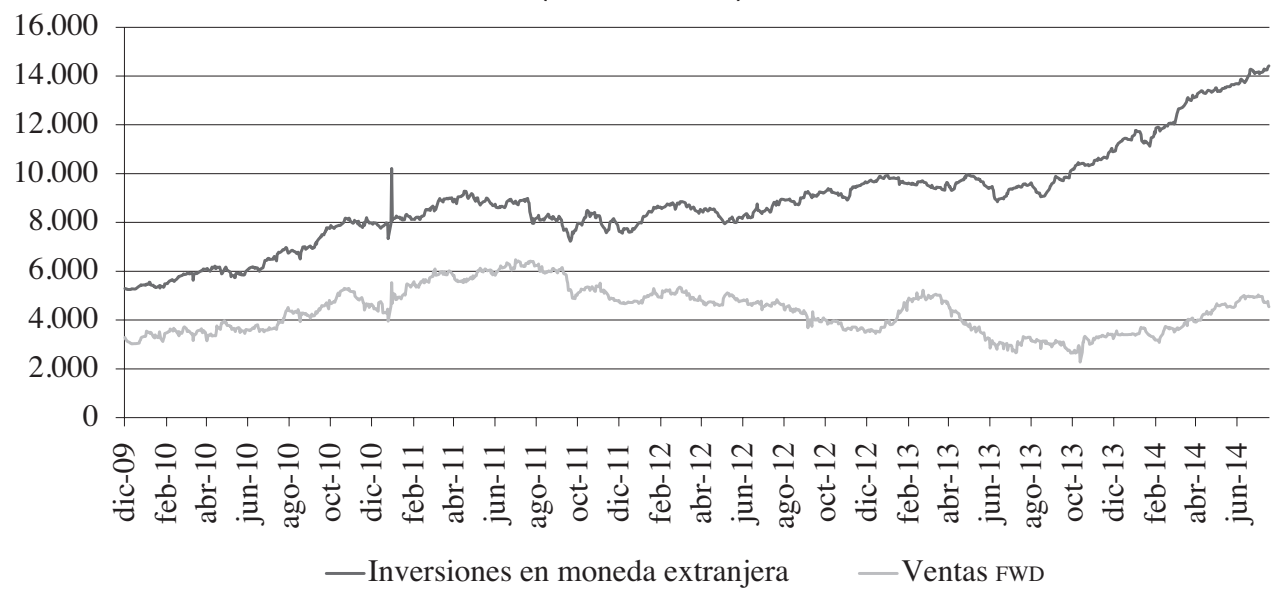

Los FPC, al igual que otros agentes, también realizan estas operaciones directamente con agentes del exterior; no obstante, como se muestra en el gráfico 42, los montos negociados con IMC son mayores (en 2014, corresponden a aproximadamente el $82 \%$ de sus negociaciones totales). Independientemente de la contraparte, estos agentes realizan negociaciones principalmente de venta de divisas ya que, en general, la regulación solo les permite utilizar este mercado para cubrir sus inversiones en moneda extranjera (gráficos 43 y 44).

Gráfico 42

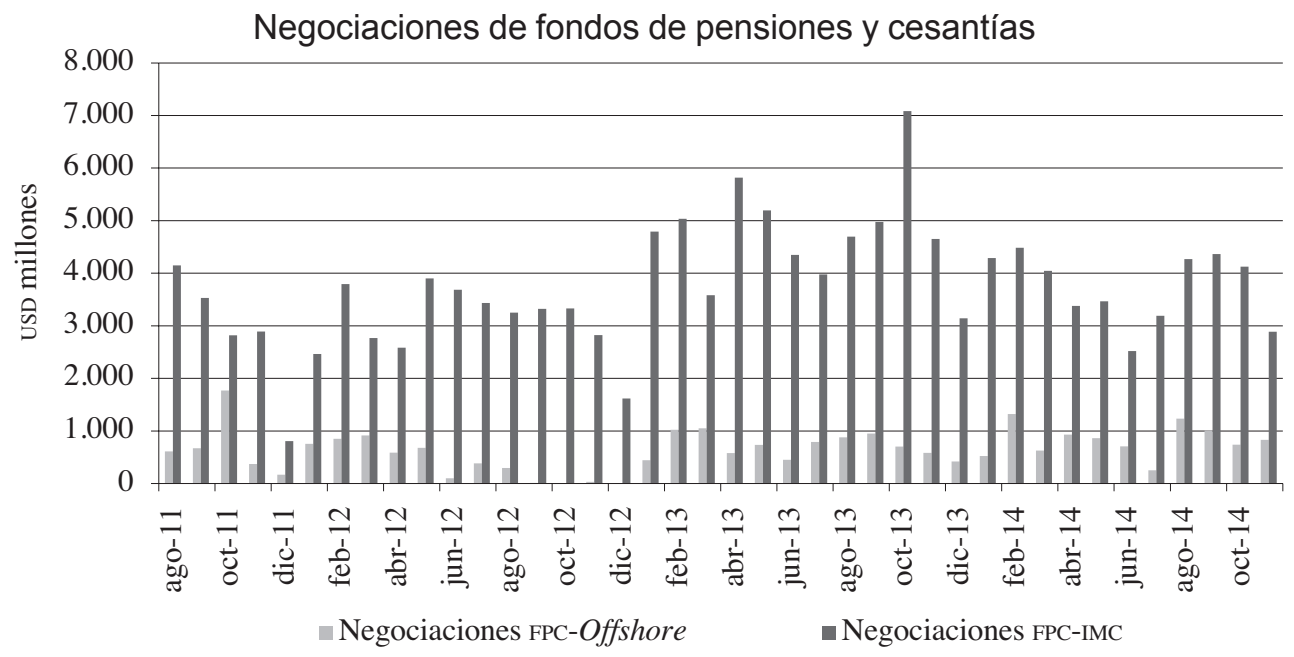

PP. 7-79 • N. ${ }^{\circ} 9 / 2015$ 
Gráfico 43

Negociaciones FPC-Offshore

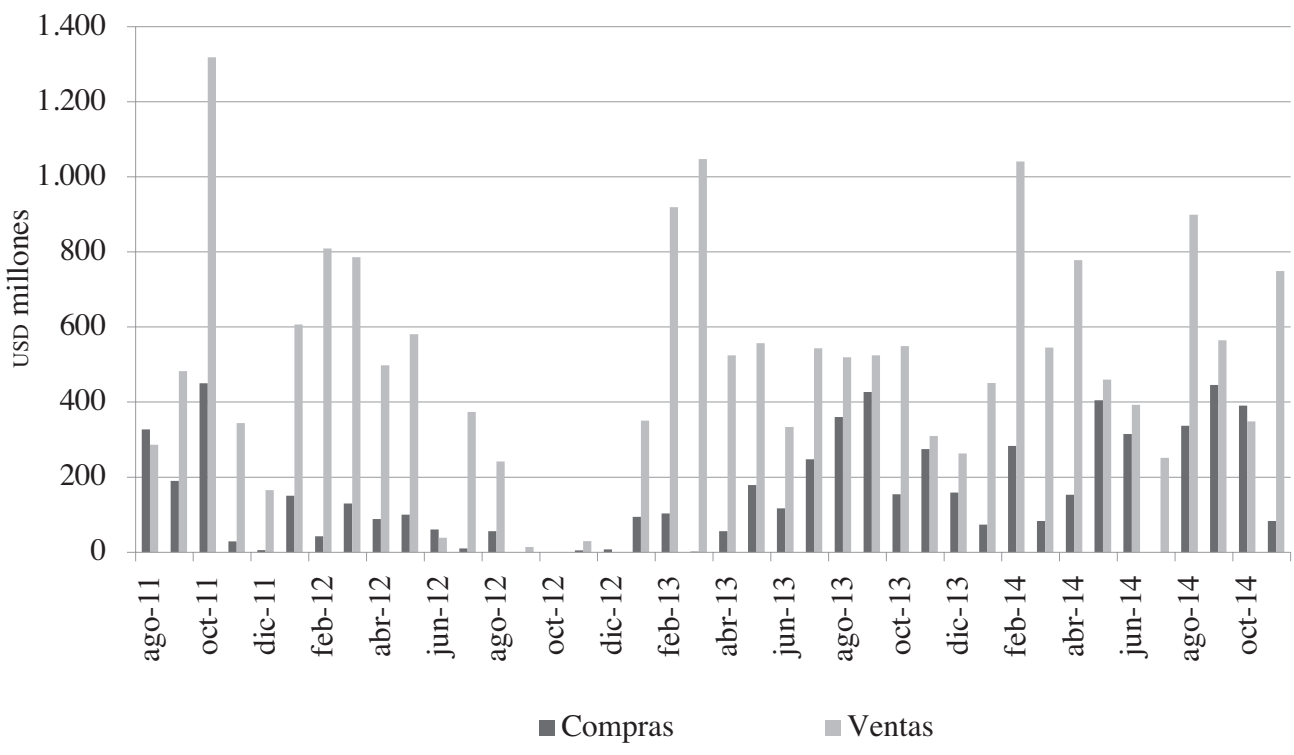

Gráfico 44

Negociaciones FPC-IMC

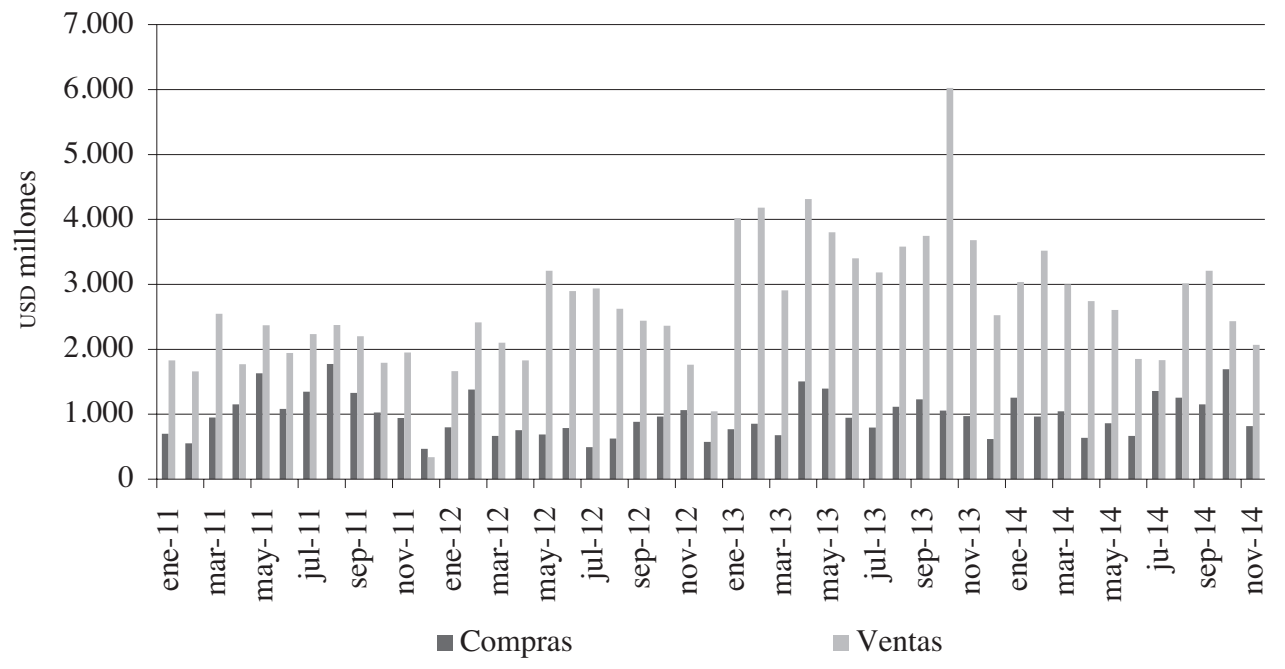

En algunos periodos parece existir una sustitución en la contraparte con la cual realizan sus operaciones (gráfico 45). La sustitución, entre finales de 2011 y comienzos de 2012, pudo obedecer a que las devaluaciones implícitas se encontraban 
por debajo de la teórica en las operaciones con los IMC, lo cual los pudo motivar a buscar ventas a un mayor precio directamente con los agentes offshore. Posteriormente, entre marzo y julio de 2014, se presentó una caída de las negociaciones con los agentes offshore que fue compensada mediante un aumento de las negociaciones con los IMC que pudo ser motivada por el deseo de los agentes offshore de mantener una posición larga en pesos, como respuesta a la recomposición del índice GBI de JP Morgan.

\section{Gráfico 45}

Saldo de ventas netas de fondos de pensiones y cesantías por contraparte

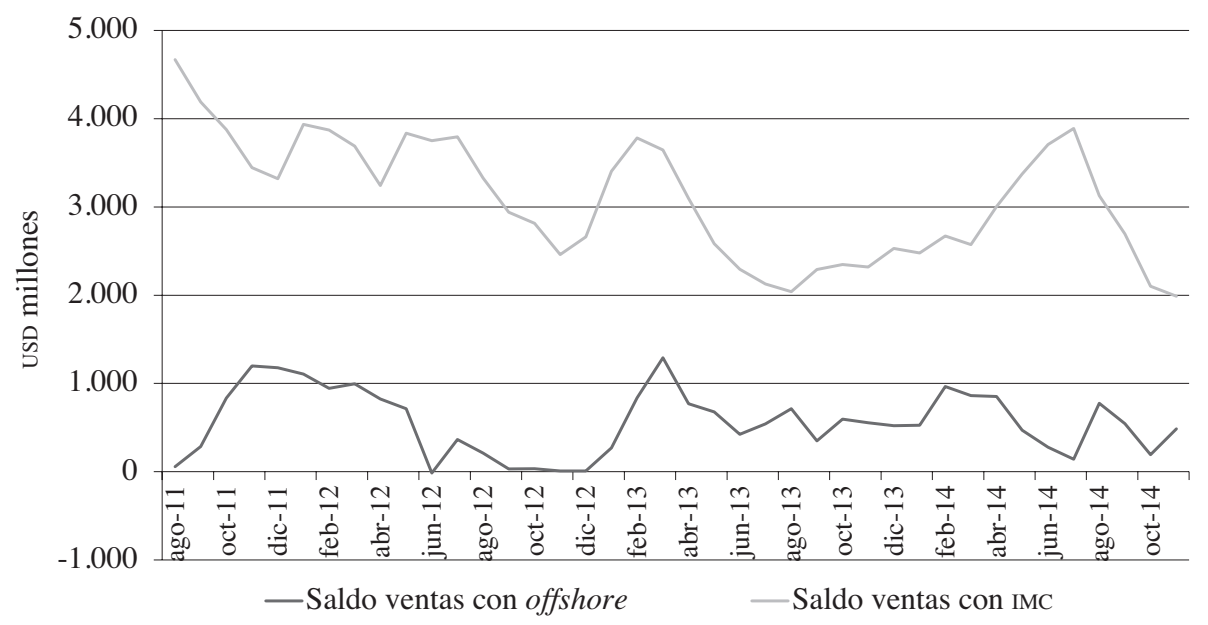

\section{a. Cross Currency Swaps}

Las negociaciones de cross currency swaps presentaron un crecimiento importante entre 2010 y 2012. Sin embargo, en los últimos dos años, el volumen de negociaciones retornó a su nivel promedio entre 2006 y 2009 (gráfico 46). Los mayores participantes en este mercado son los agentes extranjeros, aunque su participación se ha reducido en los últimos dos años. Como consecuencia de esto, las posiciones abiertas en estos contratos no han aumentado desde 2013 (gráfico 46). 
Gráfico 46A

Negociación cross currency swaps por contraparte

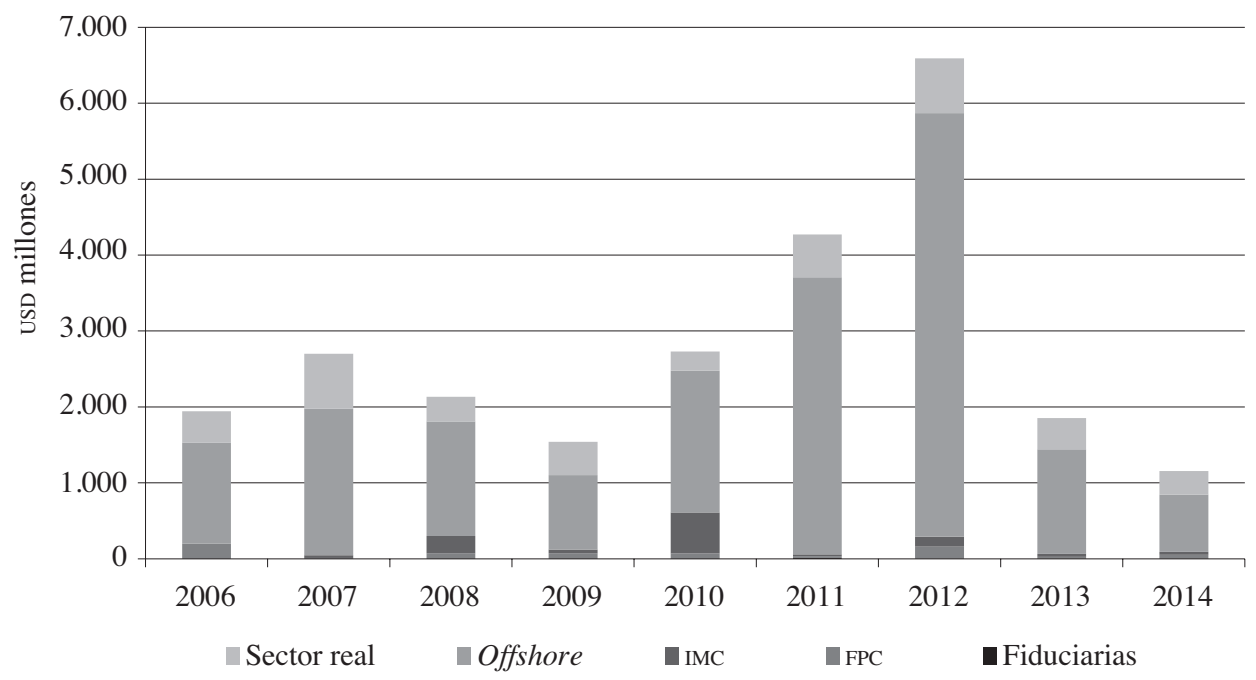

Gráfico 46B

Posiciones abiertas cross currency swaps

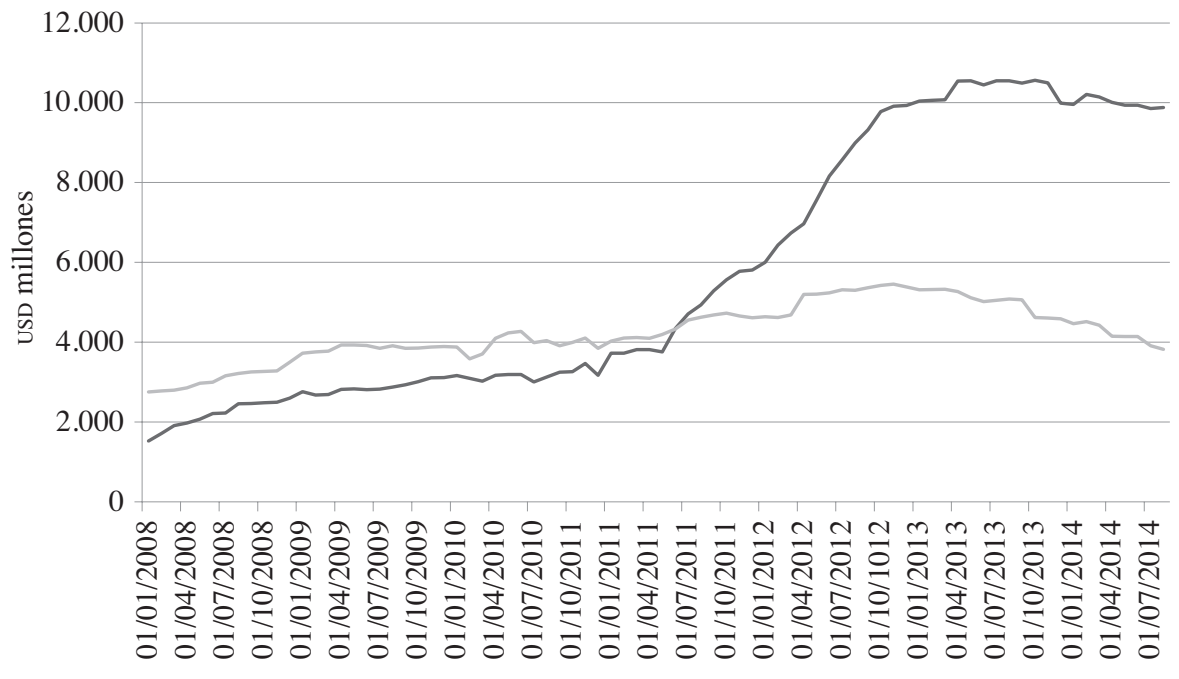

-Venta $\quad$ Compra

La reducción de las negociaciones de estos instrumentos por parte de los inversionistas extranjeros, se puede atribuir en parte a un mayor uso de otros instrumentos como swaps atados al Indicador Bancario de Referencia (IBR) (gráfico 47), cuyo 
volumen de negociación ha crecido considerablemente en 2014, y a la negociación de forwards sobre TES (gráfico 47), que les permite tener una exposición a riesgo de tasa de interés local y podría presentar una diversificación frente al riesgo cambiario que asumen utilizando otros instrumentos. En línea con esto, en el gráfico 48 se puede observar un salto importante en el saldo de estas operaciones, especialmente a partir de abril de 2014.

Gráfico 47A

Monto negociado y plazo promedio oıs swap IMC-offshore

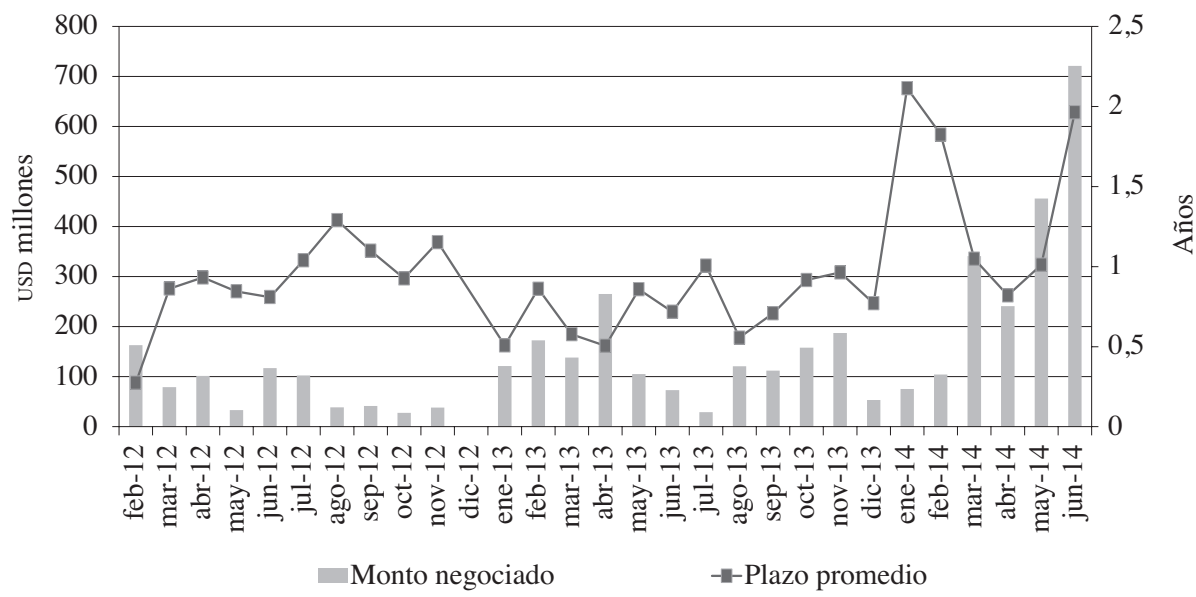

Gráfico 47B

Monto negociado y plazo promedio

forward NDF sobre TES

2013-2014

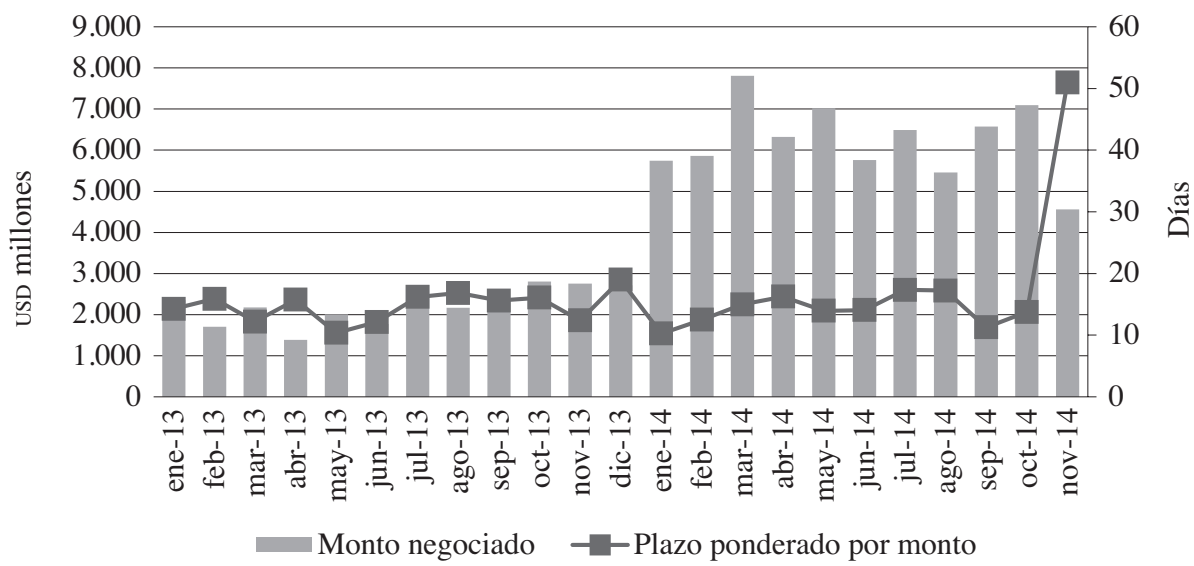


Gráfico 48A

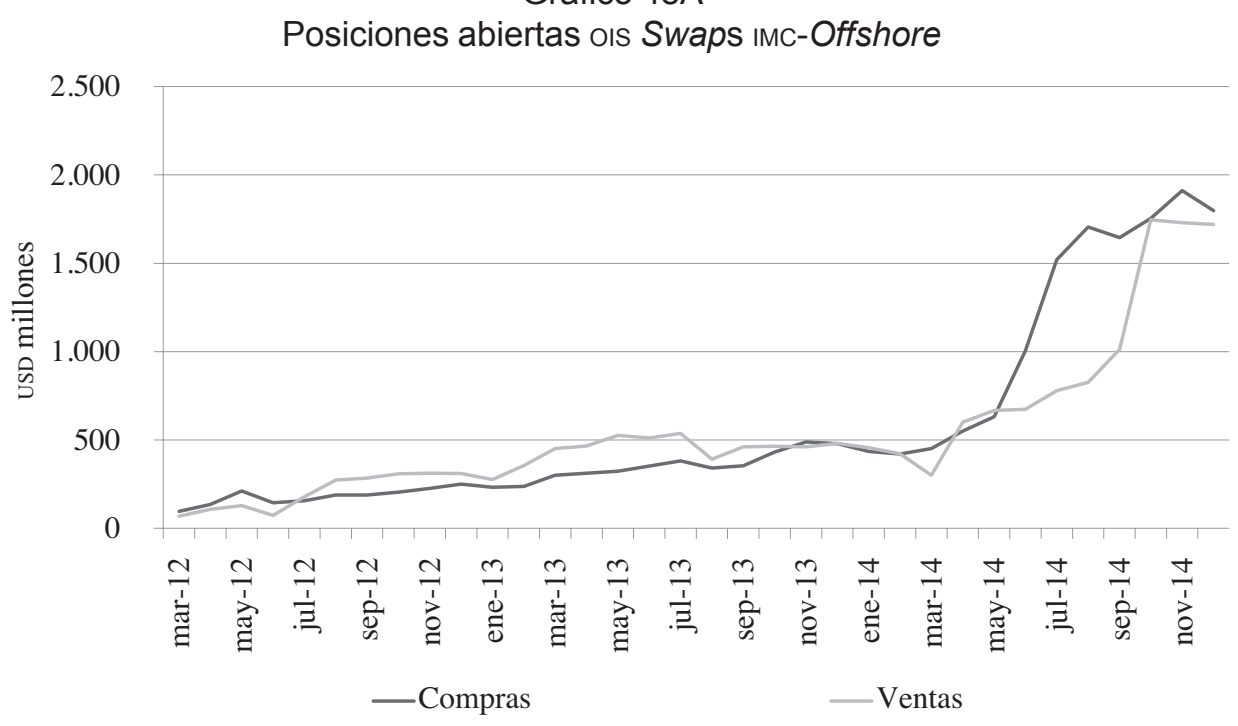

Gráfico 48B

Posiciones abiertas Forwards TES IMC-Offshore

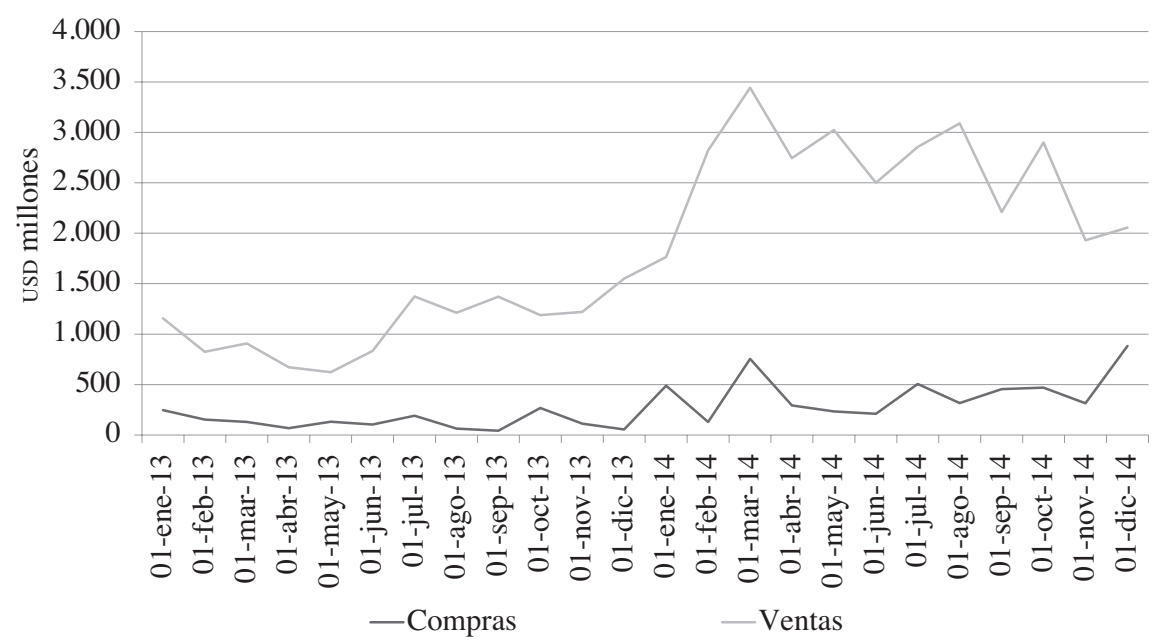

En línea con lo observado a nivel internacional y con el trabajo de Geczy, Minton y Schrand (1997), el plazo de negociación promedio de estos instrumentos es considerablemente mayor al de los otros tipos de derivados (gráfico 49). El plazo promedio de las negociaciones se ha ubicado entre 4 y 5 años, lo cual le permite a las entidades cubrir la exposición cambiaria de largo plazo generada a través de créditos, bonos u otros riesgos asociados a su balance. 
Plazo promedio negociación

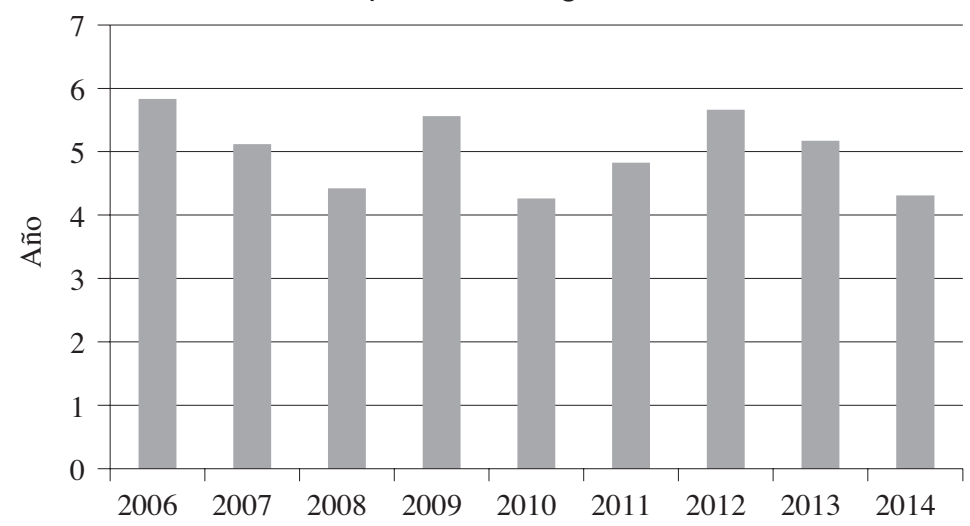

En general, las operaciones a mayor plazo han sido pactadas por los FPC, mientras que las operaciones entre IMC son las de menor plazo (gráfico 50). Por otra parte, el plazo promedio negociado por el sector real ha sido volátil, debido posiblemente a que las negociaciones se concentran en pocas contrapartes, mientras que el plazo promedio negociado por otros sectores como los agentes offshore, se ha mantenido más estable. En línea con lo observado en otros instrumentos, los agentes offshore y el sector real tienen posiciones largas en dólares a través de estos derivados (gráfico 51).

Gráfico 50

Plazo promedio por sector

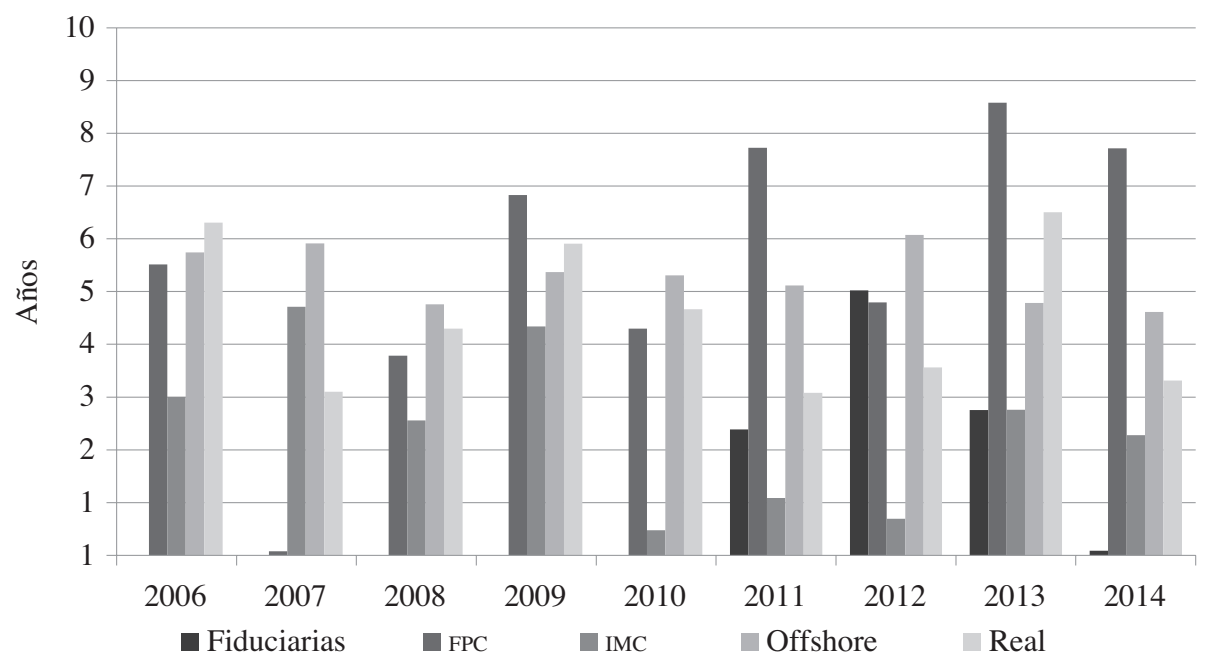




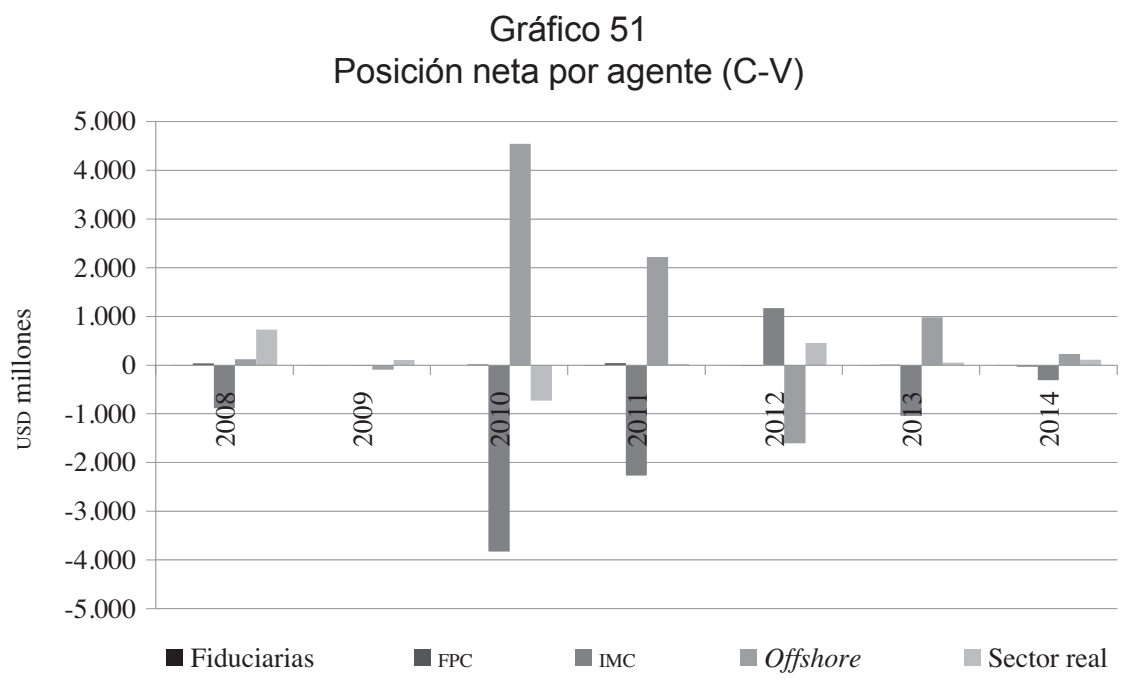

$\mathrm{Al}$ analizar en detalle la participación del sector real en este mercado, se encuentra que en su mayoría está compuesto por empresas importadoras, las cuales tienen principalmente una posición larga en dólares (gráfico 52). El plazo promedio de las operaciones de las empresas de este sector se ha mantenido en promedio cerca de los 4 años.

Gráfico 52

Negociaciones cross currency swaps del sector real

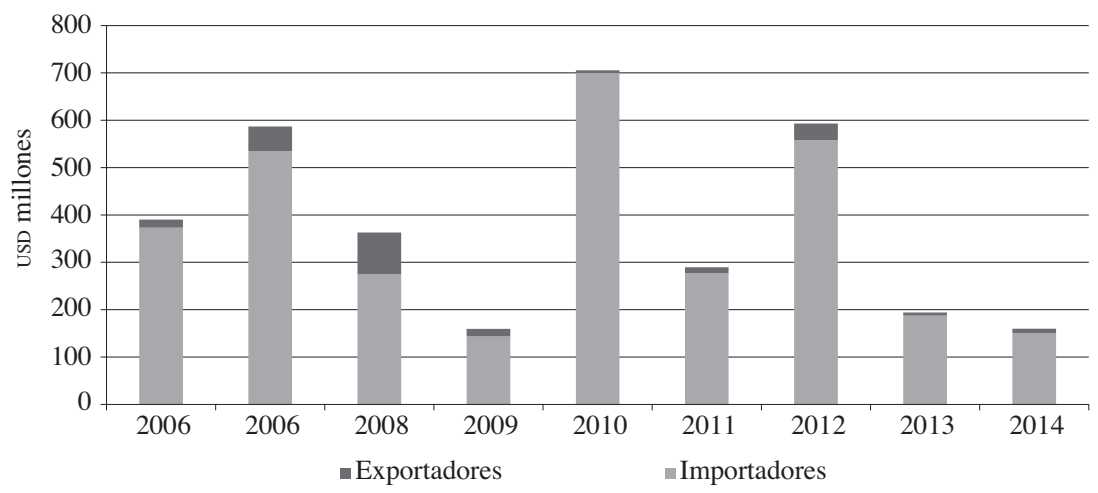

b. Mercado de opciones peso-dólar

En esta sección se buscará explicar el comportamiento de los diferentes agentes del mercado de opciones sobre tasa de cambio, y dar una aproximación sobre el tipo de estrategias que implementan. 
Para efectos del análisis, las contrapartes de las operaciones se clasificaron en cuatro grupos: i) interbancario (operaciones entre IMC), ii) agentes del sector real, iii) agentes offshore y iv) otras entidades del sector financiero. Esta última categoría incluye además de FPC, sociedades comisionistas de bolsa, compañías de seguro y compañías de inversiones, entre otras. Esta clasificación difiere ligeramente de la expuesta en la sección de forwards dado que los FPC no son agentes representativos de este mercado y, por tanto, el análisis podría ser más enriquecedor si se realizara en conjunto con otros agentes del sistema financiero.

En los gráficos 53 y 54 se observa que el monto promedio mensual negociado en el sistema financiero colombiano a través de opciones peso-dólar ascendió a los US \$1.345 millones en 2013 frente a los US\$286 millones observados en 2008, lo cual representa un crecimiento cercano al $370 \%$. En 2014, con cifras al 30 de junio, el monto promedio mensual negociado asciende a los US\$1.054 millones, lo cual representa una caída de $21 \%$ con respecto al promedio registrado en 2013.

Pese al importante crecimiento que ha presentado este mercado a lo largo de los años, las cifras confirman que los forwards peso-dólar (expuestos en el numeral $a$ de esta sección) son los instrumentos de mayor preferencia entre los agentes del mercado de derivados sobre divisas. En particular, en el primer semestre de 2014, la negociación promedio mensual en opciones peso-dólar representó el 4,2 \% de las negociaciones mensuales de forwards peso-dólar. Las razones que los diferentes agentes del mercado atribuyen al rezago de las negociaciones de opciones frente a las de forwards, están relacionadas con temas contables y tributarios. Específicamente, se afirma que en Colombia la contabilización en libros de este tipo de instrumentos no es clara y que su tratamiento tributario los hace más costosos.

Gráfico 53

Monto total transado en opciones peso-dólar

(en millones de USD)

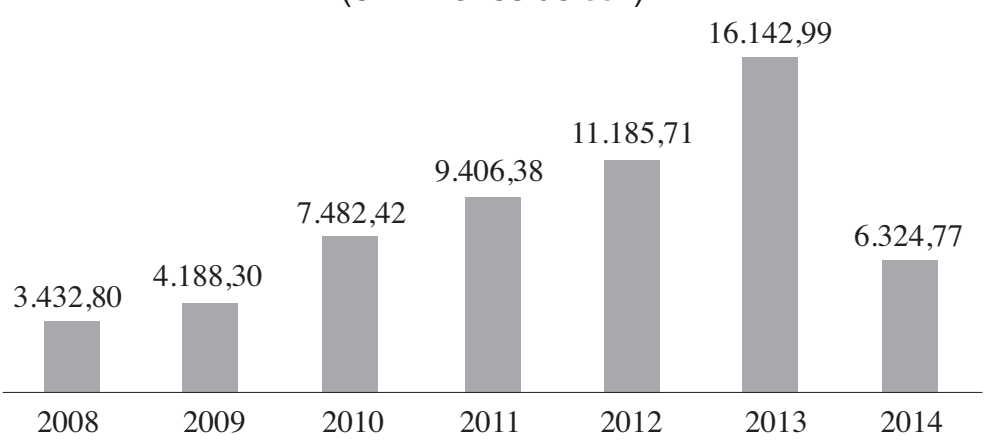

Cifras al 30 de junio de 2014

PP. $7-79 \cdot N .^{\circ} 9 / 2015$ 


\section{Gráfico 54}

Monto promedio mensual transado en opciones peso-dólar

(en millones de USD)

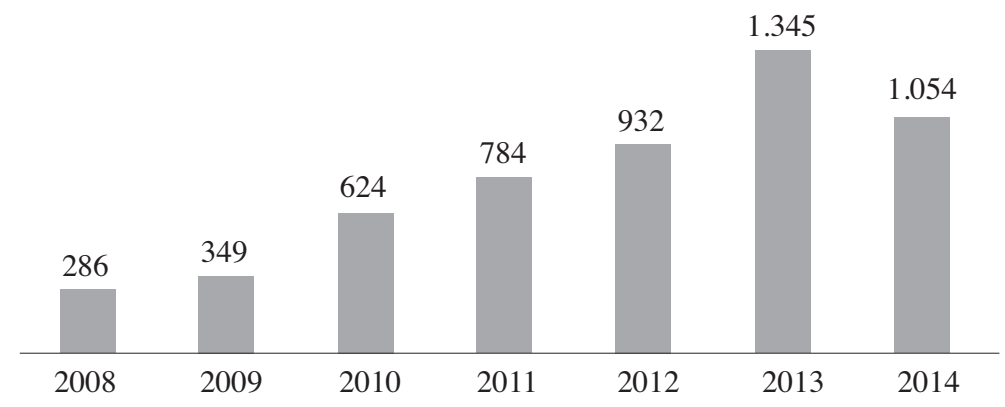

Cifras al 30 de junio de 2014

Desde el año 2008, los principales participantes del mercado de opciones pesodólar han sido los agentes del sector real seguidos por los agentes offshore (gráficos 55 y 56). En 2013, las negociaciones de los agentes del sector real representaron el $51 \%$ de las negociaciones totales y las de los agentes offshore el $36 \%$. Por su parte, las operaciones entre IMC representaron el $7 \%$ y la de otros agentes del sector financiero el $5 \%$. Estos resultados contrastan con los observados en el mercado de forwards peso-dólar, donde el principal agente es el offshore mientras que el sector real es el menos representativo.

Cabe destacar que, de acuerdo con diferentes participantes del mercado, el sector real ha ido adquiriendo mayor especialización en el mercado de derivados en Colombia, por lo cual ha comenzado a utilizar diferentes instrumentos como las opciones, no solo con fines de cobertura, sino también de especulación y arbitraje.

El crecimiento observado en las negociaciones de opciones peso-dólar también se explica por un mayor número de participantes como de operaciones. Con respecto al primer punto, es importante resaltar que, aunque el número de participantes se mantuvo relativamente estable entre 2008 y 2011 (en promedio 280 por año), en 2012 aumentó a 430 y se mantuvo en niveles cercanos en el año $2013^{17}$. Por su parte, también se observa que entre los años 2008 y 2013 se incrementó significativamente el número de operaciones transadas al mes, las cuales pasaron en promedio de 326 en 2008 a 2.279 en $2013^{18}$.

17 Con cifras al 30 de junio, en 2014 han participado 188 agentes en este mercado.

18 Para 2014, este dato asciende a las 1.523 operaciones. 
Gráfico 55

Monto nominal anual transado por agente en el mercado de opciones peso-dólar

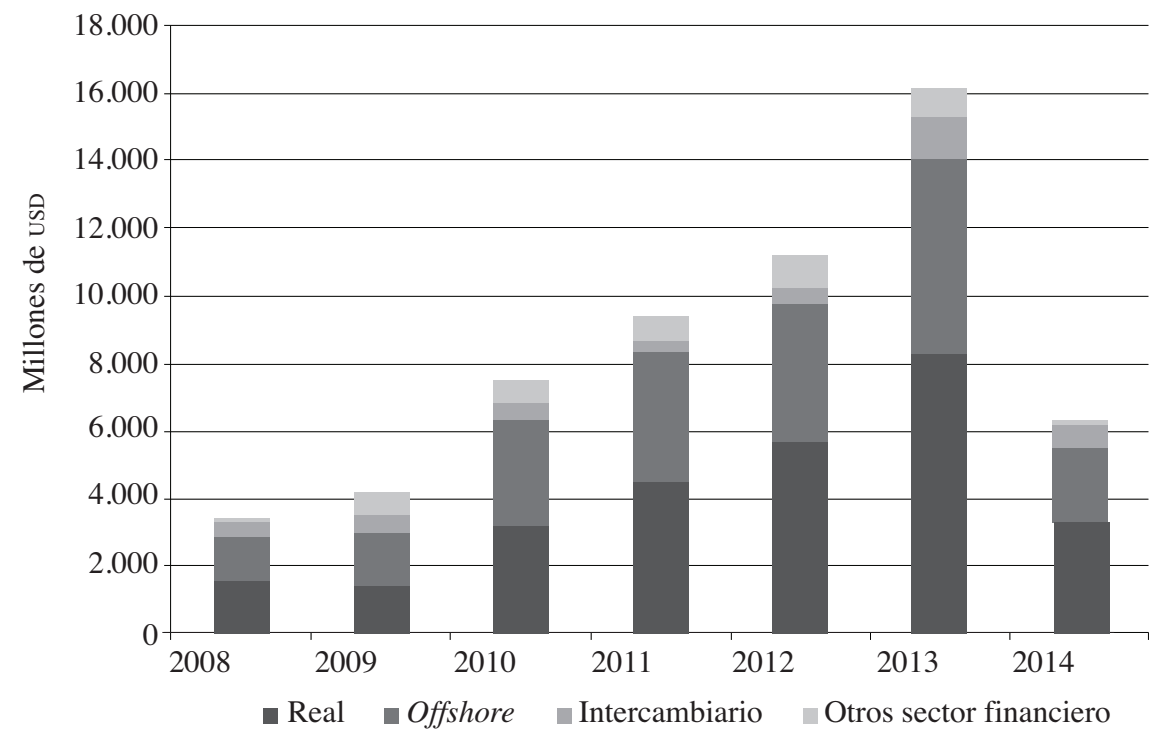

Gráfico 56

Monto nominal mensual transado en opciones peso-dólar por tipo de agente

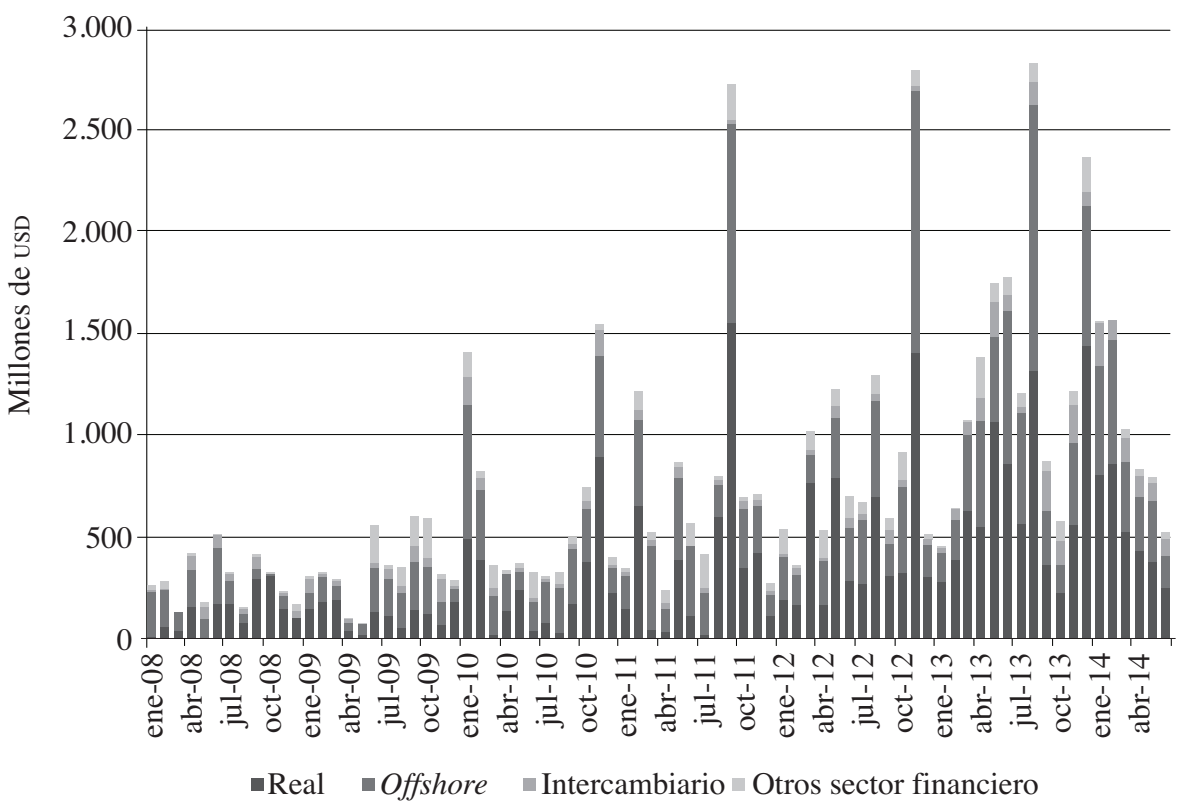


En los gráficos 57 y 58 se observa que el crecimiento en el monto negociado por el sector real se debe principalmente a la participación de un mayor número de agentes y, por tanto, a un mayor número de operaciones negociadas. Por el contrario, el número de agentes así como el número de operaciones transadas por el offshore, ha sido bajo y no ha presentado cambios significativos a lo largo de los últimos siete años, lo que indica que en promedio los volúmenes negociados en opciones por estos agentes son significativamente mayores a los de cualquier otro agente del mercado colombiano.

Gráfico 57

Número de participantes por tipo de agente

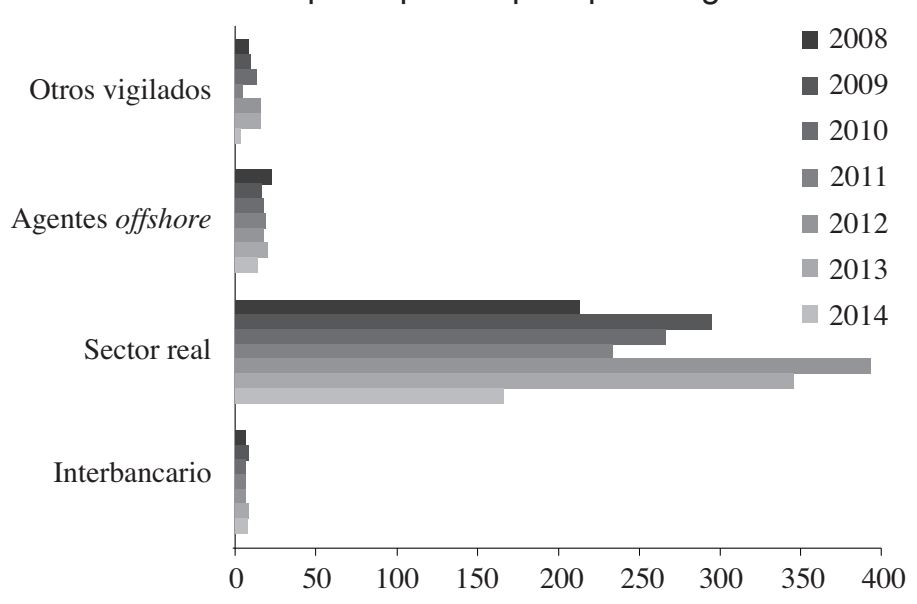

Gráfico 58

Número de operaciones por tipo de agente

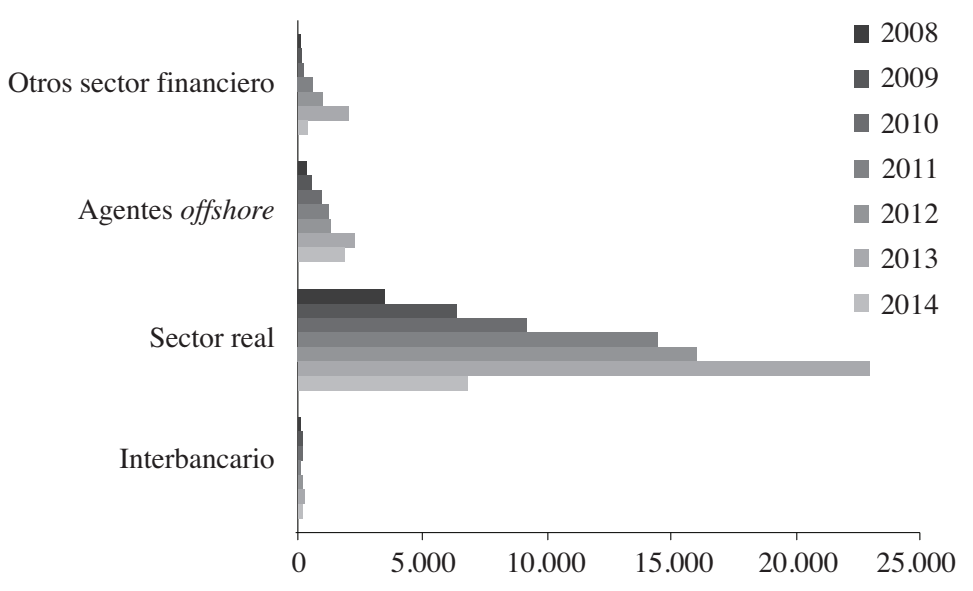


De acuerdo con la información reportada, entre enero de 2008 y septiembre de 2010, el plazo promedio de las operaciones fue de 90 días, mientras que a partir de octubre de 2010 hasta junio de 2014 este promedio se ha ubicado en 125 días (gráfico 59). Estos resultados contrastan con los observados en el mercado de forwards y de cross-currency swaps, donde el plazo promedio de negociación es de 40 días y 4,5 años, respectivamente.

Gráfico 59

Plazo promedio ponderado por monto en opciones peso-dólar

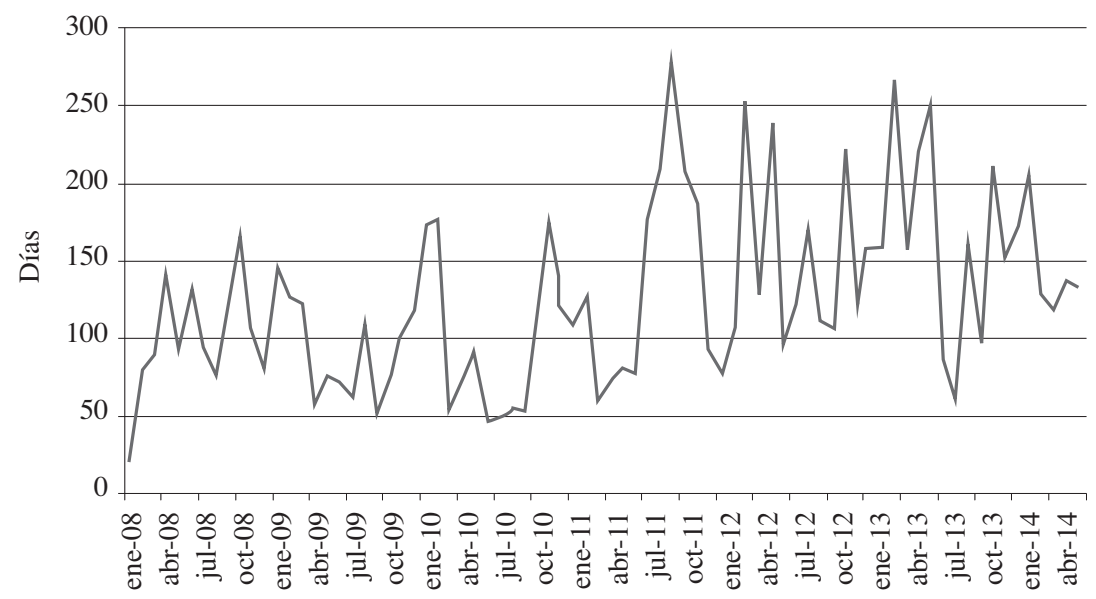

Gráfico 60

Plazo promedio ponderado de las negociaciones de opciones peso-dólar por sector

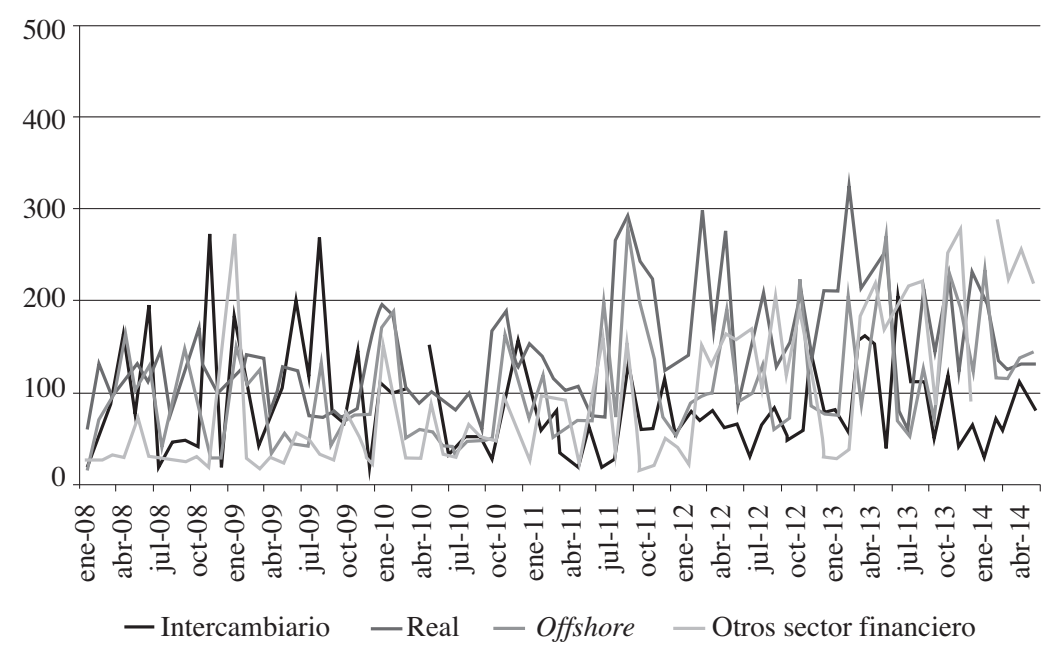


Al desagregar la información de las negociaciones por tipo de agente se encuentra que el sector real tiende a transar opciones a plazos más largos, los cuales se ubican en promedio en 126 (gráfico 60). Por su parte, el plazo promedio negociado entre IMC asciende a los 78 días, el de los agentes offshore a 91 días y el de los demás agentes del sector financiero a 94 días.

Finalmente, con respecto al tipo de opción negociada, europea (ejerce en la fecha de vencimiento) o americana (pueden ser ejercidas en cualquier momento entre su negociación y la fecha de vencimiento), en el gráfico 61 se puede ver que casi la totalidad de los contratos de opciones son del tipo europea, lo cual podría ser atribuido al hecho de que estas opciones son instrumentos de menor complejidad en su valoración y menos costosas, lo cual podría facilitar su negociación en el mercado colombiano.

Gráfico 61

Negociación de opciones americanas y europeas

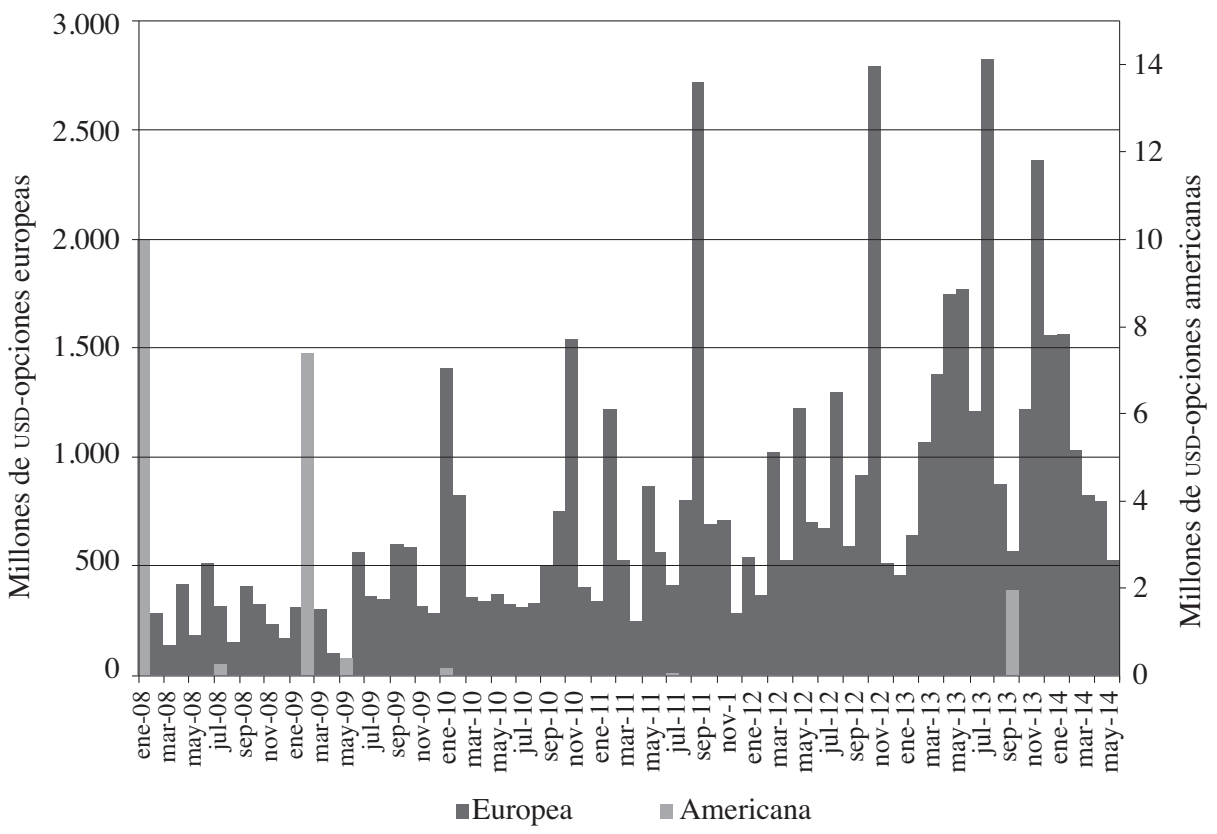

A continuación, se presenta un análisis del comportamiento del offshore y del sector real en el mercado de opciones peso dólar. El análisis se concentra en estos dos tipos de agentes teniendo en cuenta que son los más representativos y que, a diferencia de los demás agentes del sector financiero, implementan estrategias claras en sus negociaciones con opciones. 


\subsubsection{Características de los agentes del offshore}

Las operaciones de los agentes offshore representaron el 36\% de las negociaciones totales de este mercado en 2013, y el $35 \%$ en el primer semestre de 2014. Desde enero de 2013, estos agentes han negociado en promedio un monto de US\$446 millones al mes.

$\mathrm{Al}$ analizar en detalle el offshore, se encuentra que los diez agentes más representativos tanto en las negociaciones de opciones como en las de forwards peso dólar son bancos, y que en promedio estas mismas entidades participan activamente en ambos mercados aunque con volúmenes de negociación distintos (gráfico 62).

\section{Gráfico 62}

Monto negociado por los 10 agentes más representativos del mercado de opciones y forwards peso-dólar

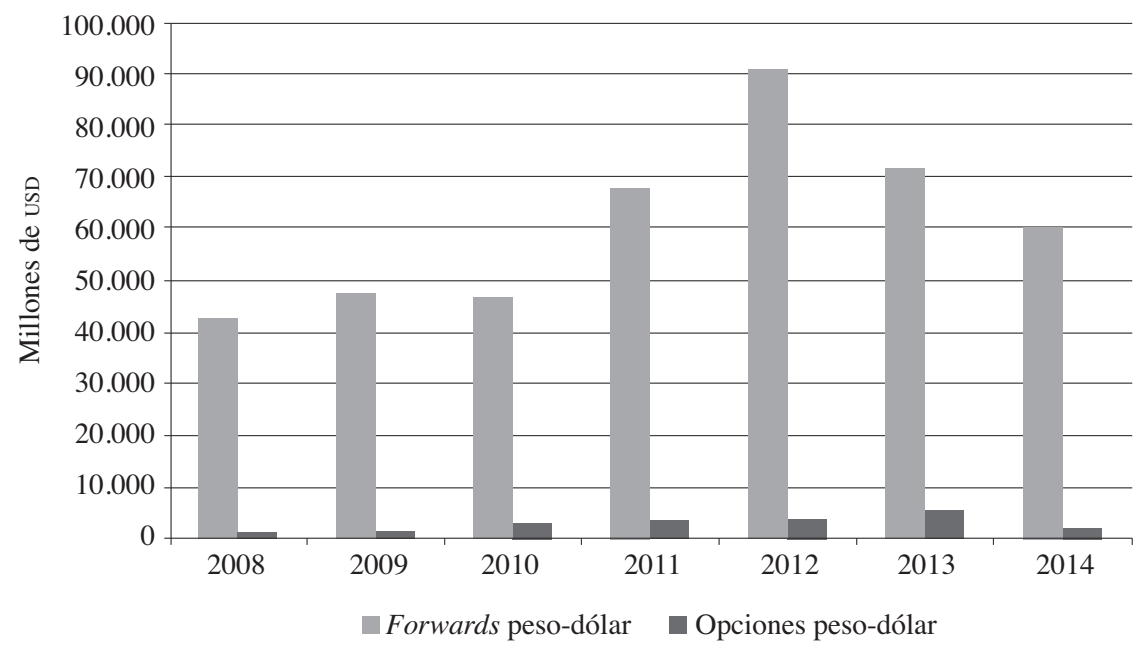

Con base en lo observado en los mercados de forwards peso-dólar, cross currency swaps y opciones peso-dólar, se podría afirmar que los agentes extranjeros han jugado un papel importante en el desarrollo del mercado de derivados sobre divisas en Colombia, en la medida en que sus operaciones abarcan una gran variedad de instrumentos y que su participación ha sido históricamente significativa en cada uno de ellos.

Al desagregar la información por tipo de opción, se observa que las compras de call son, por excelencia, las operaciones más transadas por el offshore. Lo anterior indica que estos agentes tienen una posición larga en dólares, la cual coincide con la posición adquirida a través de los demás tipos de instrumentos analizados (gráficos 63 y 64). 
Gráfico 63

Negociaciones brutas del offshore por tipo de opción

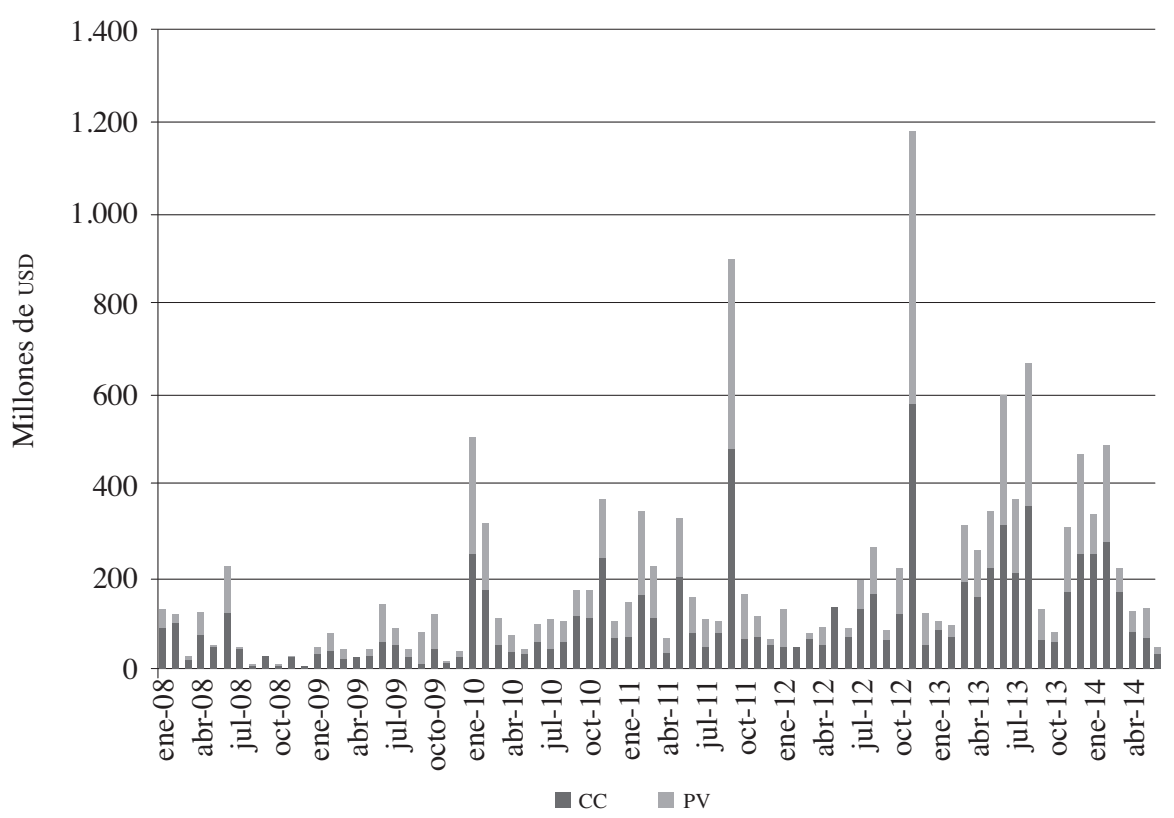

Gráfico 64

Negociaciones brutas del offshore por tipo de opción

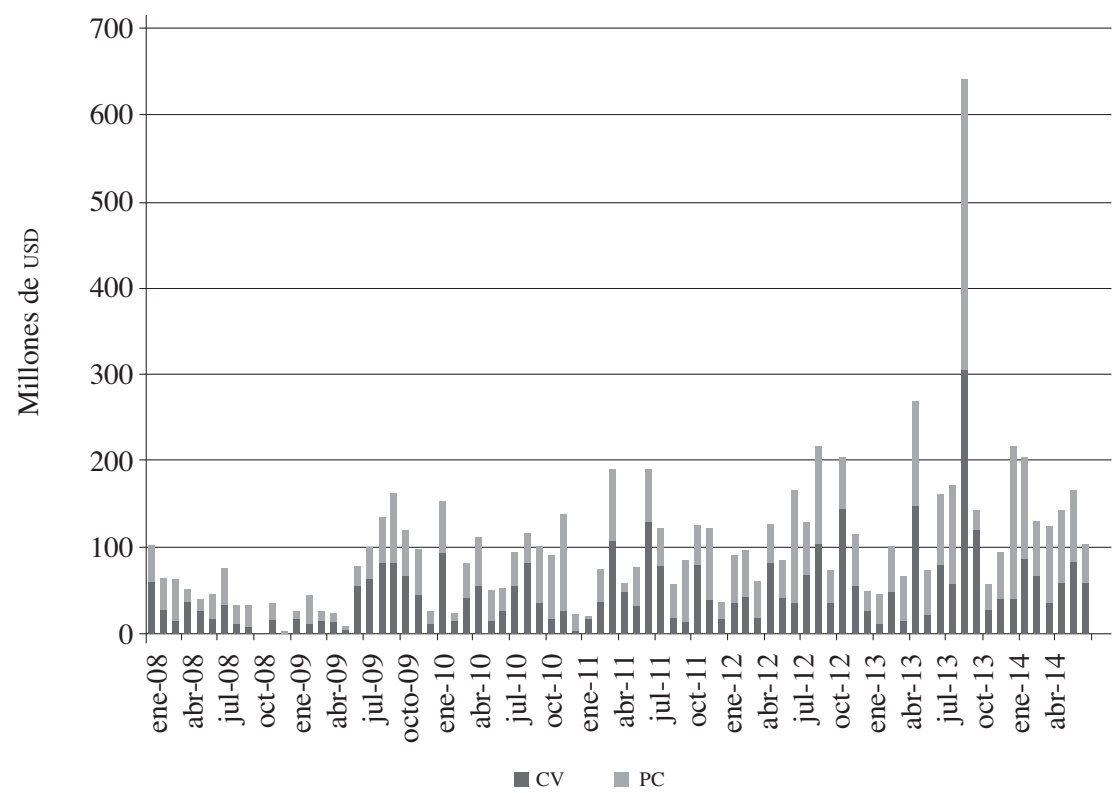


Sin embargo, vale la pena resaltar que el comportamiento del saldo en opciones put y call sugiere que estos agentes también podrían estar utilizando este mercado para implementar estrategias collar ${ }^{19}$ sobre el tipo de cambio. Esta estrategia es muy habitual en opciones dado que les permite a los agentes cubrirse a un bajo o nulo costo frente a movimientos adversos en la tasa de cambio. De acuerdo con los gráficos 65 y 66, la estrategia se realiza principalmente mediante la compra de calls y la venta de puts, lo que sugiere que estos agentes replican sintéticamente la posición larga en dólares.

Se destaca que a partir de marzo de 2014, el saldo del offshore en opciones ha disminuido como resultado de un gran número de vencimientos de contratos que no fueron renovados. Este hecho pudo estar asociado a la decisión de JP Morgan de aumentar la ponderación de Colombia en sus índices de deuda pública, dado que los inversionistas extranjeros pudieron haber disminuido sus coberturas cambiarias con el fin de aumentar su exposición al peso colombiano ante mayores expectativas de apreciación.

Gráfico 65

Saldo neto del offshore por tipo de opción

(pactados - vencidos)

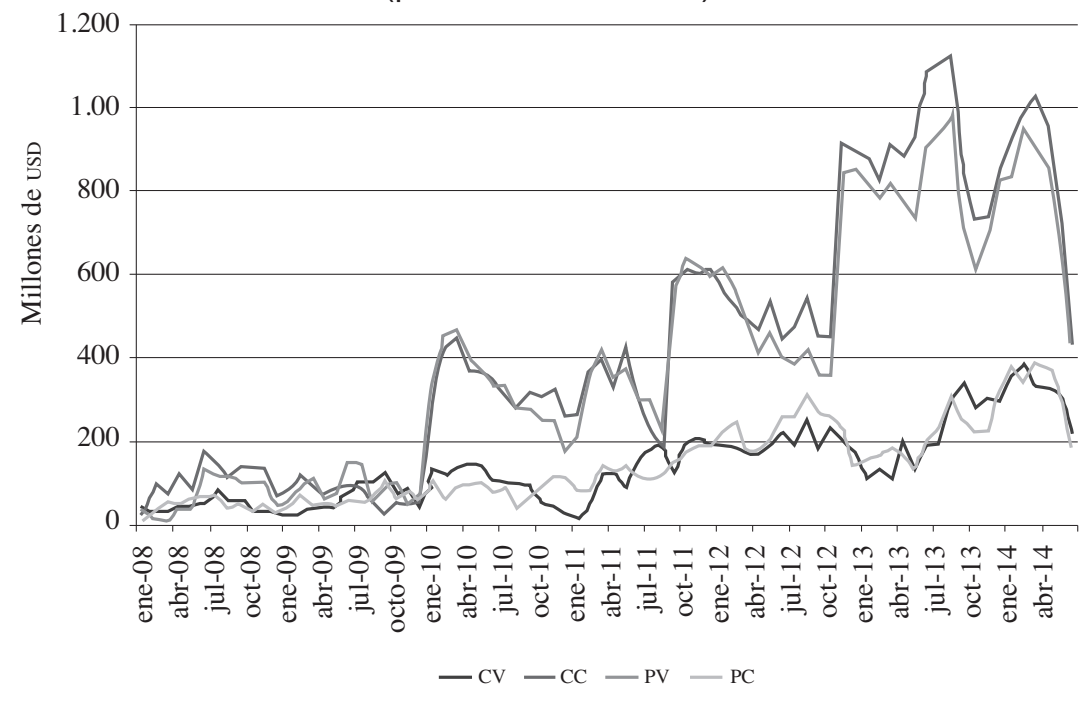

19 Collar se refiere a la compra (o venta) de una opción call y la venta (o compra) simultánea de una opción put. El objetivo de esta estrategia es compensar el precio de la prima de la opción que se va a comprar mediante la prima recibida por la venta de la otra opción. En particular, la compra de una call y la venta de una put replican una posición larga en dólares, la cual refleja una expectativa de depreciación del tipo de cambio. 
Gráfico 66

Saldos de posiciones netas del offshore en opciones peso-dólar

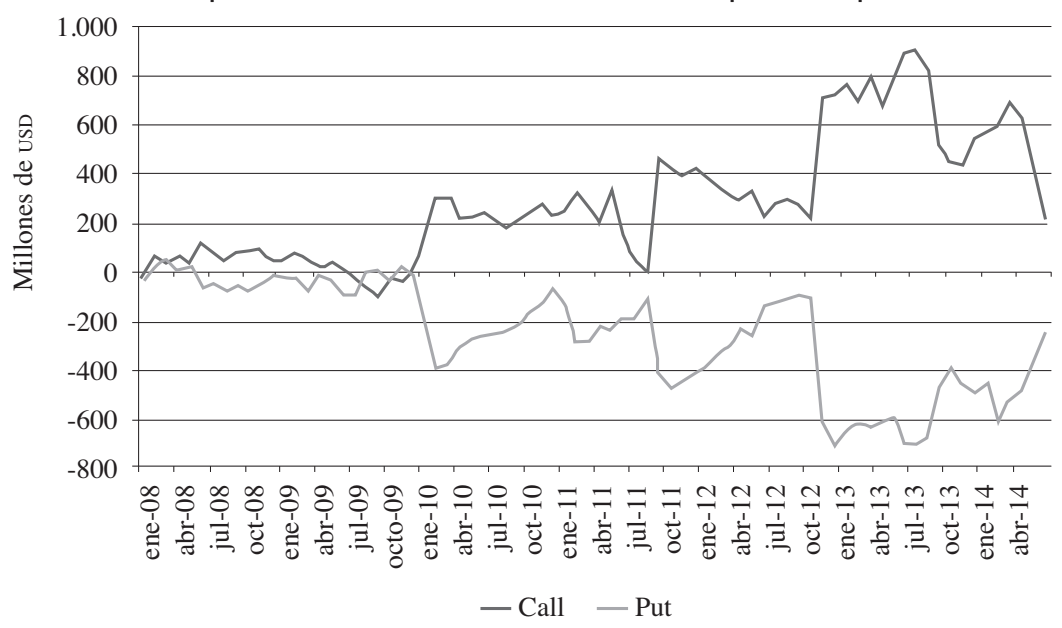

Con respecto a los plazos transados por estos agentes, se destaca que desde el año 2013 las negociaciones de este sector se realizan en promedio a un plazo de 122 días. Al calcular el plazo promedio diario negociado, se resalta que la correlación que existe entre el plazo de las compras de call y el de las ventas de put es de $52 \%$, y entre el plazo de las ventas call y las compras put fue de $40 \%$, lo cual podría indicar que estos agentes implementan adicionalmente otro tipo de estrategias diferentes al collar para gestionar su posición larga y corta en dólares (gráficos 67 y 68).

Gráfico 67

Plazos promedio ponderado de las opciones negociadas por el offshore call compras vs. put venta

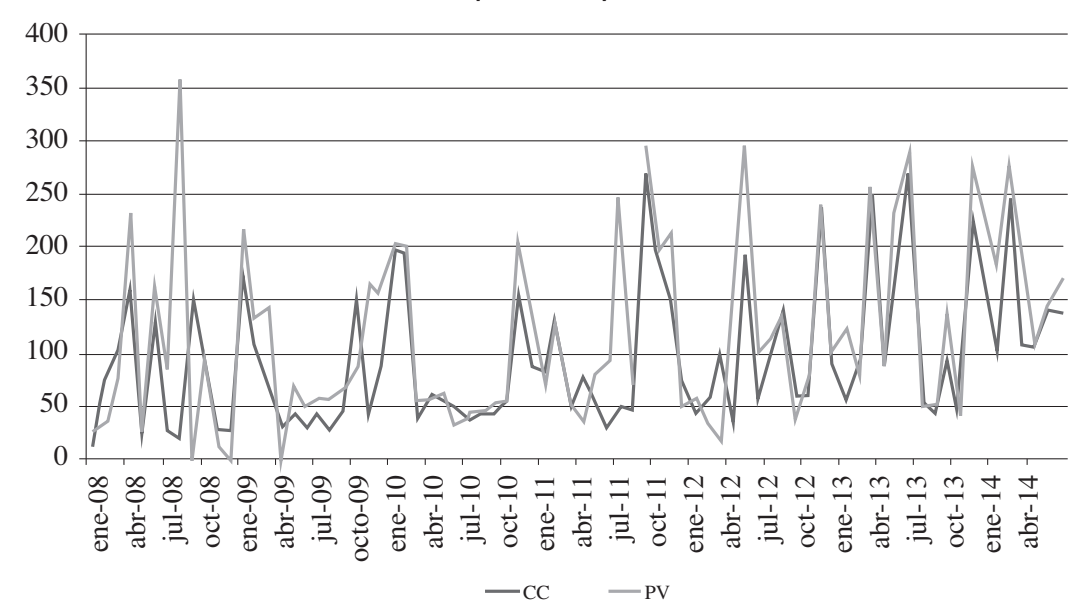


Gráfico 68

Plazos promedio ponderado de las opciones negociadas por el offshore call venta vs. put compra

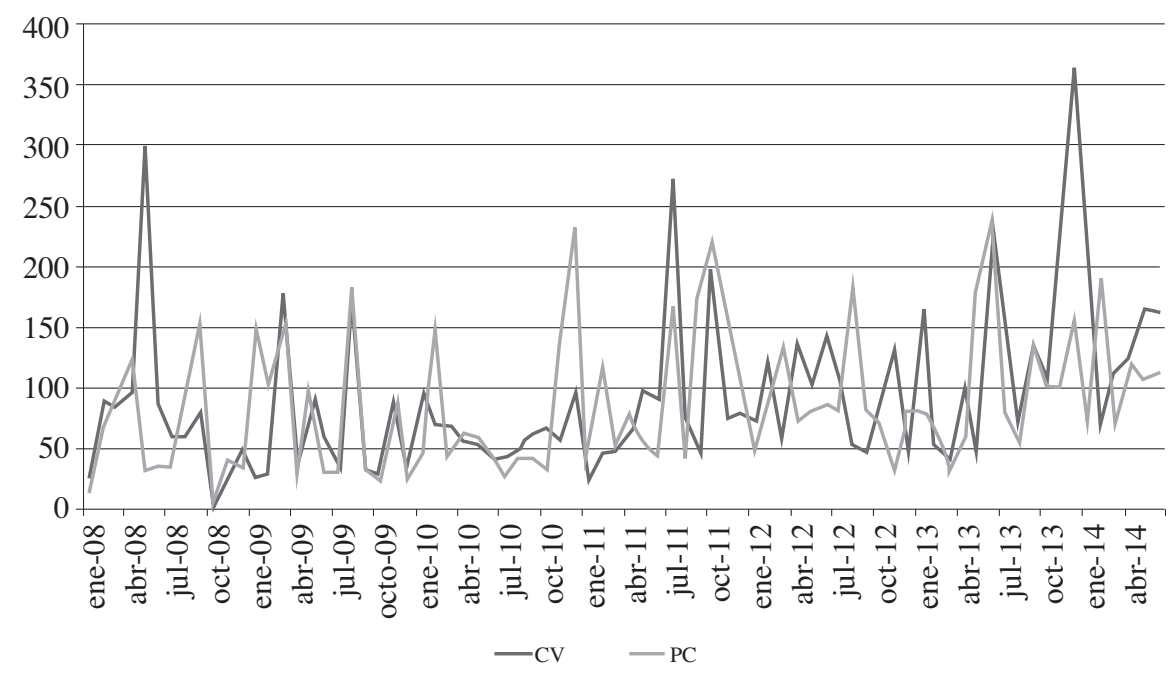

\subsubsection{Características de los agentes del sector real}

Como se mencionó, los agentes del sector real son los más representativos en este mercado con aproximadamente el 50\% del total transado. Desde mediados de 2011, se observa una mayor participación de este sector en el mercado de opciones peso-dólar. Estos agentes mantienen principalmente una posición corta en dólares, la cual se ve reflejada en un mayor volumen de ventas de call con respecto a los demás tipos de opciones (gráficos 69 y 70).

Desde enero de 2013, estos agentes han negociado en promedio un monto de US\$ 640 millones al mes, y desde marzo de 2014, el saldo de opciones ha disminuido ante menores volúmenes negociados así como por mayores vencimientos (principalmente en los meses de mayo y junio de 2014).

Con base en la evolución de los saldos por tipo de opción se puede afirmar que al igual que los agentes offshore, las empresas del sector real también implementan estrategias collar con opciones. A partir de los volúmenes transados en cada tipo de opción se podría aseverar que esta estrategia se implementa principalmente a partir de ventas de call y compras de put (gráfico 71). 
Gráfico 69

Negociaciones brutas del sector real por tipo de opción

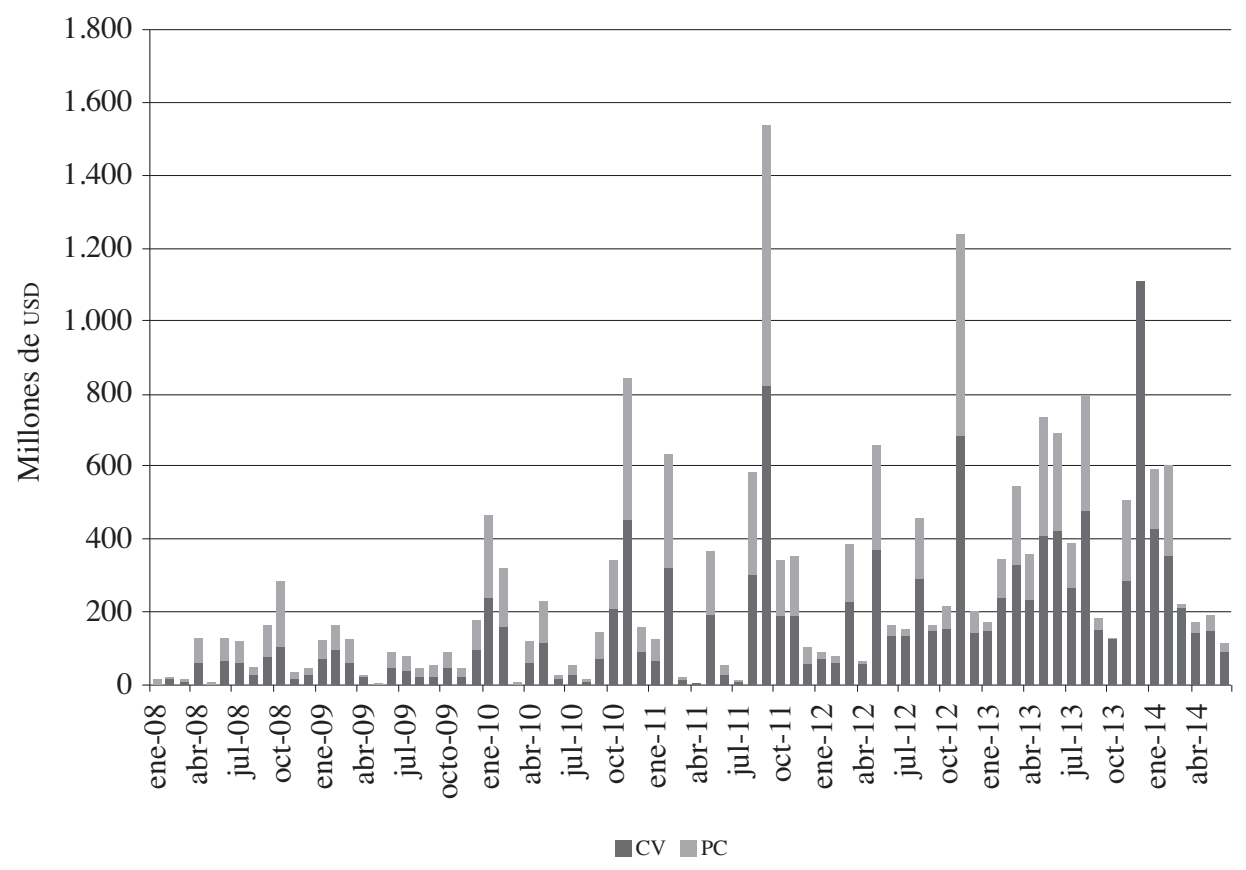

Gráfico 70

Negociaciones brutas del sector real por tipo de opción

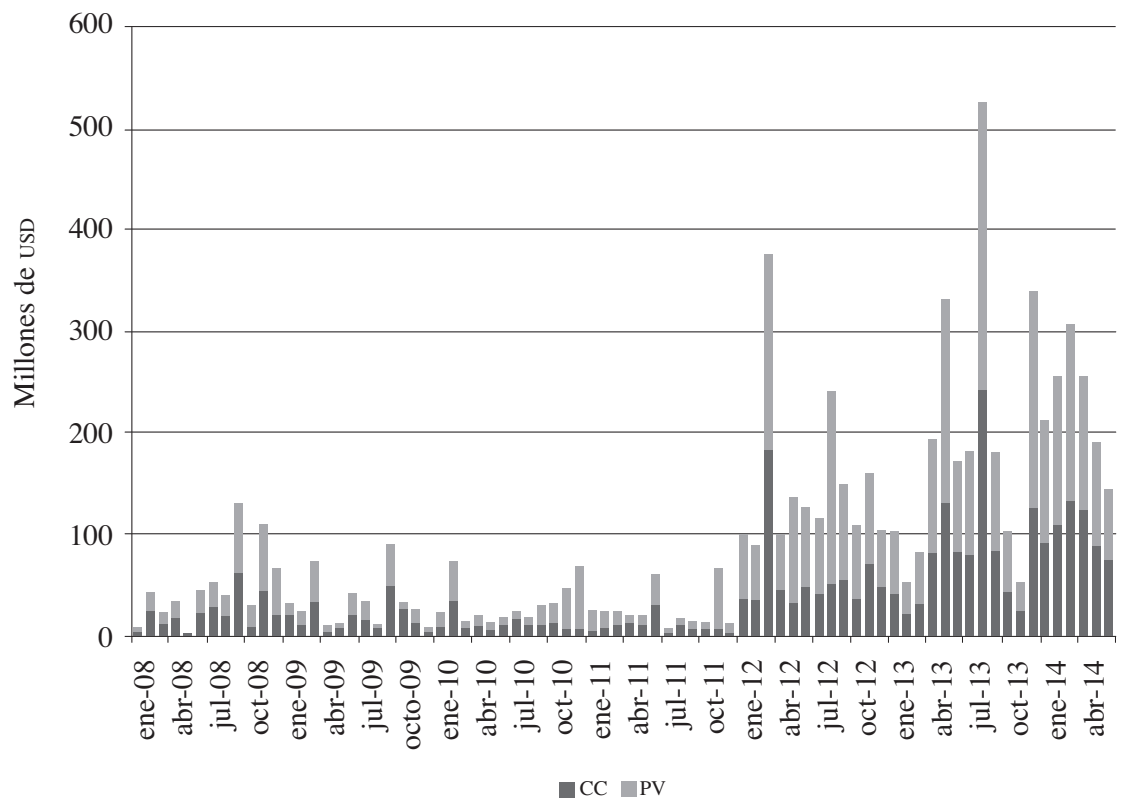


Gráfico 71

Saldo neto del sector real por tipo de opción

(pactados - vencidos)

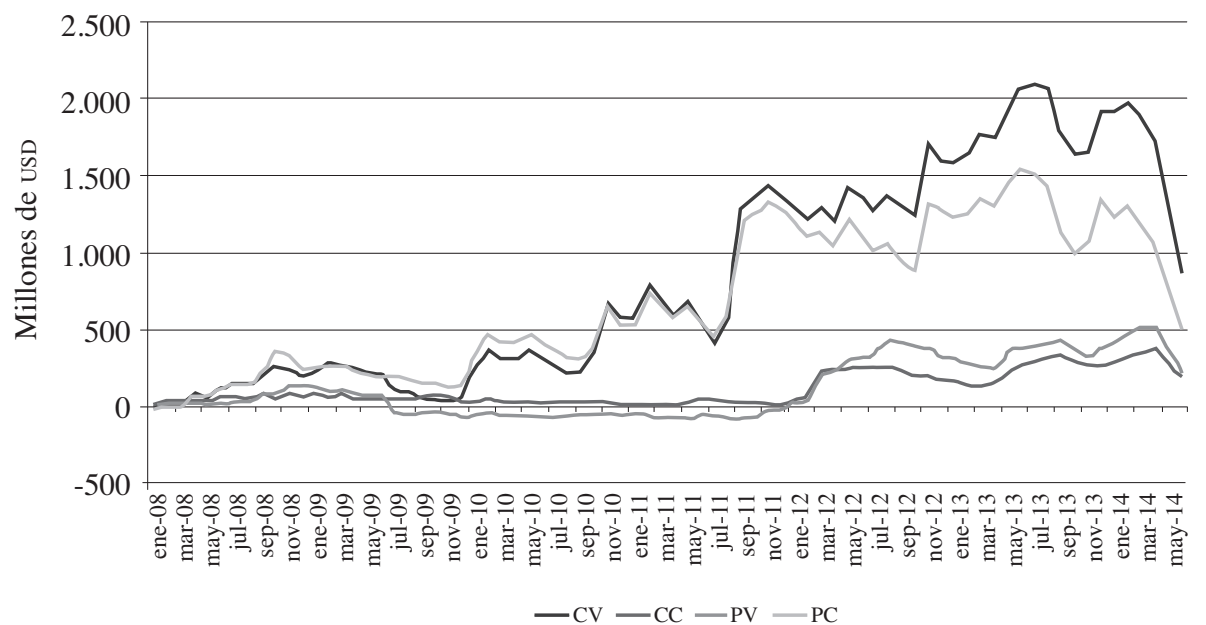

Con respecto a los plazos transados por estos agentes, se destaca que desde el año 2013 las negociaciones se realizan a un plazo de 160 días en promedio. El plazo promedio negociado en las compras de call es similar al de las ventas de put (correlación de $66 \%$ ), así como sucede en el caso de las ventas de call y las compras de put (correlación de $71 \%$ ). Este hecho podría confirmar que el collar es la estrategia que implementan con mayor frecuencia estos agentes para gestionar posiciones en dólares (gráficos 72 y 73).

Gráfico 72

Plazos promedio ponderado de las opciones negociadas por el sector real call compra vs. put venta

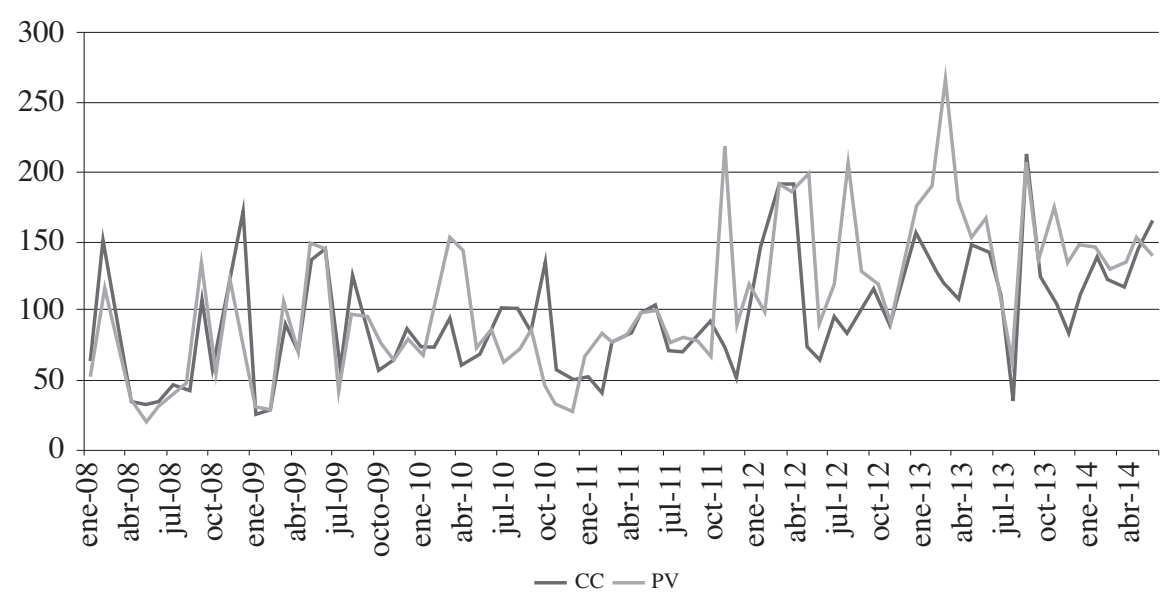




\section{Gráfico 73}

Plazos promedio ponderado de las opciones negociadas por el sector real call venta vs. put compra

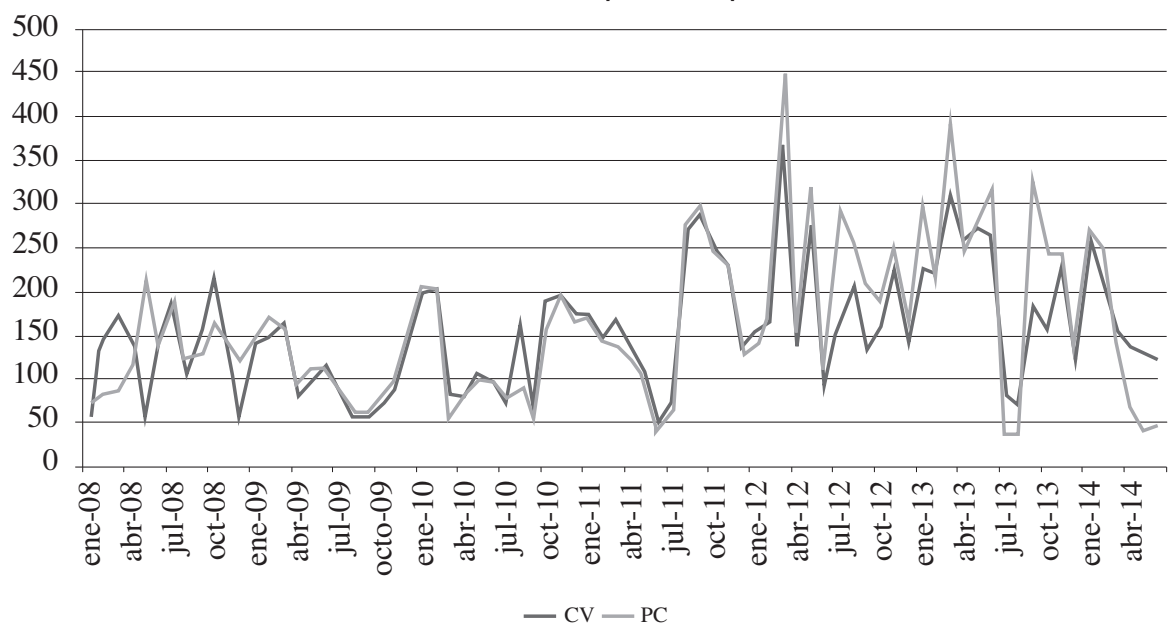

Al clasificar a las empresas del sector real por subsectores, se observa que los sectores con mayor participación son los relacionados con explotación de minas y canteras, extracción de crudo y gas natural, comercio e industria manufacturera (gráfico 74).

Gráfico 74

Distribución por subsectores en negociaciones de opciones peso-dólar

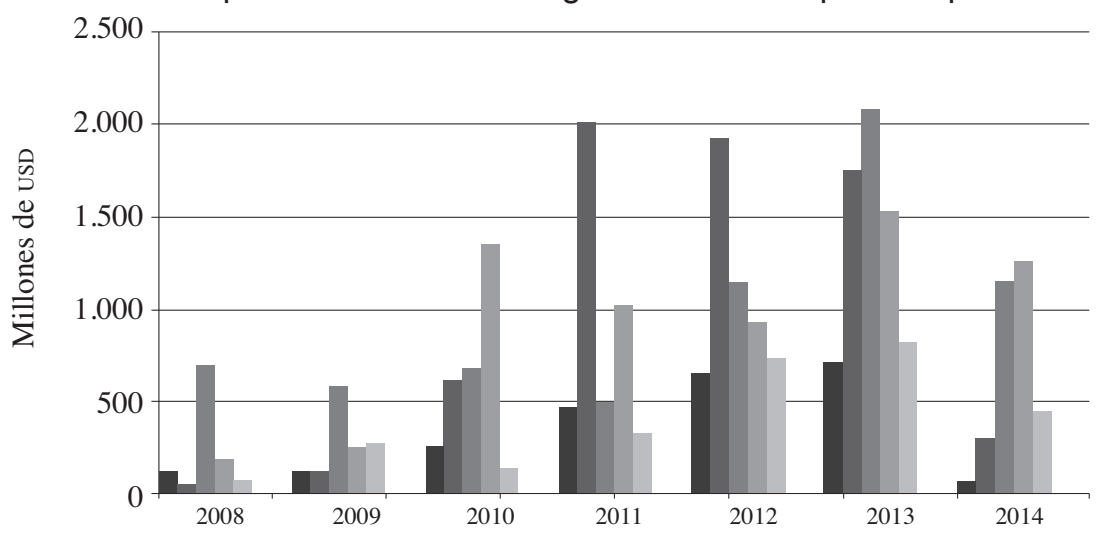

- Agricultura, ganadería, caza, silvicultura, extracción de madera, pesca y actividades de servicios conexas

- Explotación de minas y canteras, extracción de petróleo crudo y gas natural

- Industria manufacturera

- Comercio

n Actividades empresariales: actividades de inmobiliarias, alquiler de maquinaria y equipo, informática y actividades conexas, investigación y desarrollo, otras actividades empresariales 
De manera análoga a la sección de forwards, a continuación se presenta el análisis de los agentes del sector real diferenciados de acuerdo con su actividad de comercio exterior.

Características de agentes importadores y exportadores. Al clasificar las empresas del sector real de acuerdo con sus operaciones de comercio exterior, las empresas importadoras netas, de la misma forma que ocurre en el mercado forward, son las más representativas en este mercado, seguidas por las empresas exportadoras netas ${ }^{20}$ (gráfico 75 ).

Gráfico 75

Participación de los exportadores e importadores en las negociaciones del sector real

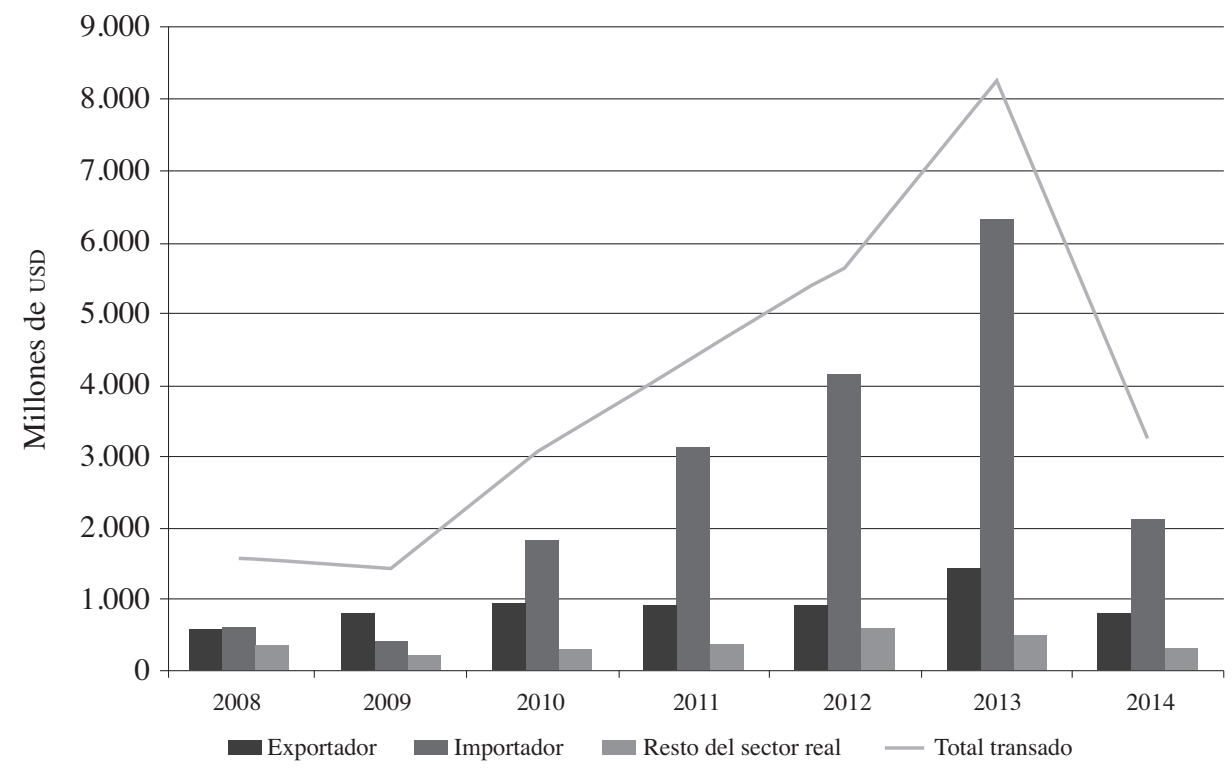

Las empresas exportadoras netas, por lo general, negocian mayores volúmenes en ventas de call, a través de las cuales mantienen principalmente una posición corta en dólares, lo cual es consistente con su actividad económica y podría indicar que utilizan estos instrumentos con fines de cobertura (al igual que los forwards, pero a plazos más largos). Desde enero de 2013, estos agentes han negociado en promedio un monto de US\$125 millones por mes.

20 El procedimiento que se llevó a cabo para determinar el tipo de actividad comercial de las empresas del sector real es análogo al explicado en el mercado de forwards peso-dólar. 
A partir de los saldos observados en el gráfico 76, se podría afirmar que los exportadores también implementan estrategias collar. Sin embargo, es importante señalar que no se observa una relación clara entre los saldos de opciones y el volumen de exportaciones, sin mencionar que los saldos se ubican significativamente por debajo de ellos.

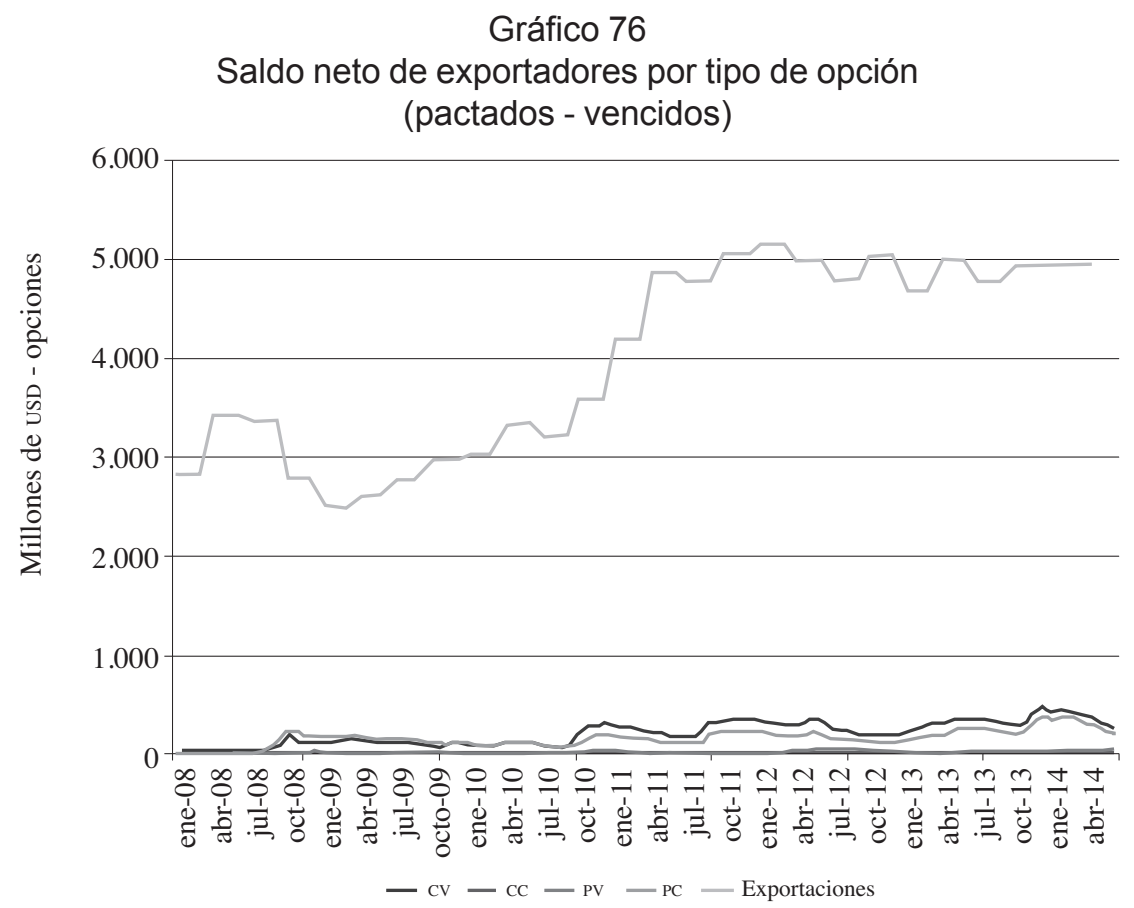

Vale la pena señalar que a finales de 2010, el monto negociado por el sector real en compras de put aumentó debido posiblemente al programa de subsidios a las coberturas cambiarias anunciado por el Gobierno nacional, el cual tenía como objetivo fomentar el uso de opciones put peso-dólar europeas entre los sectores agrícolas, pecuarios y acuícolas exportadores ${ }^{21}$. El subsidio brindado por el Gobierno cubría un porcentaje de la prima de la opción, el cual fluctuaba entre el 60 y el $80 \%$ dependiendo del vencimiento de la cobertura y del tamaño del productor ${ }^{22}$.

\footnotetext{
21 El programa de coberturas ascendió a los \$50 mil millones y fue administrado por Finagro, quien a su vez pactaba las opciones con IMC y con agentes del exterior.

22 Sin embargo, el valor del subsidio no podía superar los $\$ 80$ por dólar cubierto para los grandes y medianos productores y $\$ 100$ por dólar cubierto para pequeños y medianos productores.
} 
Al respecto, también cabe destacar que en el Plan de Impulso a la Productividad y el Empleo (PIPE) anunciado en abril de 2013, el Gobierno nacional anunció que serían destinados $\$ 65$ mil millones para el subsidio de coberturas cambiarias y de precios y para apoyos en comercialización, lo cual podría explicar el incremento en las negociaciones de opciones put en 2013 y 2014. Según el comunicado emitido por el Ministerio de Hacienda, este programa tiene como fin "proteger a los exportadores (especialmente banano, plátano, flores) frente a la volatilidad en la tasa de cambio, mitigar volatilidades en el precio del maíz, así como apoyar la comercialización de diversos productos agrícolas"23. Para el desarrollo de este programa se asignó un presupuesto de \$37.995 millones en 2013 y \$16 mil millones para 2014, con el cual se subsidiará hasta el 50\% del valor de la prima de la cobertura para grandes y medianos productores, y hasta el $90 \%$ para pequeños productores ${ }^{24}$.

A partir del anuncio, se observó un incremento de $67 \%$ en las compras put por parte de los agentes del sector real, al pasar de un promedio de US\$96 millones (entre enero de 2008 y abril de 2014) a US\$160 millones mensuales (entre mayo de 2013 y junio de 2014). Este incremento pudo estar también influenciado por la tendencia devaluacionista del peso colombiano en 2013, la cual pudo permitirle a diferentes empresas (principalmente del sector exportador) pactar coberturas de opciones a tasas más favorables y, por tanto, asegurar un margen mayor (gráfico 77).

Gráfico 77

Negociaciones brutas en opciones put por parte del sector real

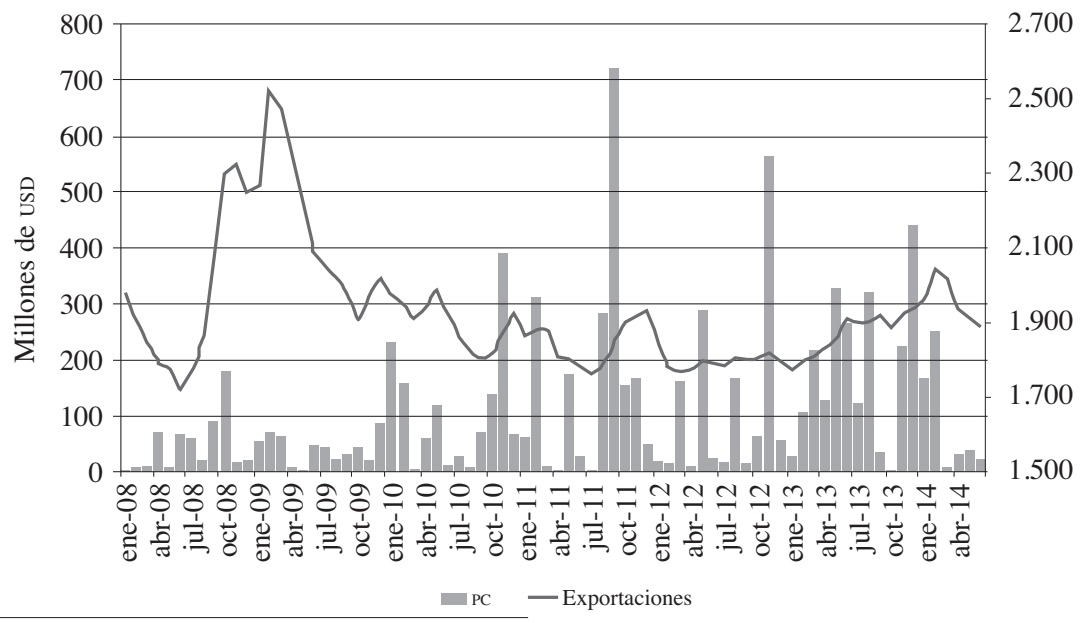

23 Para mayor información, ver el Comunicado 32 de 2013 del Ministerio de Hacienda y Crédito Público.

24 El Programa operó durante el 2014 y fue administrado por Finagro.

PP. $7-79 \cdot N .^{\circ} 9 / 2015$ 
Al calcular el plazo promedio de las opciones se observa que entre las compras de call y las ventas de put existe una correlación de $48 \%$, y entre las ventas de call y las compras de put una correlación de $86 \%$ (gráficos 78 y 79). Este podría considerarse un claro indicio de que los exportadores también toman posiciones largas y cortas de dólares a través de estrategias collar.

Gráfico 78

Plazos promedio ponderado de las opciones negociadas por exportadores call compras vs. put ventas

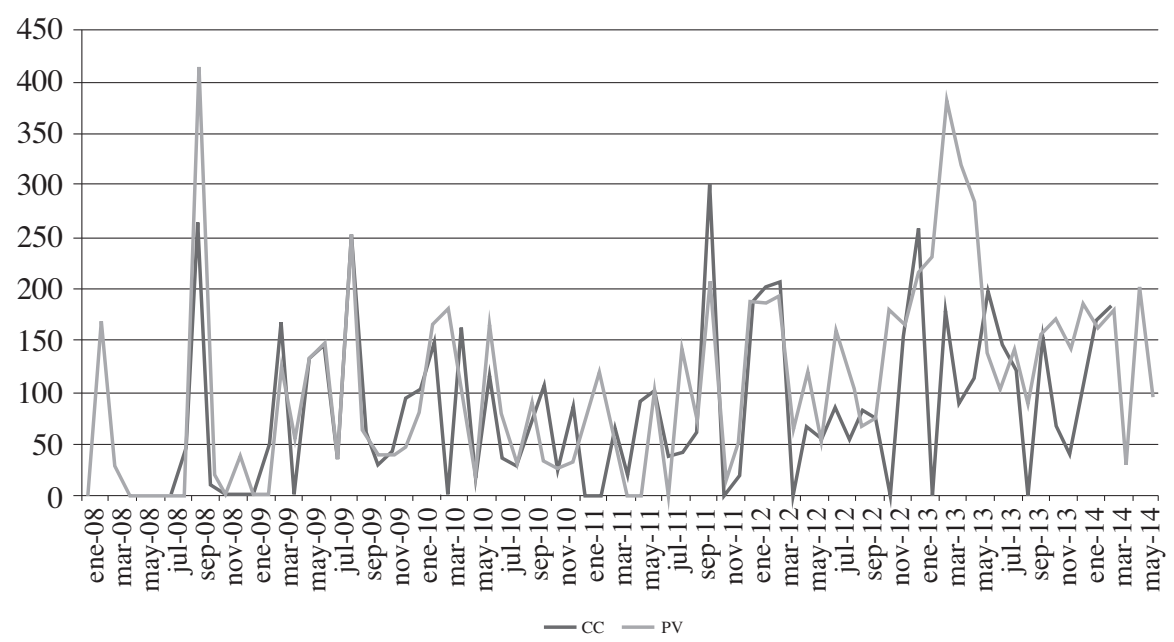

Gráfico 79

Plazo promedio ponderado de las opciones negociadas por exportadores call compras vs. put ventas

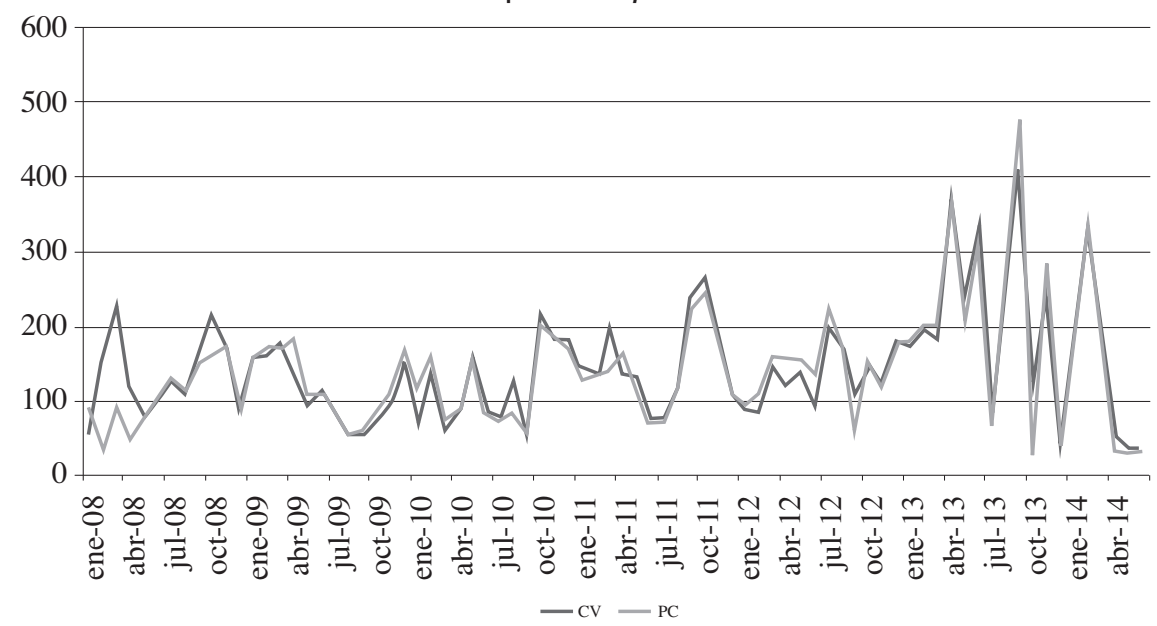


Con respecto a las negociaciones de opciones por parte de empresas importadoras netas, se destaca que desde enero de 2013 estos agentes han negociado en promedio un monto de US\$470 millones mensuales, posicionándolos como los participantes más activos en este mercado dentro de la categoría de agentes del sector real. Estas entidades mantienen una posición corta en dólares a través de negociaciones de volúmenes significativos de ventas de opciones calls y la compra de opciones puts (gráfico 80). Lo anterior podría indicar que los importadores utilizan esta estrategia con el fin obtener ganancias ante expectativas de una apreciación del peso colombiano.

En el gráfico 80, se observa que no existe una relación clara entre los saldos de opciones y el volumen de importaciones, y que además, los saldos se ubican significativamente por debajo de ellos.

Gráfico 80

Saldo neto de importaciones por tipo de opción

(pactados - vencidos)

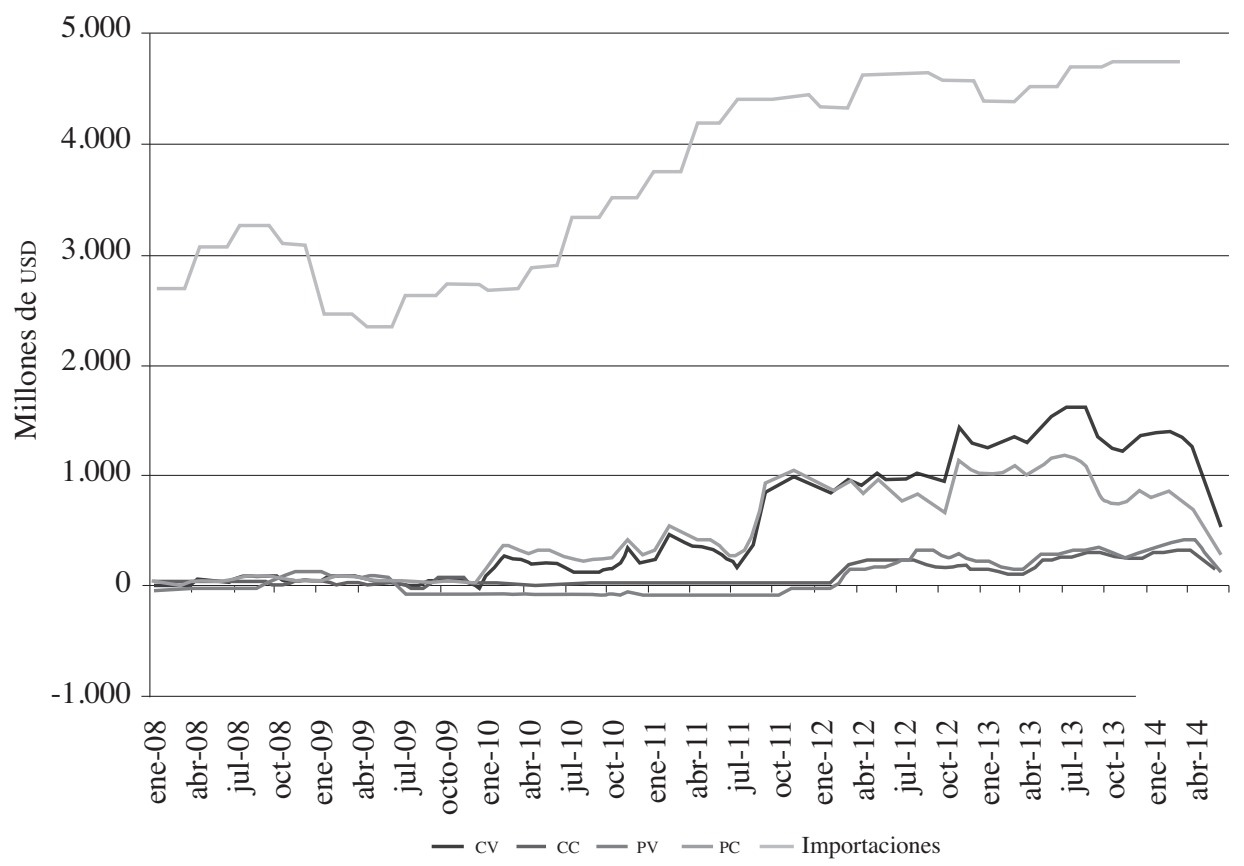

De otro lado, se observa que el comportamiento de los plazos y de los montos negociados en compras de call y ventas de put están muy correlacionados (65\%), lo cual indicaría que mediante estos instrumentos se implementan estrategias collar 
para adquirir una posición larga en dólares, aunque en montos significativamente inferiores a los registrados en los otros dos tipos de opciones (gráficos 81 y 82).

\section{Gráfico 81}

Plazos promedio ponderado de las opciones negociadas por importadores call venta vs. put compra

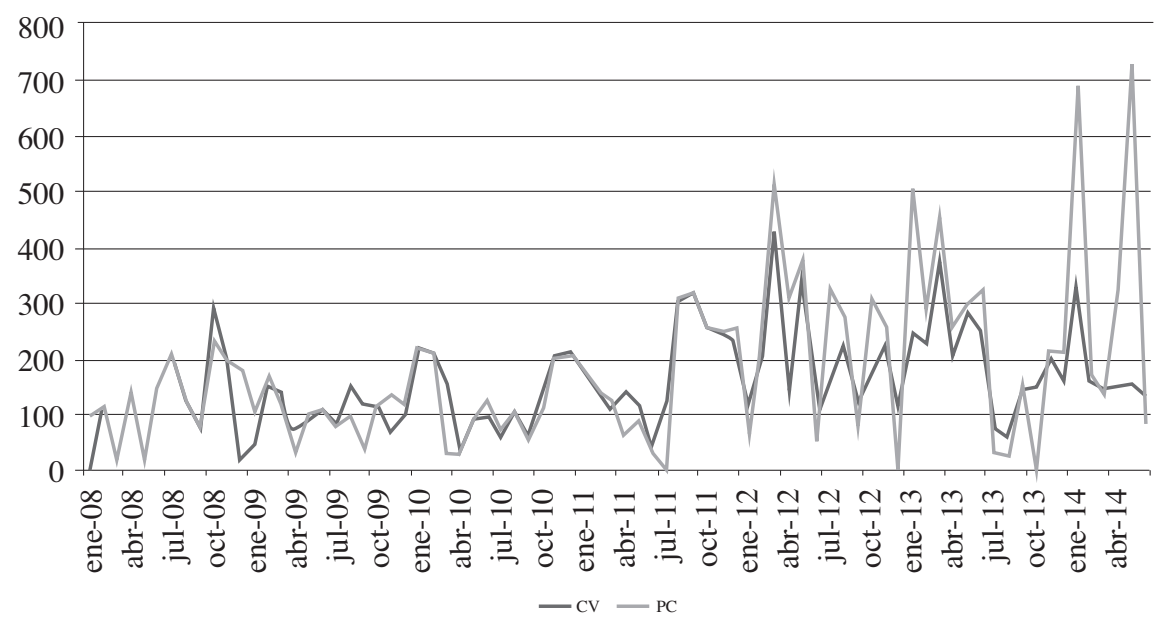

Gráfico 82

Plazos promedio ponderado de las opciones negociadas por importadores call venta vs. put compra

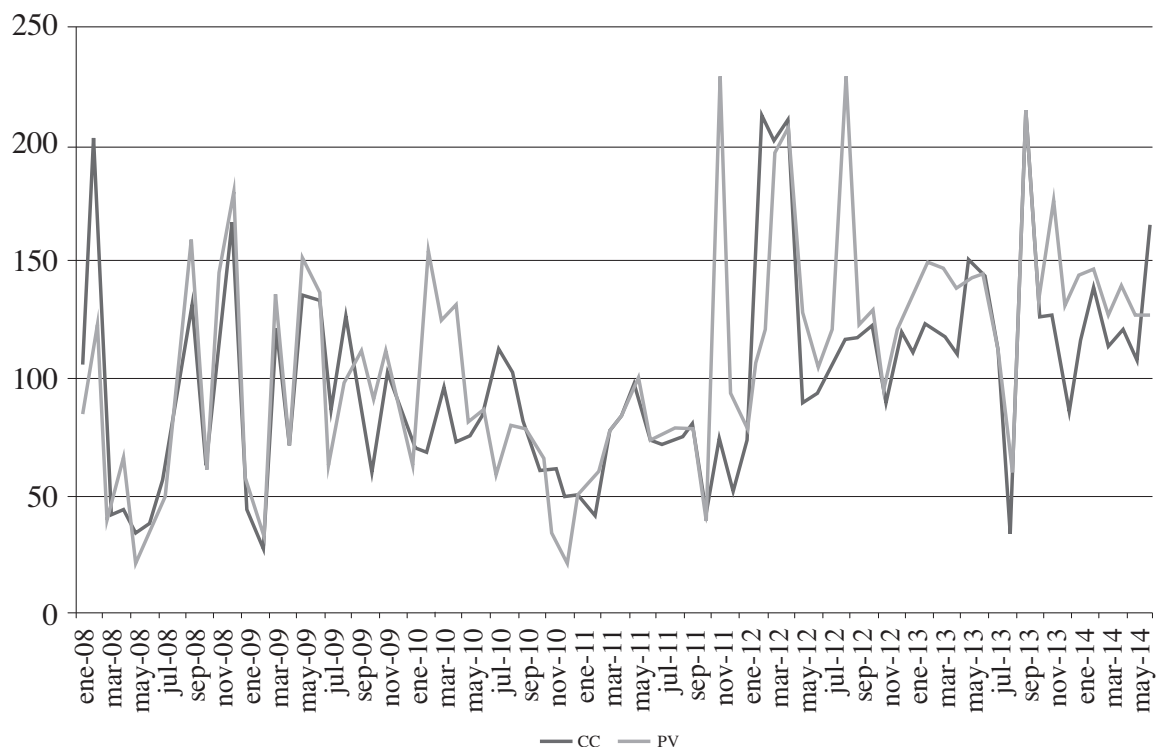




\section{Conclusiones}

En Colombia, el desarrollo del mercado de derivados se ha visto reflejado en el incremento significativo de los montos negociados en derivados de tasa de cambio, así como en un mayor número de participantes. El aumento de las negociaciones en este mercado pudo haber sido motivado por factores como mayor inversión extranjera, el crecimiento de las inversiones en el exterior por parte de los FPC, y una mayor disposición de los agentes a transferir los riesgos en el precio de sus activos, lo cual pudo incrementar la demanda por coberturas por parte de agentes como el sector real. Sin embargo, se resalta que a pesar del crecimiento de este mercado en Colombia, este continúa rezagado frente a países desarrollados y algunos países de la región.

La evidencia muestra que los forwards continúan siendo los instrumentos más transados, debido entre otras cosas a que: i) son menos costosos, en la medida en que no requieren del intercambio de flujos al inicio del contrato (por ejemplo, una prima en el caso de las opciones), ii) son más líquidos, iii) implican un menor riesgo de crédito dado que suelen pactarse a plazos cortos y pueden ser compensados a través de una CRCC (a diferencia de las opciones y los cross-currency swaps), iv) implican un procedimiento más claro para su contabilización y v) son menos costosos en términos tributarios. Adicionalmente, y considerando que los IMC mantienen su posición cambiaria global relativamente estable, las posiciones de los distintos agentes en el mercado de derivados pueden verse reflejadas en el mercado de contado y, por ende, en el comportamiento de la tasa de cambio.

En cuanto al sector real, se encontró que estos agentes pueden ser caracterizados como tomadores de precios, y han adquirido una mayor especialización en el mercado de derivados, lo cual se ve reflejado en las diferentes estrategias que implementan y en el mayor número de firmas participantes. Al analizar la composición de estos agentes teniendo en cuenta sus operaciones de comercio exterior, se encontró que los importadores netos son los principales participantes. Adicionalmente, se halló que los importadores presentan una menor volatilidad en sus posiciones con respecto a los exportadores, quienes muestran una mayor sensibilidad a los precios.

Finalmente, con base en lo observado en los mercados de forwards peso-dólar, cross currency swaps y opciones peso-dólar, se podría afirmar que los agentes extranjeros han jugado un papel importante en el desarrollo del mercado de derivados sobre divisas en Colombia, en la medida en que sus operaciones abarcan 
una gran variedad de instrumentos y que su participación ha sido históricamente significativa en cada uno de estos mercados.

\section{Referencias}

Adkins, L. C., Carter, D. A. y Simpson, W. G. (2007). Managerial Incentives and the Use of Foreign-Exchange Derivatives by Banks. Journal of Financial Research, 30(3), 399-413.

Álvarez, R. (2010). Un paseo por los derivados financieros. Trabajos de fin de grado y magíster, Universidad de León.

Avalos, F. y Moreno, R. (2013). Hedging in derivatives markets: the experience of Chile. BIS Quarterly Review, pp. 51-64.

Allayannis, G. y Ofek, E. (2001). Exchange Rate Exposure, Hedging, and the Use of Foreign Currency Derivatives. Journal of International Money and Finance, 20(2), 273-296.

Allayannis, G. y Weston, J. (2001). The use of Foreign Currency Derivatives and Firm Market Value. Review of Financial Studies, 14, 243-276.

Baluch, A., y Ariff, M. (2007). Derivatives Markets and Economic Growth: Is There a Relationship? Bond University Working Paper Series, 13.

Bartram, S. M., Brown, G. W. y Conrad, J. (2011). The effects of derivatives on firm risk and value. Journal of Financial and Quantitative Analysis, 46(04), 967-999.

Becker, C. y Fabbro, D. (2006). Limiting Foreign Exchange Exposure through hedging: The Australian Experience. Reserve Bank of Australia, 2006-09.

Carrasco, J.A. (2008). Smile de volatilidad como criterio predictor de futuros movimientos del subyacente en opciones de moneda: revisión del caso chileno y japonés. Pontificia Universidad Católica de Chile

Danthine, J. P. (1978). Information, Futures Prices, and Stabilizing Speculation. Journal of Economic Theory, 17(1), 79-98.

Diamond, D. W. y Verrecchia, R. E. (1987). Constraints on short-selling and asset price adjustment to private information. Journal of Financial Economics, 18(2), 277-311. 
Fleming, J., Ostdiek, B. y Whaley, R. E. (1996). Trading Costs and the Relative Rates of Price Discovery in Stock, Futures, and Option Markets. Journal of Futures Markets, 16(4), 353-387.

Folkerts-Landau, D. (1994). Derivatives: The New Frontier in Finance. En Frameworks for Monetary Stability: Policy Issues and Country Experiences, Washigton D.C. S574-610.

Géczy, C., Minton, B. y Schrand, C. (1997). Why firms use currency derivatives. The Journal of Finance, 52, 1323-1354.

George, J. (2009). The Effect of the Derivatives Market on the Underlying Markets. University of Waikato.

Gerding, E. F. (2011). Credit Derivatives, Leverage, and Financial Regulation's Missing Macroeconomic Dimension. Berkeley Business Law Journal, 8.

González, C. y Ochoa, I. (2007). Evaluación del mercado de opciones sobre tasas de cambio: perspectivas para una mejor utilización. Revista EIA, 7, 145-158.

Gupta, R. (2004). Derivatives markets and real economic activity. Doctoral dissertation, Victoria University of Technology.

Kamil, H., Maiguashca, A. F. y Pérez, D. (2008). How Do Firms Manage Currency Risk as Derivatives Markets Develop? New Micro Evidence for Colombia: 1998-2006. LACEA papers, 572.

Kavussanos, M. G., Visvikis, I. D. y Alexakis, P. D. (2008). The Lead-Lag Relationship Between Cash and Stock Index Futures in a New Market. European Financial Management, 14(5), 1007-1025.

Knop, R. (2013). Manual de Instrumentos Derivados - Cuatro décadas de Black-Scholes. Ediciones Empresa Global.

Merton, R. (1992). Financial Innovation and Economic Performance. Journal of Applied Corporate Finance, 4 (4), 12-22.

Sill, K. (1997). The Economic Benefits and Risks of Derivative Securities. Business Review, 15-26. 
Sivakumar, A., y Sarkar, R. (2008). Corporate Hedging for Foreign Exchange Risk in India. 11th Annual Convention of the Strategic Management Forum, Indian Institute of Technology, Kanpur, May.

Tsetsekos, G. y Varangis, P. N. (1998). The Structure of Derivatives Exchanges: Lessons from Developed and Emerging Markets, (No. 1887). World Bank Publications.

\section{Anexo 1. Paridad cubierta de tasa de interés}

La paridad cubierta de tasa de interés parte del principio de no arbitraje, lo cual implica que el rendimiento esperado en moneda local de las siguientes estrategias debe ser equivalente: un peso podría ser utilizado para comprar divisas y ser invertido a la tasa de interés externa, o se podrían comprar divisas a futuro en el mercado de derivados, invirtiéndolo a la tasa de interés local por un periodo equivalente a la madurez del contrato. En ausencia de arbitraje, la expresión para el precioforward de los dólares (en este caso sería la cantidad de pesos equivalentes a un dólar) en el periodo $t$ se puede expresar de la siguiente forma:

$$
\text { donde: } \frac{F_{t, T}}{S_{t}}=\frac{\left(1+r_{\text {interna }}\right)^{T-t}}{\left(1+r_{\text {externa }}\right)^{T-t}}
$$

$F_{t, T}=$ precio del forward negociado en el periodo $\mathrm{t}$, con vencimiento en $\mathrm{T}$ $\mathrm{St}=$ tasa de cambio (en este caso peso-dólar) en el mercado spot en el periodo $\mathrm{t}$.

Adicionalmente, en la expresión se tienen las tasas de interés interna y externa al plazo respectivo del forward.

Con base en la expresión anterior, se denomina devaluación implícita teórica a la relación que debería existir entre la tasa forward y la tasa de contado en el periodo t de acuerdo con la relación de paridad, dadas las tasas de interés interna y externa observadas al plazo de la operación:

$$
D e v_{\text {Teórica }}=\left[\frac{\left(1+r_{\text {interna }}\right)}{\left(1+r_{\text {externa }}\right)}\right]^{T-t}
$$

Por otra parte, una vez observadas las tasas forward y de contado, y la tasa de interés externa, se puede calcular la tasa de interés doméstica equivalente como la tasa interna implícita en la relación de paridad: 


$$
\left(1+r_{\text {dom_equiv }}\right)^{T-t}=\frac{F_{t, T}}{\mathrm{~S}_{t}}\left(1+\mathrm{r}_{\text {externa }}\right)^{T-t}
$$

Sin embargo, se debe resaltar que aunque de acuerdo con la literatura las tasas pactadas de los forwards de tasa de cambio tienen un componente relacionado con la paridad de tasas de interés, estas también incluyen un componente adicional relacionado con las expectativas del comportamiento del subyacente. De acuerdo con esto, las tasas pactadas en estos contratos se podrían considerar predictores sesgados de la tasa de cambio, y podrían ser utilizados para entender la expectativa del mercado sobre su evolución.

\section{Posición propia, posición propia de contado y posición propia de apalancamiento}

De acuerdo con la circular reglamentaria externa DODM-139, los intermediarios del mercado cambiario (IMC) deben cumplir con unos límites en su posición propia (PP), posición propia de contado (PPC) y posición bruta de apalancamiento (PBA).

La PP se refiere a la exposición cambiaria de estas entidades, y se calcula como la diferencia entre todos los derechos y obligaciones en moneda extranjera. Por otra parte, la PPC está relacionada con la exposición cambiaria de corto plazo, y se define como la diferencia entre todos los activos y pasivos denominados en moneda extranjera. La PBA se refiere a la suma de los derechos y las obligaciones de los contratos a futuro en moneda extranjera, incluyendo las operaciones de contado con cumplimiento posterior a un día hábil bancario, y las contingencias deudoras y acreedoras producto de las opciones de tasa de cambio. Esta última medida no permite neteos entre posiciones deudoras y acreedoras, por lo cual limita la negociación total en operaciones de derivados; sin embargo, de acuerdo con la regulación del Banco de la República, las operaciones que se liquiden a través de una cámara de riesgo no hacen parte del cálculo de este indicador. 


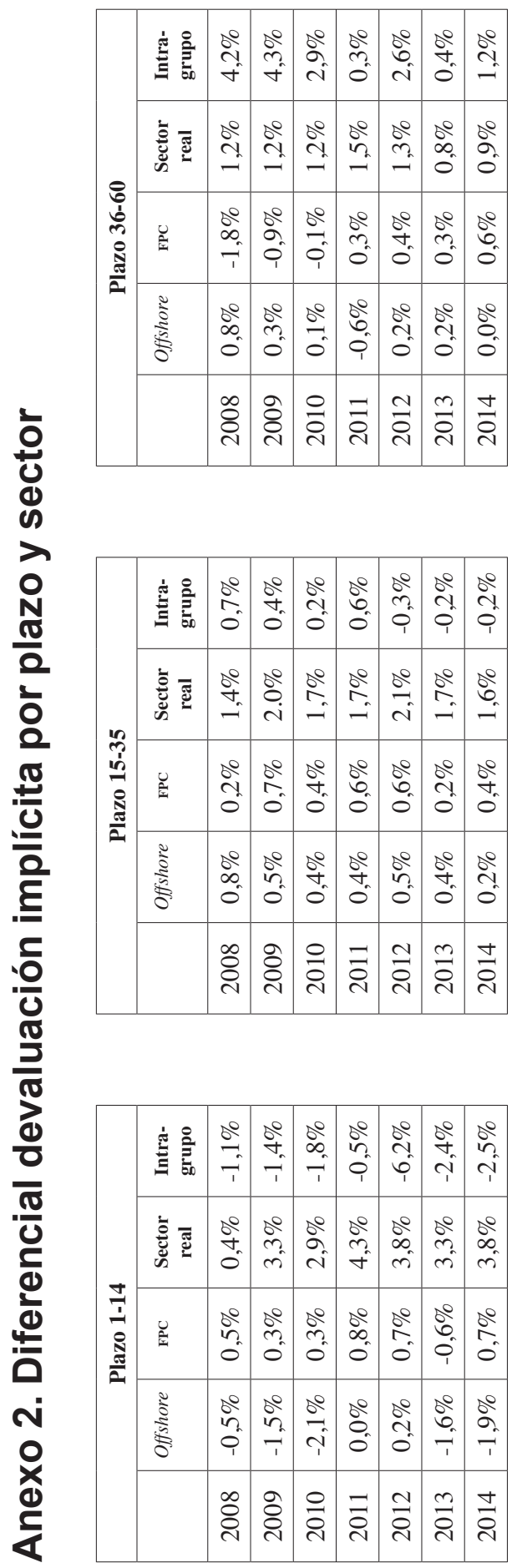

\begin{tabular}{|c|c|c|c|c|c|c|c|c|}
\hline \multirow{5}{*}{ 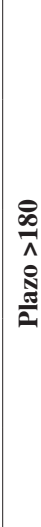 } & 焉 & $\stackrel{0}{=}$ & \begin{tabular}{l}
$\stackrel{0}{2}$ \\
\multirow{2}{*}{} \\
0
\end{tabular} & $\begin{array}{l}\stackrel{0}{0}^{\circ} \\
\stackrel{-}{-1}\end{array}$ & 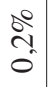 & $\begin{array}{l}80 \\
0 \\
\dot{r}\end{array}$ & $\ddot{0}_{0}^{0}$ & $\frac{0}{0}$ \\
\hline & 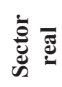 & 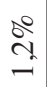 & $\begin{array}{l}\stackrel{0}{2} \\
\text { ?. }\end{array}$ & $\begin{array}{l}\delta^{0} \\
\infty \\
0 \\
0\end{array}$ & $\frac{\stackrel{0}{2}}{0^{\circ}}$ & $\begin{array}{l}0^{0} \\
\infty \\
0\end{array}$ & $\begin{array}{l}0^{0} \\
\text { ñ } \\
0\end{array}$ & $\frac{0}{0}$ \\
\hline & 气 & $\frac{80}{i}$ & $\begin{array}{l}b_{0}^{0} \\
\stackrel{i}{i} \\
i\end{array}$ & $\begin{array}{l}\stackrel{0}{2} \\
\sigma_{1}\end{array}$ & $\begin{array}{l}\stackrel{0}{+} \\
\stackrel{0}{0} \\
\stackrel{0}{*}\end{array}$ & $\begin{array}{l}\infty \\
\infty \\
-1 \\
T\end{array}$ & $\begin{array}{l}\infty \\
\infty \\
0 \\
1\end{array}$ & $\begin{array}{l}0 \\
0 \\
0 \\
0 \\
0\end{array}$ \\
\hline & 竎 & $\begin{array}{l}\stackrel{0}{c} \\
\text { in }\end{array}$ & $\begin{array}{l}\stackrel{0}{2} \\
\because n\end{array}$ & $\begin{array}{l}0 \\
\dot{0} \\
0 \\
0\end{array}$ & $\frac{\circ}{0}$ & $\begin{array}{l}\circ \\
0 \\
i\end{array}$ & o̊ & $\frac{0}{0}$ \\
\hline & & 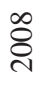 & \&્ণ & $\stackrel{\circ}{\stackrel{2}{\circ}}$ & $\overrightarrow{\vec{c}}$ & 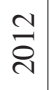 & $\stackrel{m}{\stackrel{2}{\sim}}$ & $\frac{\text { d }}{\stackrel{d}{d}}$ \\
\hline
\end{tabular}

\begin{tabular}{|c|c|c|c|c|c|c|c|c|}
\hline \multirow{5}{*}{$\begin{array}{l}\frac{\infty}{1} \\
\frac{\sigma}{\sigma} \\
\frac{\pi}{\pi} \\
\frac{\pi}{2}\end{array}$} & 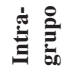 & 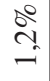 & $\begin{array}{l}00 \\
i \\
i\end{array}$ & $\stackrel{0}{=}$ & $\begin{array}{l}0 \\
0 \\
0 \\
0\end{array}$ & $\begin{array}{l}0 \\
? \\
i \\
i\end{array}$ & $\frac{\stackrel{\circ}{?}}{0}$ & $\begin{array}{l}0 \\
0 \\
0 \\
0\end{array}$ \\
\hline & 悹 & $\begin{array}{l}\stackrel{0}{2} \\
\stackrel{2}{-2}\end{array}$ & $\stackrel{\circ}{=}$ & $\stackrel{\circ}{2}$ & $\frac{\stackrel{0}{\circ}}{0}$ & $\frac{\circ}{0^{\circ}}$ & $\begin{array}{l}\stackrel{0}{0} \\
\dot{0} \\
0\end{array}$ & $\begin{array}{l}\circ \\
0\end{array}$ \\
\hline & 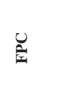 & $\begin{array}{l}\stackrel{0}{i} \\
i \\
i\end{array}$ & $\frac{80}{n}$ & $\begin{array}{l}0 \\
2 \\
2 \\
0 \\
1\end{array}$ & $\frac{80}{2}$ & $\frac{0}{0}$ & $\frac{\stackrel{0}{7}}{7}$ & $\frac{b^{0}}{7}$ \\
\hline & 悹 & $\begin{array}{l}\stackrel{0}{2} \\
\dot{m} \\
0\end{array}$ & $\begin{array}{l}\stackrel{0}{0} \\
\text { in }\end{array}$ & $\begin{array}{l}\stackrel{0}{r} \\
\stackrel{0}{0}\end{array}$ & $\begin{array}{l}\stackrel{0}{n} \\
0 \\
0\end{array}$ & $\begin{array}{l}\stackrel{0}{0} \\
1 \\
0 \\
i\end{array}$ & $\begin{array}{l}\stackrel{0}{2} \\
\text { ô }\end{array}$ & $\frac{0^{\circ}}{0}$ \\
\hline & & 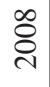 & ஓి & $\stackrel{0}{8}$ & $\bar{\Xi}$ & $\frac{1}{8}$ & $\stackrel{m}{\stackrel{1}{d}}$ & $\frac{+}{8}$ \\
\hline
\end{tabular}

\begin{tabular}{|c|c|c|c|c|c|c|c|c|}
\hline \multirow{5}{*}{$\begin{array}{l}8 \\
\frac{1}{6} \\
8 \\
\frac{\pi}{2}\end{array}$} & 焉总 & $\begin{array}{l}\stackrel{\circ}{-} \\
f\end{array}$ & $\begin{array}{l}00 \\
\infty \\
-1\end{array}$ & $\begin{array}{l}\delta^{0} \\
\infty \\
0\end{array}$ & $\begin{array}{l}b^{\circ} \\
\text { ?. }\end{array}$ & 告 & o̊ & $\begin{array}{l}\dot{b}_{0}^{\circ} \\
\text { o. }\end{array}$ \\
\hline & 密 & $\stackrel{\circ}{2}$ & $\stackrel{\stackrel{\circ}{+}}{\stackrel{\sim}{\sim}}$ & 욕 & $\begin{array}{l}0 \\
0 \\
0 \\
0\end{array}$ & $\begin{array}{l}0 \\
n \\
0 \\
0\end{array}$ & $\begin{array}{l}0 \\
\infty \\
0\end{array}$ & $\stackrel{\circ}{\stackrel{\circ}{ت}}$ \\
\hline & 言 & $\begin{array}{l}\frac{2}{r} \\
\stackrel{r}{1}\end{array}$ & $\begin{array}{l}\stackrel{0}{+} \\
\dot{r} \\
r\end{array}$ & \begin{tabular}{l}
0 \\
\multirow{2}{0}{} \\
0 \\
$i$
\end{tabular} & $\begin{array}{l}\stackrel{0}{+} \\
\stackrel{0}{0}\end{array}$ & 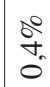 & i̊ & \\
\hline & 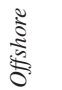 & $\begin{array}{l}{ }_{0}^{0} \\
\infty \\
-\end{array}$ & $\begin{array}{l}\stackrel{0}{+} \\
\underset{-}{+}\end{array}$ & 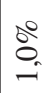 & $\begin{array}{l}0^{0} \\
n \\
0\end{array}$ & 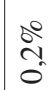 & $\stackrel{\circ}{\stackrel{0}{0}}$ & \\
\hline & & $\begin{array}{l}\infty \\
\stackrel{\sim}{8} \\
\stackrel{0}{2}\end{array}$ & \&ి & 을 & $\bar{\Xi}$ & $\stackrel{ }{\stackrel{2}{N}}$ & $\stackrel{m}{\stackrel{2}{2}}$ & \\
\hline
\end{tabular}

